




\title{
det
}

\section{Elaterialismuts in Englanto.}

\author{
Cin Horterg
}

gebalten

in Dex Dex [ammlanty dex Buttilly Alloctation

in Belfaft

bon

\section{Iobn $\mathbb{C}$ minall.}

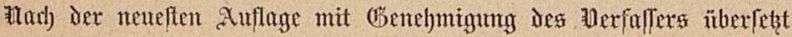
voit

Bmil Behmann.

Jueite Dittuhgefelgette Aufluge.

193

פerlitt.

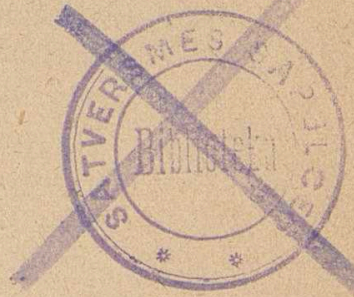

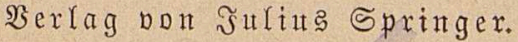

1876

\section{Bücherei}

beim

Höh. 44-U. Pol, - Fahrer f. d. Ostland 


$$
\nabla 38|80| 40181(6)
$$




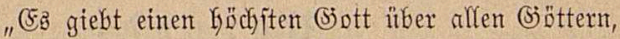
Der göttlicker ift als Sterbliche, Deffent (s)eftalt nidjt Der Des Nenfichen und eben fo wenig jeiner Natux gleidft. Aber ettle Sterbfiche mähnen, Dǻ (S)̈tter gletid) ifnen felbit mit menichlictjen (smpfintungen, menjchlicher Stimme und Eörperlichen (B)liedern erzengt murben. So mürden, wenn Dhfien oder Römen Şände

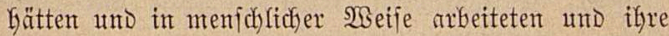
Borftellung yon Der (Sottheit mit Meipel ober Sinfel zur Daritellung bringen fömten, SPferde (S) D̈tter wie

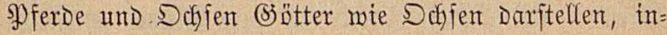
Dem jebe 2 (rt Die (S) ottbeit mit iffer eigenen (Sieftalt uni) Natur ausftatten mürbe."

Xenophanes aus frolophon (600 v. (5Gx.) "Iteber bie Ratur."

"Es wäre beffer itberall gar feine Borftellung von (5)ott zu Gaben, als eine feiner unwütrotge Sorftellung; Denn bie eine ift Unglsuben, Die andere $\mathfrak{B e r b o ̈ h n u n g . " ~}$

Baco. 


\section{1) $\mathfrak{n} \mathfrak{I} \mathfrak{x} \mathfrak{i} \mathfrak{x}$.}

Der গ̂tufforderung meiner Şerrent Berleger folgent,

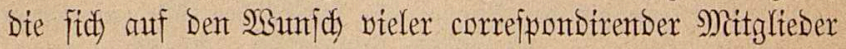
ftützen, übergebe idd Diejen $\mathfrak{B o r t r a g}$ mit einigen $\mathfrak{B}$ erände= nutgen aur's Nente Dem Drutfe.

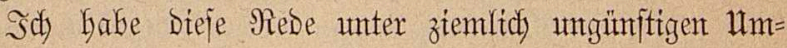
ftänden in Diejem sabre in Den Allpen gejdyrteben unto ftüct=

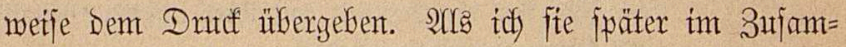

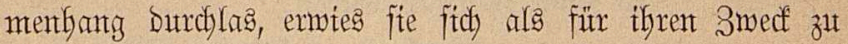

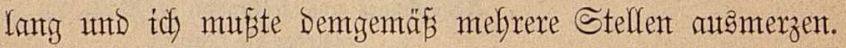
Sintige von biefen Stelfen find bier mieder aufgenommen.

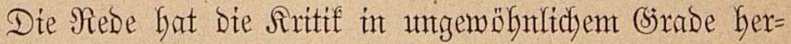
autigeforbert. Diejer Stutrm wird fith legent utto icly febe

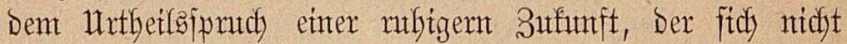
auf eingebtlibete Simnden, jondern auf minflidje Ifjatjachent ftütsen miro, zuwerfidstlid entgegent.

Heber bie inzäbligen Strectstmeifungent into theifmeije

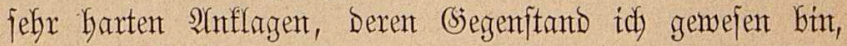
will idf midh bier ntidft meiter auslaffen; auf eintge wentige

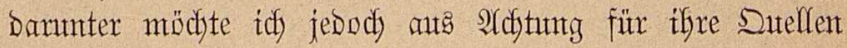
furz ermidern.

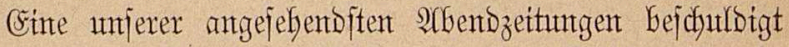

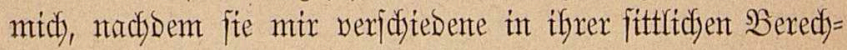


tigung mebr ober mentger beftreitbare 3medfe unts Btele zu= gejdyrteben hat, idy habe midy von bem Seifalle metnes

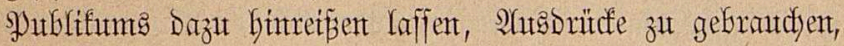
Derent fidf) fein Sintgefunter, ofne Die jomerite Derantmort=

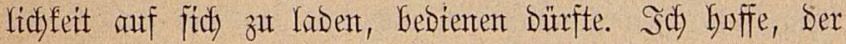
Urbeber Diejer sfnflage wird mir geftatten, ifn in aller 5öf=

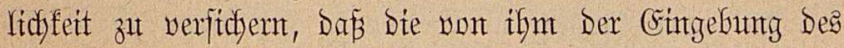
2) waren, dafj fie in Dem gebutiften (Exemplar Der Rede, nads meldyer idy meinen Sortrag gebalten habe, ftanden, Daj̇ biejelben feinte Betdyen des Seifalls Gervorrtefen, fonbent mit ethem Sdywetgen aufgentommen wutroen, bas viel auts=

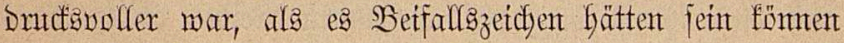

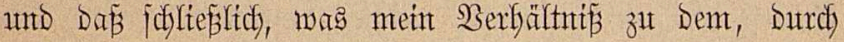
meine Rede exregten Seifall ober Mitffallen anlangt, mein Berbalten fidont lange, Gevor idf es wagte die Berjanmlinty in Belfaft antureben, wohl überdadyt und fejtgeftellt mar.

Sin ) Mitarbeiter eines fefr bebeutenden theologifichen Slattes jidildert midy wie jemand "Der Die Reltgiton ftreidjelt." Der Giedanfe gebönt unftreitig ifm, nicht mix. Die Ibat= facken Des religiojjen (siefübls fteben für midy fo fert mite Die Ibatiactsen Der Shbyfti. SUber Die SBelt mird metrtes

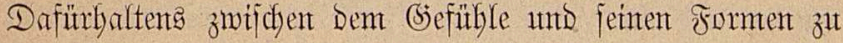
unterjichetben und bie lescteren in Heberetnitimmuntg mit Dem geiftigen 3uftande des Seitalters zu modifizimen baben.

Sid) mill nicht bei $\mathfrak{A}$ ngaben vermeilen, weldye bedentenden Männem zugejdrieben werden und vielleidyt in Den Şlättern unvollfommen wiebergegeben finto anto idy getse baber über eine von Dem SBijchof oon Manchefter angeblidy fürzlich) gebaltente Drebigt mit Der Semerfung binmeg, Dafi jemand, 
Der in einer jo vielfeitigen und mie id) nidft bezmeifele im

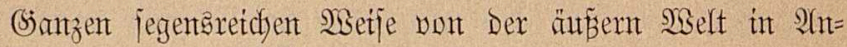
iprud) genomment ift wie er, idywerlich złt Denent gebörent fant, weldhe am fritheftent bie mefyr innerlichen unto geiftigen Beichen Der Beit unterfcheiden unt Den Buftant, meldyen Die= jelben voratsperfïnden, vorbereiten.

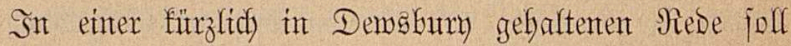

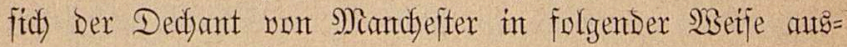
geiprodben Gaben:

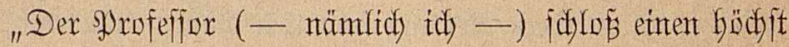

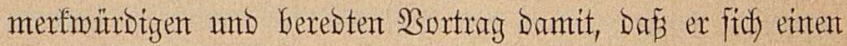

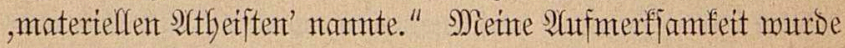
auf Dieje Acufentutg Des Dechantent (Sombe Durdy einent (5orrejpondenten bingelenft, weldyer biefelbe als unter Den vielen fonderbaren Serfeumbungen, mit meldyen meine 290 orte angegriffent wordent fint "bejonters Gervorragend" bezetdynete.

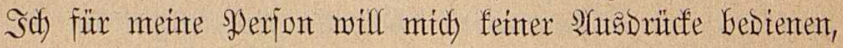

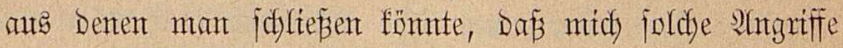
verlebert. Sie haben thre firaft zut vermumbent oder fube= leibigen verlorent.

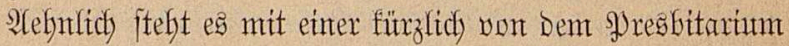

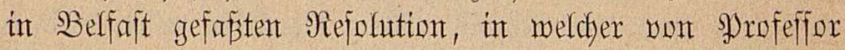
5utrler) und mir gefagt mird: "mir ignorirten Die Exiftenz (Sottes 1tnd rebeten eintem nacten Materialismus Das 230 ort."

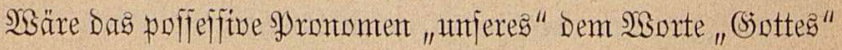
vorangegangen, und mären Dem 290 orte "Inadten" Die 23 orte "nach unjeren Segriffen" vorangeftellt, fo märe bie :Angabe objeftio walyr gewejen; aber unt fie dazı zu madyen, wäre Diefe Bezectimuting erforderlich gemejent.

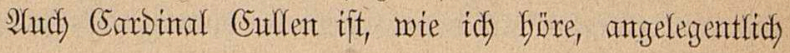




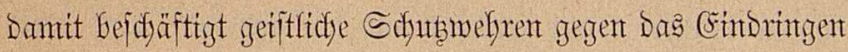
Des Itnglautbents in Srlanto zat erridytent. Seinte Cemintenz

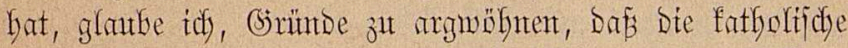

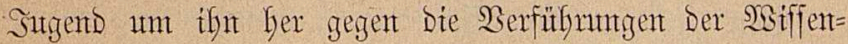
idyaft nidyt gefeiet ift. Irobs feiner Stärfe halte idy thit

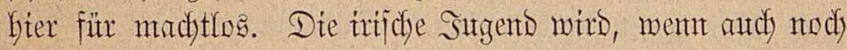

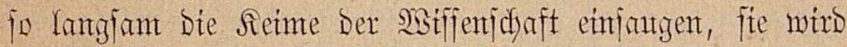
fich, went autd) nodh io alfmatlig mit ibrem Sautenteige

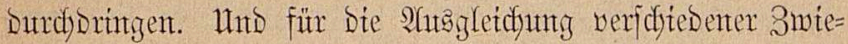
fpaltigfeiter, - unter weldyen jente mittelalterlidyen $\mathfrak{D}_{\mathrm{r}} \mathrm{r}=$ zedurent, weldye zum Sfantorl unt zum Stauttent ber Sntellt=

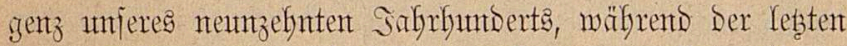
betoen Sabre mieder in's Reben genfent worden fints, obentan fteben -, vertrate idy mebr auf bie inmere mobifizitrente Siraft bes Ratholizismus als auf tirgento einte proteftantifche Dropaganoa oder andere äutere Cimflüffe.

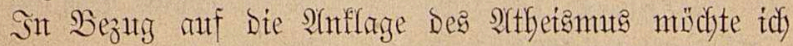
mix nod) eine Semertung erfautbert. Shriftlidye Miämer baben, wie ifre Sdyriften bemeifen, ifre Stuntoen Der Sdymäche und des 3meifels fo gut wie ifre Stumben ber Stärfe unt der Heberzeugung und Miämter wie idy werden in ibrex 2 setje gleidhfalls von biejen wedfjelntDen Stimmuntgent

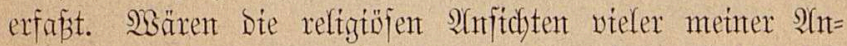

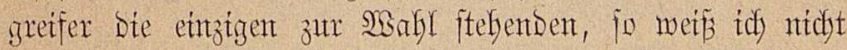
mit mefdyer Siraft Die Doftrin Des matertellen 2(theismuts

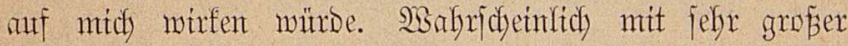
Siraft. F(ber wie Die Dinge ftefent, hatbe tidy währento Sabre

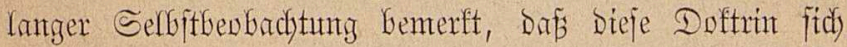

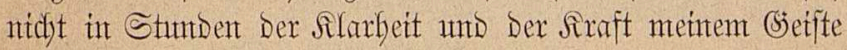
empfieflt und Dafi fie bor ftärferen und gejüntberen (Sje= 
Danfen immer wieber zerffieft und verichwindet, Da fie feine Röfung Des Minftertums bietet, in welcyem wit berbarrent unt you welifyem wir einen Ibeil bilden.

Bon gröberen Shgriffent unt Demuctationten nebme id) feine Notiz; audb babe idf feinen eigentlictlen (Sinnto

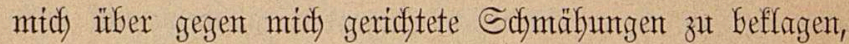
wie fie Seute, bie mit ihrem Shriftentfyum prunfen, mie leidyt Bemiejent merben finnte, fein Bebenfent tragent gegent eintantber zu gefrautchent. Mitr bleibt ntr noch bie ange= nefmere S2ufgabe, Denen zu Danfen, meldye Den, ment auch

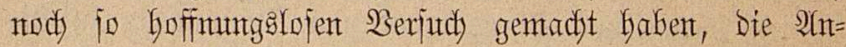
fdyutbigntngen in Den (sirenzent Der (sieredytigfeit zut Galten

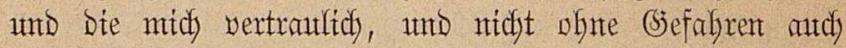

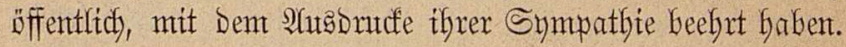

ROMDOH.

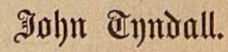

15. September 1874. 
(in Dem Menjujen eingeborener Irieb lentte feine (̋edanfen uno 3meifel früfzeitig auf bie Duellen ber Raturerjideinungen. Derjelbe angeerbte Irieb bitbet verftärlt auth heute Den Sporn

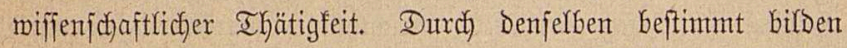

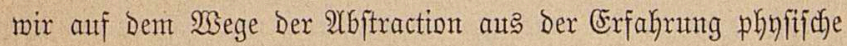
Theorien, weldhe über Das BBereidy Der Erfahrungen Ginaus Yiegen, melche aber Das $\mathfrak{B}$ erlangent Des (Beiftes, jebes natürlidje $\mathfrak{B}$ or=

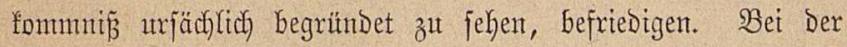

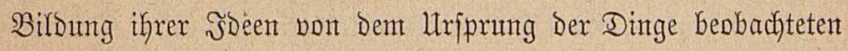
unfere früheften hiftorifchen uno, Dürfent wir unzmeifellgaft hitt=

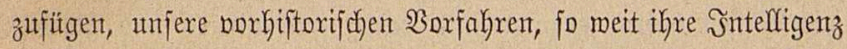
es ifnen geftattete, Dafferbe Serfahren. 2tutch fie gingen auf bie

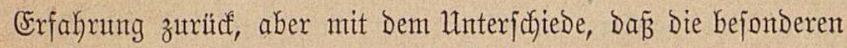

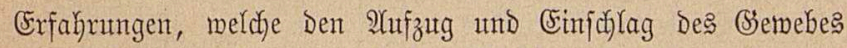
ifyer Iheorien Yieferten, nicht bem Stubum Der Natur, jontorn Der ifnen viel näher liegenden Beobachtung Der Mienfiden ent= nommen war. Demgemäß nahmen ifye Iheorien eine anthro= pontorphifde Beftalt ant. Die Beberridunt und Reitung Der

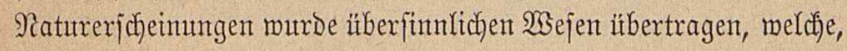
"wenn audd mädftig und unfidutbar, Doch nidfots maren als eine

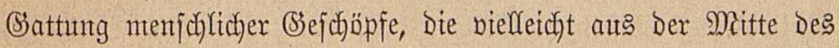

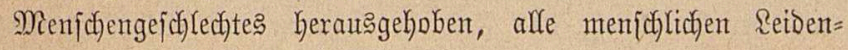
(id)aften und Begierben befielten *)."

*) Hume: Natural History of Religion.

İnoall, Naterialismus. 


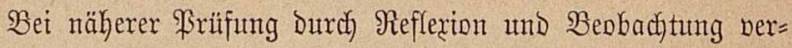
mochten bieje erften Joben auf bie Dauter bie fdarffinnigeren (Seifter nidgt zu befriebigen. Sn frühen hiftorifdhen Iagen fin= Den wir Männer bon ungemöhnllicher $\mathfrak{B}$ egabung, bie fich at? Der Menge Kerautheben, Dieje anthropomorphijden Worftellungen

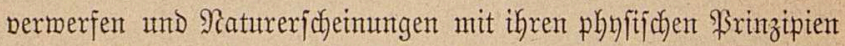

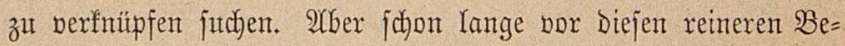

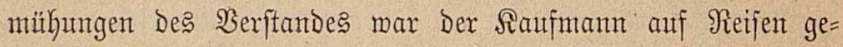
gangen und Katte Dem Raturforjhyer Die WSege gebahut; Der

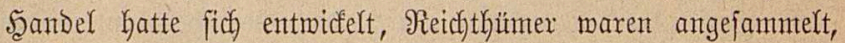
Mure zum Reijen und zur Spefulation war gemonnen uno

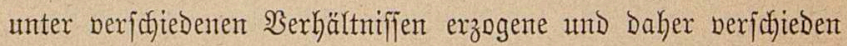
unterrichtete uno begabte $\mathfrak{B}_{\text {ölfer }}$ hatten in iffrer gegenjeitigen $\mathfrak{B}_{e}=$

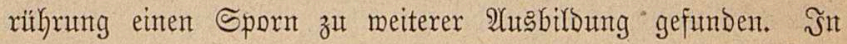
jenen Segenden, tov Die Scandelsariftofratie Des alten Briedjen=

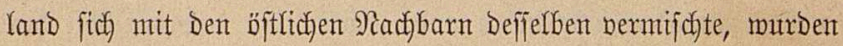
Die Wiffenfichaften geboren unt Durdh fretbentende und muthige Männer genährt unı entwidelt. Der 3uftand Der Dinge, meldyex Durch) einen andern zu erjeţen mar, fann aus einer von Scume citinten Etelfe Des Euripides geidlofifen merDen: "J̃n Der Welt

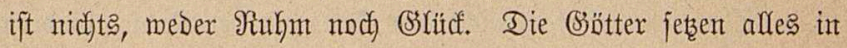
Serwirrung, wermifichen jebes Ding mit feinem Begentheil, auf

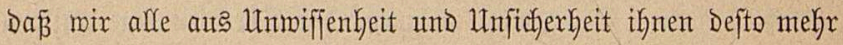
Efrrfurcht und 2(nbetung ermeifen." Da nut bie Wififenjidaft

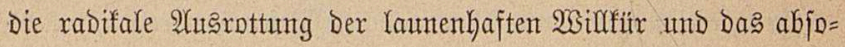
lute Bertrauen auf Die Naturgefeţe perlangt, entfand mit Dex

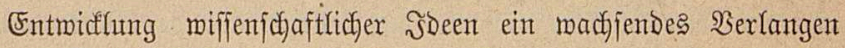

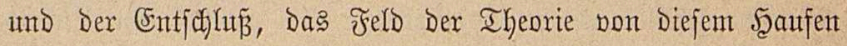
won SB̈̈ttern und Dämonen rein zu fegen und Die Naturer= fajeimungen auf eine, Denferben entjprechendere Bafit zat ftellen. 
Das Froblem, weldyem man fid früber wont oben her ge= ntäbert hatte, murbe ję̧t bon unten her in 21ngriff gentomment. Die theoretij(t)en Berjutche gingen nom Ueberfinnlichen zum Unter=

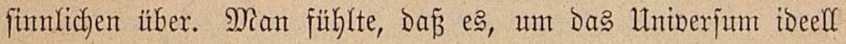
auffubauten, nothmendig jei, eine Borftellung von feinen Beftant = theilen, von Dem zut geminnen, was Sutcretus fpäter bie "exften

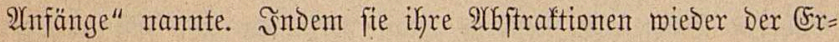
fahrung entnahmen, gelangten bie Fühlyrer ber wiffenjodyaftlidyen Spefulation endlidd zu ber folgenreidjen Doftrin Der 2tome uno Der Moleculen, Deren neutefte Entwidflungsphaje in Der Yeşten Berjammlung Der British Association fo flar Dargelegt morbent ift. Das Denten hatte fid ohne 3 weifel lange unficter ichman= fend mit biejer Doftrint bej fäftigt, bevor fie bie Fräzifion und

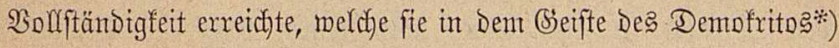

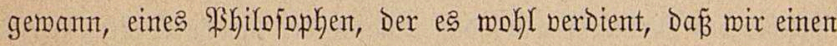
2(tugenblid bet ihut permeilen.

"Wentge grop̧e Miänner, “ jagt Rantge, ein Miçyt= Materialift, in feiner vortrefflidfen Beidfidfte Des Materialisnub, Deffen (Beift

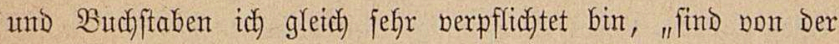
(Siechichte fo fajledft befjandelt worbent mie Demnfrit. Int Den Durrif) unmiffenf(c)aftliche Irabitionen auf uns gefommenen ent= ftellten Bildern Gleibt won thm faft nichts übrig als Der Name Des lachenden \$̧Gilojophen, während fich (Sieftalten von unendich

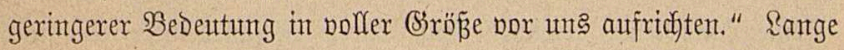
fpricht Dann non Baco's hoher Sdjäţıung Demofrit's. Sffenbar fielt Baco Demofrit für einen Miann von gewidftigerm B̈efalt

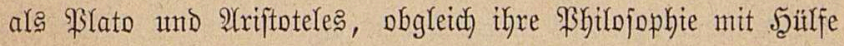
Der pomphaftent 2tnpreifungen bon Frofefforen in Den Sdyulent

*) geboren 460 vor 巨̧̧r. 
Yaut gefeiert und verbreitet murbe. Nituft fie jeboch, fontorn (Senferich) und Aftitla und bie Barbarent waren es, welche bie atomifitiche \$hitojophie zerftörten: "Denn zu einer 3eit, mo

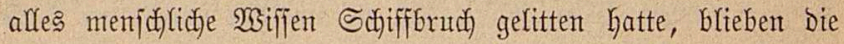

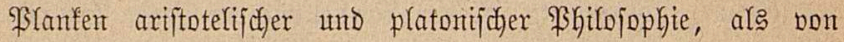
reidfterm unto luffigerm Stoff erbalten und famen auf uth, mährend Dinge von fefterm Stoff verjanfen uno fajt in $\mathfrak{B e r}=$ geffenheit geriethen."

2(IS Soln eines reidjen Waters verwandte Demofrit feit ganzes ererbtes $\mathfrak{B}$ ermögen auf Die 2Uuffildung jeines Beiffes.

Er reifte viel umber, bejutchte 2 then zut einer 3 eit, wo autid Sofrates und Plato Dort waren, verliḗ aber bie Stadt mieber, ofne fid befannt gemadjt zat habent. Der bialettifiche Rampf, Dent Sofrates fo fefrr liebte, hatte feinen Reiz für Deunofrit,

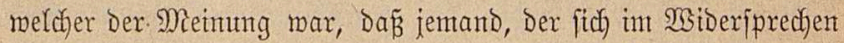
gefällt und gern biele Worte mad)t, unfähig fei, nirgend etwas

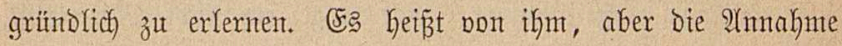
ift zmeifelthaft, Daß̧ ex Den Sophiften Frotagoras entbectt und erzogen Kabe, Defien fdyarfijimige Unterhaltung ihn nidft minder frappirte als jeine 2 Yrt, Das Scolz in Büntel zu bindent, - er mar Scolzhater. Demnfrit fehrte arm vont jeinen Reifen zurüd; ;eine

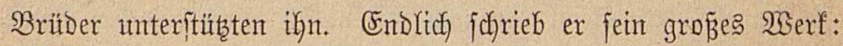
"Diafosmos" Das er Bfffentlich in feiner Vaaterftadt vortrutg.

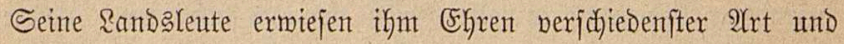
ex ftarb heiter in hohem arter.

Die bon Dentofrit ausgepprodyenen Frinzipien offenbarten jeinen unverpöhntichen 21ntagonismus gegen Diejenigen, weldje bie Naturerichetmungen auf Die Raunent Der (Sötter zuriưffüffrten. Dieje Frinzipien find furz Die folgenden:

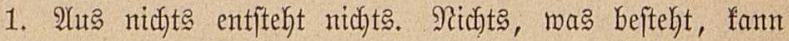




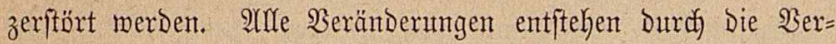
Ginoung unt Trenmung Der Mioleculent.

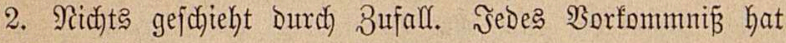
feine Itrjache, aub Der es mit Notfinendigfeit folgt.

3. Die einzigen exiffirenten Dinge fint bie 2 tome unt Yeerer Raum; alles andere ift mur 2 trifidyt.

4. Die 2tome find umendlidy an 3 ahl und unendlich ber= fodieden an Beftalt; fie ftopen an einanber und bie Seitenbe= megungen unt Schiningungen, weldhe fo entftehen, fint bie $2(1)=$ fä̀nge von 2 Belten.

5. Die Mannigfaltigfeit aller Dinge hängt pon Der Man= nigfaltigfeit ihree 2 ttome an 3 ahl, Beftalt und Mengung ab.

6. Die Seele befteht auts freien, glatten, rumben 21tomen, wie bie Des Feuers. Das find bie bemeglicffften aller 2ltome. Sie Durdjoringen Den ganzen $\Omega_{0}$ rpper und in ifren BBemegungen entftehen Die Ericheinumgen bes Rebents.

Die fünf erften Säķe fann man ars Dent Jnbegriff Deffen bezeidfnen, was noch heute jür bie atomiftijche \$shilojophie gilt. Was Den jeçsten anlangt, jo ließ̄ Demofrit jeine glatten, rum=

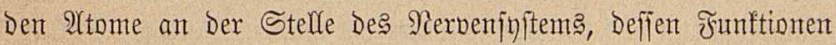
Damals unbefant waren, fingiren.

Die 2ltome Des Demofrit find einzelnt ofne Empfindung. Sie verbinden fich, indem fie medfanijdyen (Befetzen gehordhen unto nidgt mut organifde Formen, fondern aud bie Ericheimutn= gen Der Empfintung und Des Denfens find Das Ergebnifí ifrer Verbindung.

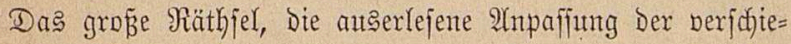
Denten Theile Des Srganismus an einander und an bie $B e=$ Dingungen Des Rebens, insbejondere Die Conjtruction Des menjd)= lidyen Rörpers zu löjen, madhte Demofrit feinen פ̉erjucty. 
Empedofles, ein Mann bon feurigem Iemperament und

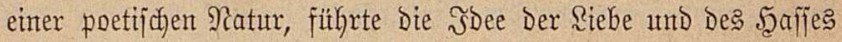
in bie Attonte ein, int ifre Berbindung unto Trentung zu ex= flären. $2(15$ ex Dieje Süffe in Der Refre Des Demofrit, entDedte, trat er mit Dem, menn audid) mit einigen bermegenen Speft=

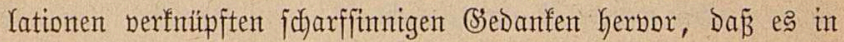
Der Ratur jenter Berbindungen, meldje ifren 3meden entjpräiben, mit anderen $\mathscr{B}$ orten mit ifgren Untgebungen in Einflang ftänden,

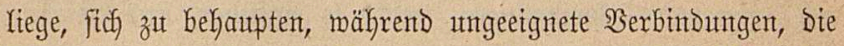
feine eigentliche Seimathgberechtigung haben, rajcher jojwinden mitffen. So Gatte fafon por mehr als 2000 Sabrent Die Sebre Des "lteberlebens des Fäbigiten," meldje in unjeren Iagen nicht auf (S)und pager (Eonjecturen, fondern pofitiven Wiffens Durd) Darmit zu auperorbentlicher Bebeutung erbobent morben ift, einen mindeftens theilmeijen Utaborut gefunden*).

(Epifur*:), angeblid Der Sohn eines armen Sdhullebrers auf Samos, ift bie nächite herborragende Beftalt in Der Sise=

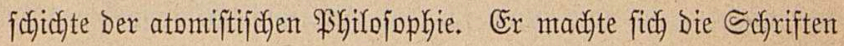
Des Demofrit zu eigen, hörte $\mathfrak{B}$ orlejungen in 2 (then, fehrte nach) Samos zurüd und Durdjreifte fpäter veridjtedente Sänder. Sdjlief̧=

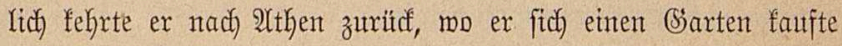
und fid) mit Sdyullern umgab, in Deren Mitte ex ein reintes Geiteres Seben füfyrte und eines friedlichen Iodes ftarb.

Demofrit betrachtete bie Seele als Den beredelnden I geil Des Menjohen; jelbft Sdjönheit ohne Beift gehörte fïr ifn zunt

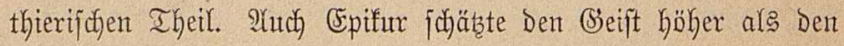
Rörper; Das Sergnügen Des Rörpers max für ifn ein vorüber= gehendes; wäbrend Der Beift Der 3ufunft und Der Bergangen= beit zugleicf theilfaftig merben fonnte.

*) \&ange. 2. 2uffl. pag. 23.

***) geboren 342 vor (cf)x. 
Seine PGilofophie war mit Der Des Demofrit faft toentif d), aber ex citirte nie meder Frreunt noch F̌eind. Ein Scauptzmect Des CFifur war, bie Welt vom 2 Kberglauben und Der Tobes= furcht zu befreien. Den IDd behandelte ex als etwas gleidid= gültiges; er beraubt une nur der Empfindung. So lange wir exifftiren ift ber ToD nidyt und ment ber Iod ift, find wir nitcht. Das Reben bietet feine Hebel mebr fint Den, Der mit fidf

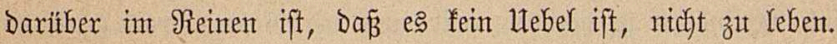

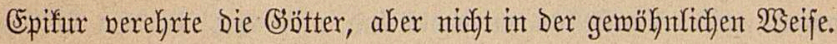
Die angemefien gereinigte Эoee Der göttlichen Miact)t hielt er

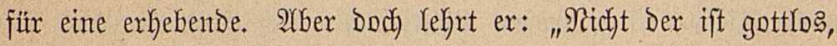

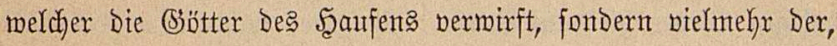
welcher fidd zu ihnen befennt." Die (Sö̈tter maren fïr ithn emige umb unfterbliche 2 sejen, Deren Seligfeit jesent Sredanfen an

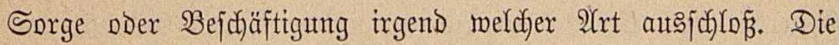

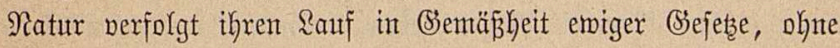

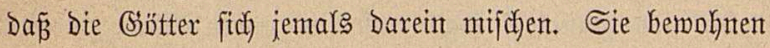

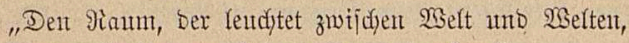

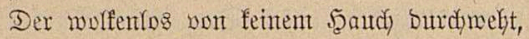
2So nie som Sajnee ber ffeinfte Flofent fällt, Noclf ie ber Domer leife rollento tönt,

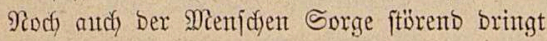

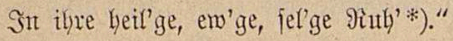

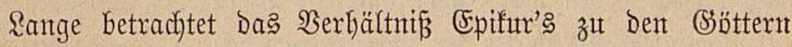
"als jubjectiv," wahricheinlich) Die Neigung eines ethif hen $b e=$

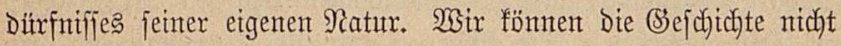

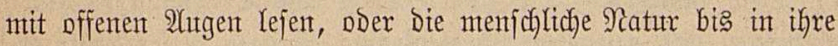

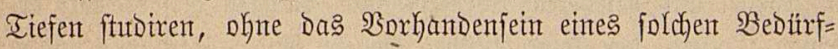
niffes anzuerfennent. Der Mienfich hat fid) nie mit Den Dpera=

*) Tenntion's sucre?. 
tionen und Brodulten bes Berftandes allein begnügt und wirb fitc) nie Dantit begnitgen; Daker fann Die Raturmiffenfichaft nidjt

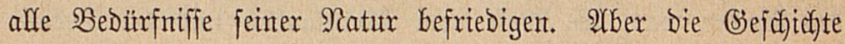

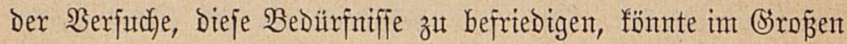

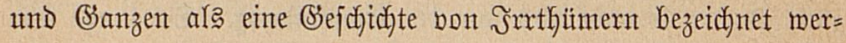
Den, indem Dex Эrrthum zum gropen Iheil Darin befteht, Dafis man bas fuxiren mill, mas jeiner Ratur nach flüffig ift, was fich berändort je nachben twir ung veränbern, mas grob ift ment unjere $\mathfrak{B}$ orftellungen grob fint und was in Dem Mape wie unfere ₹raffungsfraft fidf ermeitert abftracter und erbabenter mird. Heber einen grofen \$intit fühlte fich Epifur's Beift be= rubigt. Weber fier auf Erben noch fpäter jutfte ober ermartete

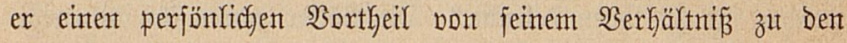

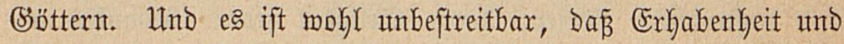

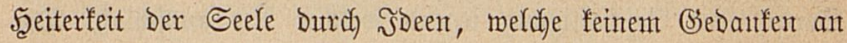

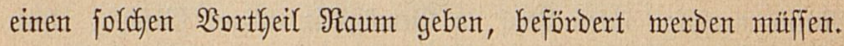
"WWenn idf nicht glaubte," jagte einft ein grofier Mann zu mix,

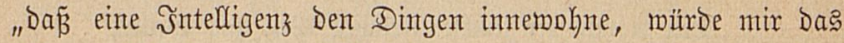
Reben auf Eroen unerträglich fein." Der Diejen 2(usjprutch that,

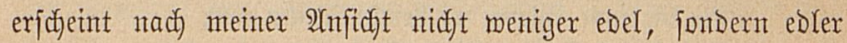

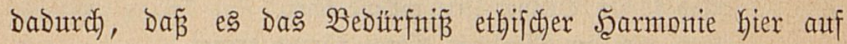
(ErDen und nicht Der Sedante an einen perjönltchen Sortheil nach Diefem Seben mar, mas ifm jene Bemerfing eingab.

Menfojen, die weber ber hödjften noch Der niebrigften geiftigen Sphäre angebören, ‘äß̈t oft bollfommene Silarkeit auf Mangel an Tiefe fobliepen. Sie funden Troft und Erbaunth in einer abftracten und gelehrten \$hrajeologie. Einigen Diejer Reute er=

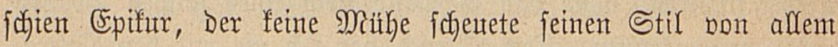
Trüben und Itnflaren freizumachen, eben beshalb oberflächlich. (Fr Katte jedody einen Sdjulfer, Der ę für feine unmürdige $\mathfrak{B} e=$ 


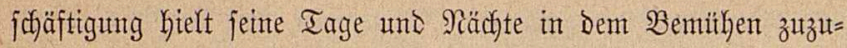
bringen, Die Rlarheit jeines Refrers zut erreichen uno weldyent

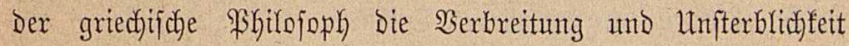

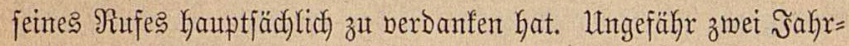
humberte nach) Dem Tode (Epifur's fajrieb Sucrez*) fein grofées

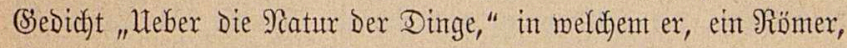

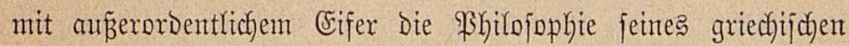

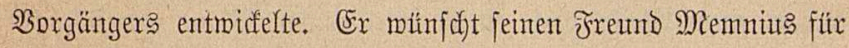
Die Schule Des (Epiffur zut geminnen uno, obgleich) er ifym feine Belohnung in einem fiunftigen Reben zu bieten hat, obgleid jein 3 medf ein rein negativer zu jein jofeint, rebet er zut feinent Freunde mit Dem Feuereifer eines 2(poitels. Sein 3meef ift, mie Der jeine?

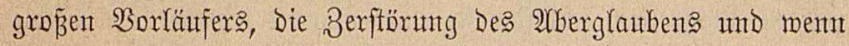

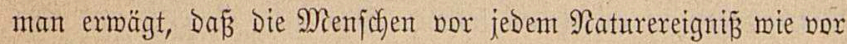
einer Directen Mahnung Der (Sötter zitterten und Daj fie audf) emige Sualen ermarteten, Darf man bie Freikeit, welche \&ucrez anftrebte, vielfeicht als ein pofitives (3iut betrachten. "Diejer

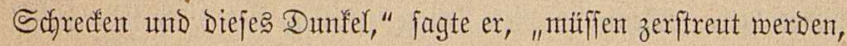
nicfyt Durrch Die Strablent Der Sonne und Die glänzendent \$ffeile

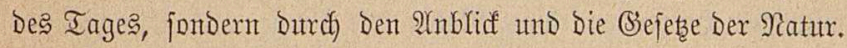
Ex miserlegt bie Borftellung, Dap (Etwas aus Nidcts entfehen fömne, oder, Daß mas einmal entfantanen jei, wieder in bas Nidjts

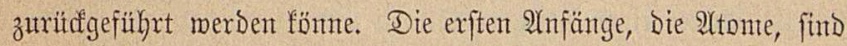
unzerftörbar und in fie fönnen fdhfiepllid) alfe Dinge wieber auf= gelöft merben, Rörper fint theils 2tonte, theils $\mathfrak{B}$ erbintoungen von 2Ytomen; aber bie 2 tome fönnen Durch nichts zerftört merden.

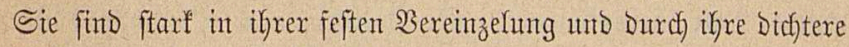
Verbindung fönnen affe Dinge eng zufammengebrängt merden

*) geboren 99 vor (Ef)r. 
und Dauternde Rraft geminnen. Ex leugnet, Daß̃ bie Materie un=

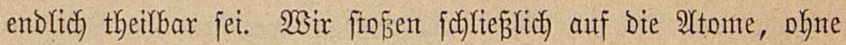
melche, als eit unzerftörbares Subftrat, alfe Sromung in Der Erzergung und Entwidflung Der Dinge pernichtet merden mürbe.

Da Der medjanifache 3ufanmenfto

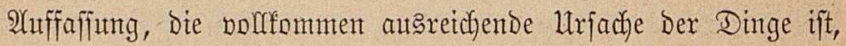
fo befämpft er Die Sorftellung, Daß̧ Die Billoung Der Natur in irgend einer Weije nach einem intelligenten Flane bor fid ge=

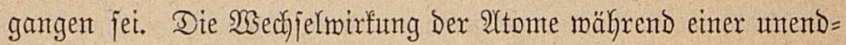

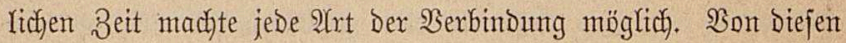

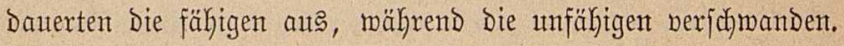
Nidut nady meifer Heberlegung ftellten fich Die 2Ytome an Den

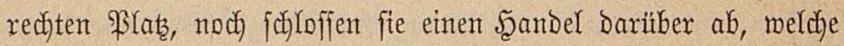
Bemegungen fie annebmen jolltert. Bon alfer Eroigfeit her fint fie zufammen getrieben und nachdem fie Bermegungen und $\mathfrak{B} e r=$ einigungen jeber $2($ rt berjudft hatten, famen fie zulleţt in bie Rage, auts melcher fich Der gegennärtige 3uftand ber Dinge herantsge= bild bet Kat. "Went Du Dieje Dinge erfaffen und fefthalten millft,

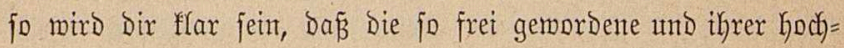
mütfhigen Scerren entledigte Ratur alfe Dinge, ohne Eimmiicdunt Der (Götter, unmilffiurliç) von felbft thut." Utm Dent Einmantse,

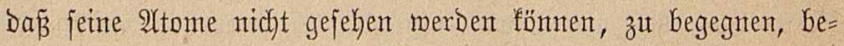

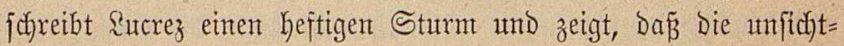
Garen Iheildent der Ruft in Derferben $23 e i f e$ verfahrent, wie bie fidftbaren Theilchen Des 23 affers. So gemahren mir aud bie berjdjiebenen (Sereildhe Der Dinge und jehen fie Dod) niemals an

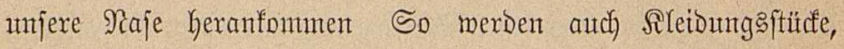

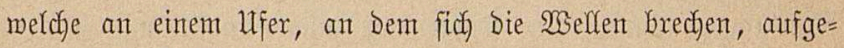
Gängt find, feudft uno bann wieber, wenn fie in Der Sonne auts= gebreitet waren, troden, obgleid) fein 2 luge meder bas Sceran= 
naken, noch Das Serjominden ber Waffertheildyen jeben fann. Fin lange am Jinger getragener Ring mirb Dïnner, ein Iropfen

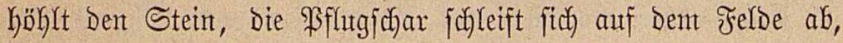

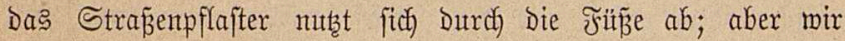

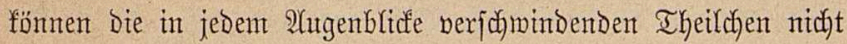
jeken. Die Natur wirft Durdi) unfid)tbare Theildyen.

Die vorftekenten 2 ngaben bemeijen, Daf́ suterez eine lebhafte,

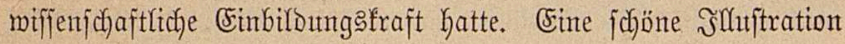

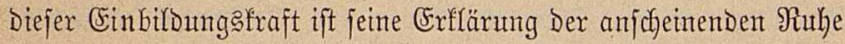

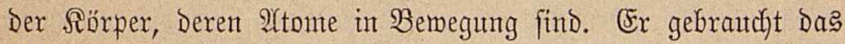
Billo von Schafen mit Kïpfenden Sänntern, weldye ants ber Ent=

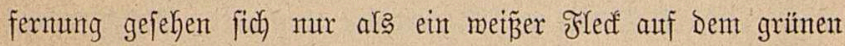
Şitgel Darftellen, währent Das Springen Der einzelnen \&ämnter ganz unfict)tbar bleibt.

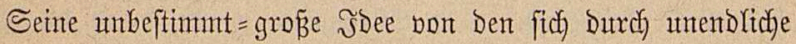
Reiken von 3eit und Raum funmeigend exgief̧enden 2Ytomen gab Sint bie von ifm zuerft aufgeftellte Scypothefe in Setreff ber Rebelfterne an bie Scano. Weit über bas Bereid) unjerer fidht= baren Welt hinats finden fich unzählige 2ltome, welche niemals zu Sörpern bereinigt waren doer welche, wenn fie es je waren,

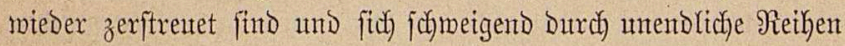

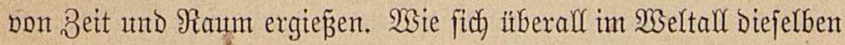

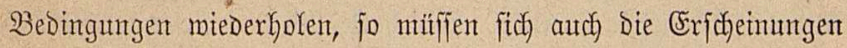

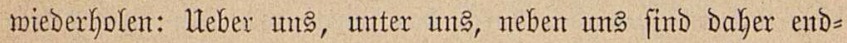

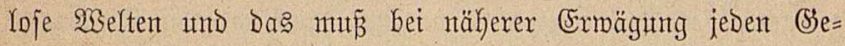

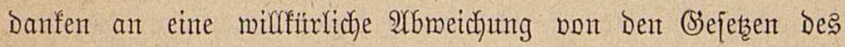
Inniverjume Durd́) Die (G̈ötter zerftrenten. Die Welten fommen

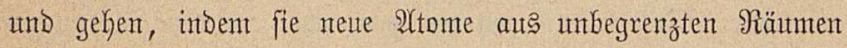
anziehent.

Der befannte Iod Des Rucrez, Dex Dem fdbönen (Sebidfte 


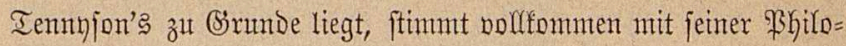
jophie ïberein, welche ftreng und rein war.

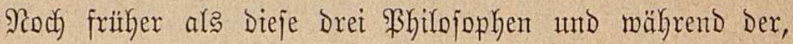

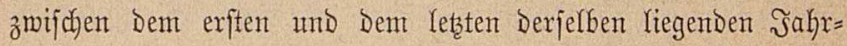

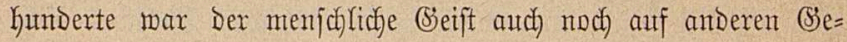
bieten thätig. Futhagoras batte eine @dyule von Miathentatifern

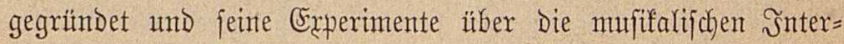
walle gemadjt. Die Sophiften hatten ihre Saufbahn Durdgemaddt. In 2Athen waren Sofrates, Flato unt 2lriftoteles erjojienten, meldye bie Sophiften ftitrztent und Deren Sod) nod) bis auf Diefe Stunde nidgt völlig abgejdyüttelt ift. Während biejer ßeriode murbe autd) Die Sdfule pon Iffexandrien gegriundet. (Euflid idfrieb feine "Elemente" uni madite einige Fortfdritte in Der Sptif. Urchintedes hatte Die Theorie Des Şebels und Die \$rrinzipien Der Schoroftatif feftgeftellt. Die 2Yftronomie murbe Durdy Die Ent=

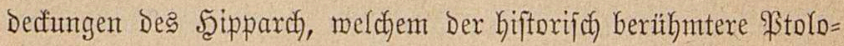
mäus folgte, auferordentliç) bereichert. Die 2(natomie mar zur Bafis ber miffenjidfaftlidjen Mesizin gemacht morden uno nady Draper's*) Bebauptung madfte man Damals Den 2hnfang mit Der Bivifection. In Dex That hatte bie Wififenjdyajt Des alten

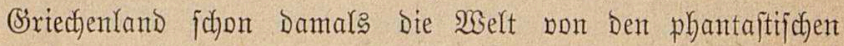
Billdern bon Bottheiten gereinigt, welche nach igrer Willfiur mit Pratureridjeinungen fdalten. Sie hatte fid bon Diejer furdftlojen Unterfuctung "Yesiglich Durch Das imere Ridyt Des (Beiftes frei gemacht," melder wergebens werjucht hatte itber Die Erfahrung

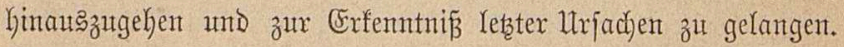
Statt zuffälliger Beobachtung hatte fie zmedfbemuß̈te Beobachtung eingeführt, Jnftrumente murben gebrautcht, um Den Sinnent zu

*) History of the Intellectual Development of Europe p. 295. 
Şülfe zu fommen und wiffenidjaftliche Methode murbe ourch bie Bereiniguttg von Snduttion und Exfahrung in bohem Sirabe vervollfommnet.

Was that Denn feinem fiegreichen Fortidyreiten Einhalt? Warunt murbe ber miffenichaftlidye (Seift genöthigt, wie ein er=

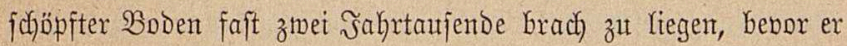
Die zu jeiner Frudbtbarfeit und fraft nothmendigen Elemente miebergeminnen fonnte?

Baco bat uns bereits mit einer Utrjache befannt gemadjt; Wrhemell fanreibt dieje ßerinde Des Stillftandes vier Urjachen

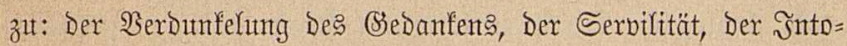
Yexanz uno ben Enthufiasmus und bringt für jede biejer $1 \mathrm{r}=$

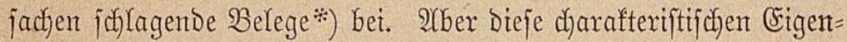
idaften mitffen ifgre Utrjacjen gebabt Kaben, weldye in ben Ver= bältniffen der Beit lagen. Font und die übrigen Städte des

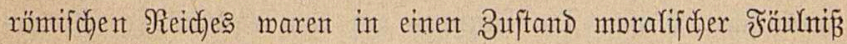
gerathen. Das Ehriftenthunt max exjefienten, Gatte Den 2(rment Das Evangelum gepredigt und Katte Durch Befördenung einer mäßjigen, menn nicht ascetijden Sebensmeije praftijd gegen bie Sermorfentheit Des 3eitalters proteftirt. Die RetDen der erftent Chriften und Die außzerordentliche Begeifterung, welche fie in Dent Stand jetzte, über bie teuflijdyen Martern, mit Denent fie ge= peinigt murben, zut trimmbliren, mitffen nicht reidft vertilgbare Spuren bei thnen zurüclgelaffen Kaben. "Sie verachteten Die

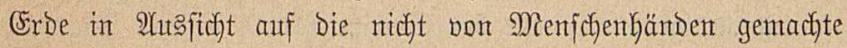
emige 2 bohnutg in Scintmel." Die Sdyriften, weldye zut $\mathfrak{B} e=$ friebigung iffrer geiftlichen B̧ebitrfniffe dienten, bildeten auth Das

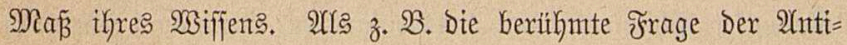

*) Tiistory of the inductive Sciences. Volume I. 
poden zut Erörterung fam, war bie Bibel für viele bie leţte

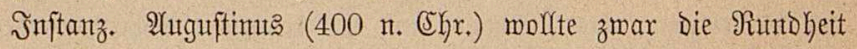
Der Erobe nidft lengnen, molf aber Die Mëglichfeet ber Exiftenz won $\mathfrak{B}$ ewohnern auf ber andern Seite, "meil feines folchen Stanmes in Der heiligen Sa)rift unter Den Niachlonmen 2 (Dam?'s

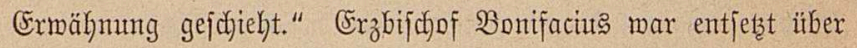
Die 2 mahme einer "2Welt boll memjoflidjer 2 ejen, Denen bie Mittel Des Şeiles nidft erreidjbar feier." $\subseteq_{0}$ eingeengt hatte

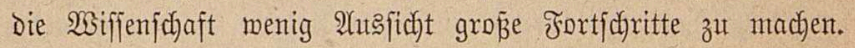
Später mur ber von Doraper io anjchaulfich) gejchilderte politifche

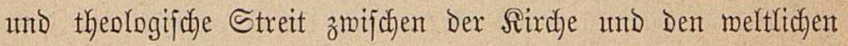

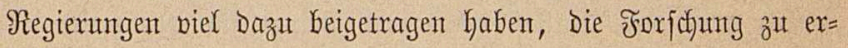
fitifent.

Whemell macht viele fodarffinnige unt portreffliche SBemer= fungen in Betreff Des Beiftes Des Mittefalters. Es mar ein fnechtifcher Beift. Die Forjcher auf Dem (Bebiete Der Siatur= miffenjidaft hatten jene Sutelle Yebendigen Wajfers, Den Directen Itppelf an bie Natur Durch Benbachfing uno Experiment ver=

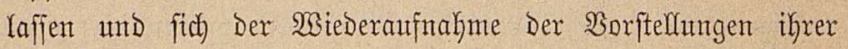
Voorgänger Kingegeben. Es war eitre 3eit, mo der (Bjedante werachtet mar und mo Der 2lutoritätşglaube, wie er es immer in Dex Wiffenj(d)aft thut, zu geiftigem Iobe füfhrte. Natur= exeigniffe murben amftatt auf phyfifde auf moralifdje Utractjent

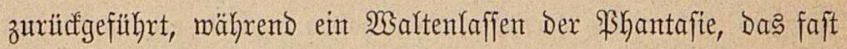
fo entmitrdigend war wie Der Spiritualismus unjerer Tage, an Die Stelle miffenfichaftlicfer Spefulation trat. Dam fam Der Minfticismus Des Mittelafters, Magie, Alfchemie und Die nen= platonijche \$Bgilojophie mit ifrent vifitonären, menn autd) erbabenent 2(bffractionen, weldye Die Menjofen Dazu brad)ten, fich ihree

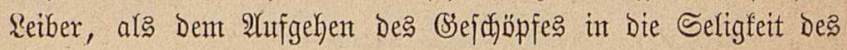




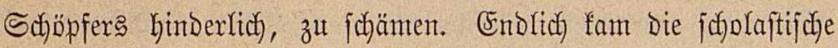

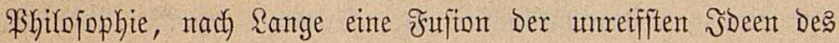
2lriftoteles mit Dem Cohriftenthum Des Weitens. Das Rejultat

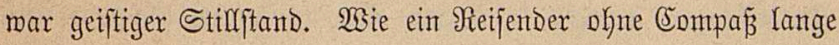

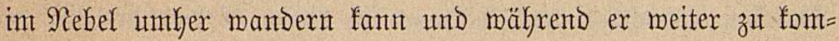
men glaubt, fich nadf ftundenlangem, anftrengendem Maridje mieder an feinem 2lutgangapuntte befindet, befanden fidy bie Sdyolafitifer, nadjoem fie biefelben Sinoten gefnutpft und gelöft

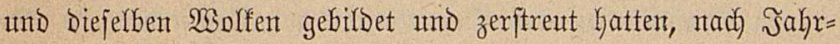
Gumberter noch auf Demferben Funfte.

Heber Den won 2rriftoteles im Mittelalter und, wem aud

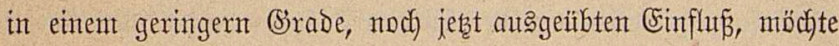
idi) mir eine Bemerfung erlauben. Wenn ein menjodficter (Beift

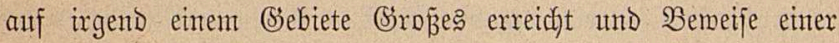
auferorbentlidjen Begabung gegeben hat, fo madjt fid eine $\mathfrak{T}$ en = Denz geltento, Demfelben einte ähnlict)e Begabunt auf allen an= Deren Bibbieten zuzutrauten. So haben Theologen Iropt, und

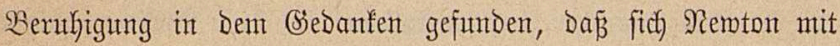
Der Frage Der Sffenbarung bejdäftigt habe unt baben Dabei

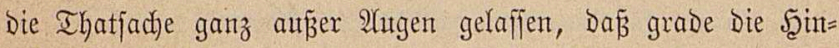
gabe jeiner Ŝäfte mährent jeiner beften Rebensjakre an einen ganz anbern Jocenfreis, ganz abgejehen won einer etwaigen

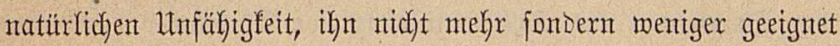

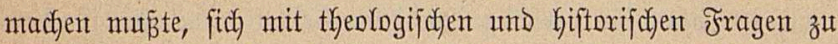

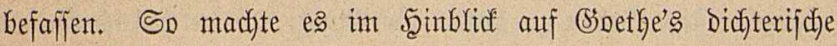
(Bröß̈e und auf feine pofitivent Entbectungen int Biebiete Der Raturmiffenjidaften, auf bie Deutfdyen Maler einen tiefen Ein=

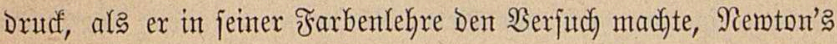
Jarbentheorie über Den Scaufen zu merfen. Die Theorie fielt

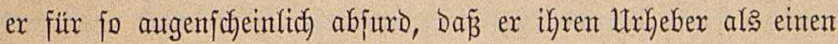


(E)arlatan betradfete uno ifn mit einer, biejer 'luffafiung ent= fprechenden Retienidjaftlichfeit Der Sprache angriff. SUuf Demt Gebiete Der Naturmiffenichaftent Gatte (Soethe wirflich bedeuttende Entbecfungen gemadjt, und mir find in hohem (Srabe zu Der

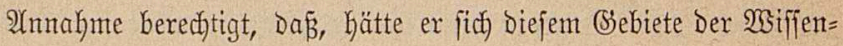
jofaft ganz gemiomet, ex auf Demfelbent eine, feiner bichterifdent

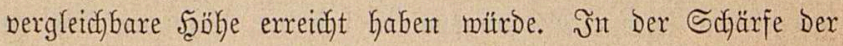

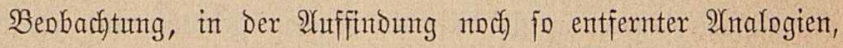
in Der Rlafifififation uno Drganifation von Thatjacten, in (Bes

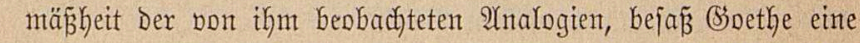
तuperoronentliche Begabung. Diefe Elemente miffenfichaftlicher Ulnterjuthung fallen mit Den für Den Didjter erforderliden Eigen= ichaften zufammen. Writbererjeits aber fant ein für bie Ratur= wiffenifdaften fo reid) begabter (Beift in Bezug auf Die inn entgern

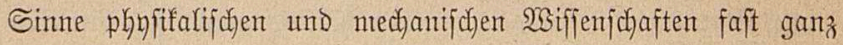
unbegabt feir. So war es bei (S)othe. Er fornte feine beftinumte

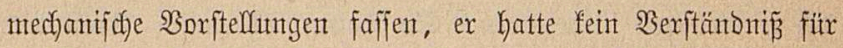
Die Sraft mechanifcher 2lrgumentationen, unt auf Biefieten, melche non folchen 2 rgumentationen beherrfdyt merden, war ex nur ein ignis fatuus für biejenigen, welche ihm folgten.

Эa) habe mir bismeilen exlaubt, 2Yriftoteles mit (5oethe zut vergleidyen, Dem Stagiriten eine faft übermenjobliche Jä̆bigfeit Dex Sammllung und Eyftematifirung von Thatjadjen zuzuerfen=

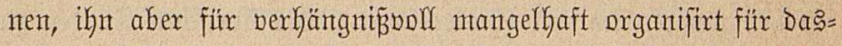

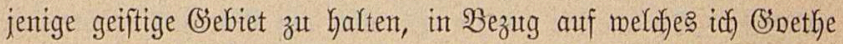
als umzulänglichy begabt bezeichnet habe. Whkemell führt bie Jrr=

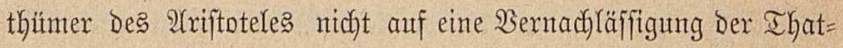
fachen, jombern auf eine Bernachläjfitgung Der Den Thatjacjent

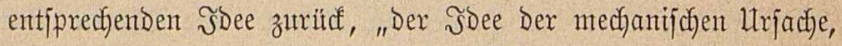
melche Siraft ift und Die (Erjeţung Diejer Joee Durd) page Doer 
unanmenobare $\mathfrak{B}$ priftellungen, Die mur räımlidje $\mathfrak{B}$ eżiehungen ober Gefühlle Des Staunens enthalten." Das ift unzmeifelfaft ridytig;

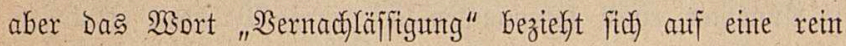
geiftige Mifleitung, während es bet Ariftoteles mie bei (Spethe,

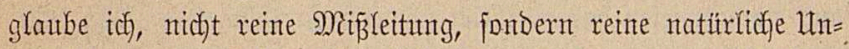

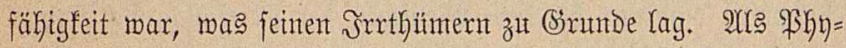
fiter entwickelte Âtriftoteles, was wir für bie fdjlect)teftent Eigen=

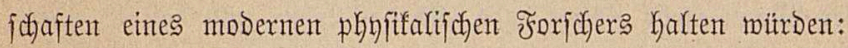
Itnflarkeit Der ŞDeen, geiftige Bermirrung und eine zuverfichtlidje

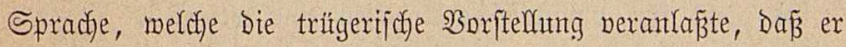
mirflidi) jeinen Begenitano beherridje, währento er nod) nidd

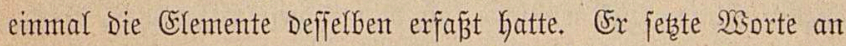
Die Stelle von Dingen; Subject an bie Stelle pon Sbject. Ex

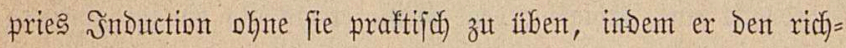

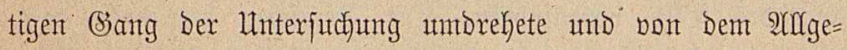
meinen zum Bejondern, ftatt bom Bejondern zum 2ulgemeinen vorfdyritt. Er madfte aus Dem Univerjum eine gefdylofiene Sphäre, in Deren Mittelpuntt er bie Eroe febte, indent ex bon alfge= meinen \$rinzipien aus, zu feiner eigenent und zu Der faft zwei= taujendiäbrigen Bienugthuung Der $2 \mathfrak{S e l t}$ bemies, Dẩ fein anderes Uniberjum nöglid fei. Seine Begriffe bon Bemegung waren böllig umphyfifalifach. Die Benegung war igm "natïrlich ober un= natürlich," "beffer ober fochlechter," "ruthig Doer heftig;" aber

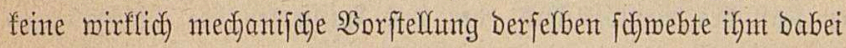
bor. Ex berficherte, Daj es fein Vacuum geben fönne und be=

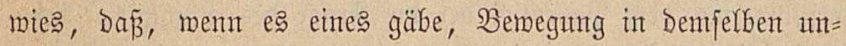
möglich) jein mirrbe. (Ex beftinmte a priori, wie viele 2 frtent bon Thieren es geben muiffe, unb zeigte auf (Sintub allgemeiner Frin= zipten, warunt Thiere biefe uno jene Igeile babent min̈sten. Went ein bebeutender zeitgenbifificher Naturforidger, Dem folche 
Srrtbümer fern liegen, fich Der Mi thode eximert, fo wird er das Mistrauten Der \$hyfiter gegen

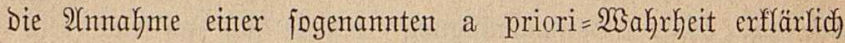

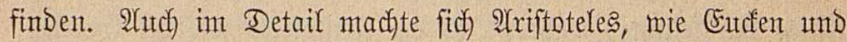
Sang nadfgemiefent habent, vieler fdymerer Jrrthümer ichulbig. Ex

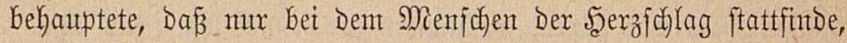

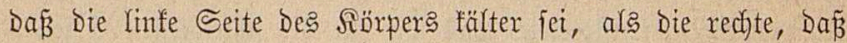

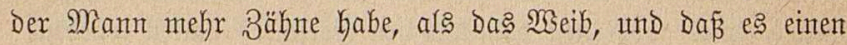

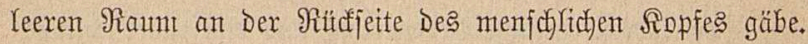

(5) giebt für phyjitalfijche 2(rbeiten eine mejentliche Eigen=

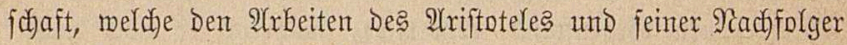

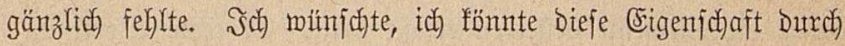
ein, nicht Durch) Nebenvorftellungen irreleitendes 23 ort bezeidynen; es bedeutet eine Fäfigfeit, Dem Beifte etmas als ein zufanmen= Gängendes Bild borzufühfren. Die Deutfchen bezeichnen das

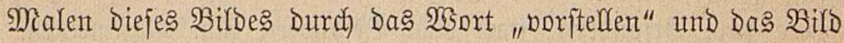
nennent fie eine "Borftellung." 23 ir Gabent in Englifchen fein Woxt, weldyes unjern Bedurrfniffen beffer entipräctje als "Imagination," und menn man es mit ben nöthigen Einjd)ränfungen

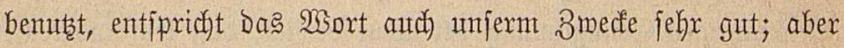
wie idf es bereits oben angedentet habe, ift Der Bebrauth Des

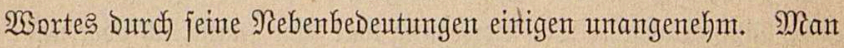
vergleiche in Şinbliff auf Dieje Fähigfeit geiftiger Vorftellung Den Fall Des Ariftotelifers, Der Das 2 utffteigent Des Waffers in einer Frumpe auf Den 2lbjfelt Der Natur vor Dem Vacuum zit=

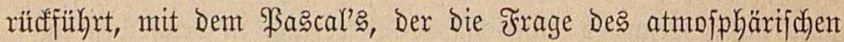
Drutfes Durd) Das Befteigen des Puy de Dome z̆ löfen pro= pontrte. Snt Demt einent Falle mollent fith Die Momente Der Er= flärung nicht zu einem phyfiftalifden $\mathfrak{B}$ illo zujammenfügen, in Dem anbern ift bas Bitlo beutlid), indem das Falfent und Steigen 


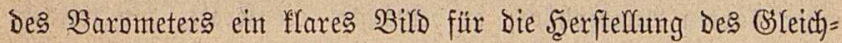
gemidates zmifden zmei fajmanfenten und einander gegenúberfte= bendent Drutfent gemährt.

Während Diejer Dürre Des deriftlidfen Mittelalters war Der arabifche (Beift, wie Draper es anjuaulich entmicfelt hat, thätig.

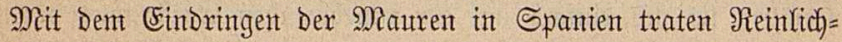
feit, Dronung, WBiffen und Berfeinerung an bie Stelle Der ent= gegengejeţten Eigenjdaftent. Bont Rranffheit Keimgejucht, jutchte

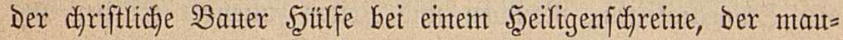
rifche bei einem interridyteten $\mathfrak{A}$ rzte. Die $\mathfrak{A}$ raber munterten zu

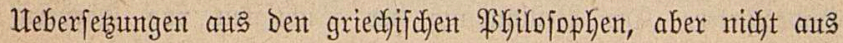
Den Didgtern auf. Sie mandten fidy mit (Effer pon ber Itnzüich)= tigfeit umferer ffaffifichen Ninthologie ab und Demmeirten jede Berbindung Des unreinen olympifdyen Zets mit Dem Şödfften als eine unverzeihlidge Blasphente. Draper verfolgt bie Spuren

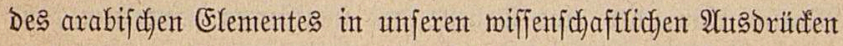
nod) tweiter ats 23kemell. (Ex giebt Beifpiele von Dem, was arabijche Mäntuer Der Wiffenjchaft Yeifteten und vermeilt nament= lich bet 2llkazen, Dem erften, welcher bie platonifche Borftellung,

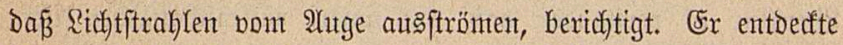

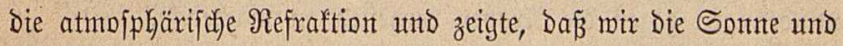
Den Miono nod), nachoen fie untergegangen fint, fehen. Er er= flärt bie $\mathfrak{B}$ ergröß̈erung Der Sonnte und Des Miondes unt bie Berfiurzınng Der bertifalen Diameter Diejer beiDen Rörper, went

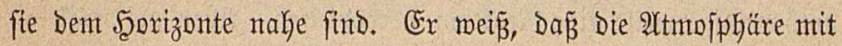

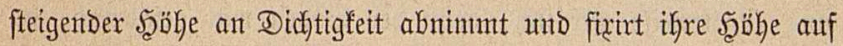

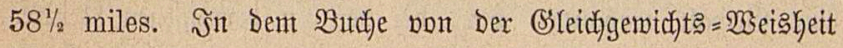
febt ex Den 3ufammentang Des Bemidytes Der 21tmofphäre mit ihrer zunehmenten Didjtigfeit aubeinander. (Er zeigt, Daß̃ Daß Gemicht eines fiörpers veridjiebent ift in einer bünnen und in 


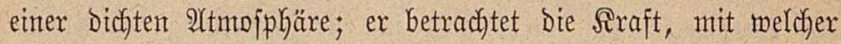
berjentte Begenftände Durch) fabmerere Media emporfteigen. Fr berfteht die Rehre bon Dem Sdyexpunft und mentet fie auf Die Unterjudtung bon Waagen und Sdynelfwaagen an. Er an= erfennt Die Sifnere als eine Sraft, obgleidy ex in Den Jrrthunt berfällt, fte fich einfach) mit Dex zunehmenden (Entfermung ver= mindern zu laffen und fie zu einer mux für indijache Serbältniffe anwentbaren Siraft zu madjen. Er fennt bie Beziefung zwijhen

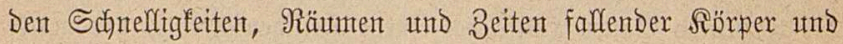
Gat beftimmte Joeen über (Eapillar=2Attraftion. Er verbeffert Den Schorometer. Die SBeftimmung Der Didftigfeit von fïrpern,

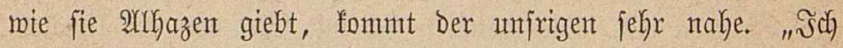
fchlief̧e mich," jagte Draper, "Dent frommen Bisbete Arrfazen's an, Dẩ am Iage Des jitngften (Seridjtes Der 2rmbarmkerzige

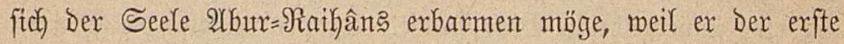
Menich war, ber einte Iabelle des ipeziffichen (Semidjtes con= ftrtirte." Wenn alles das hiftorijche Wabrheit ift, unt ich babe bolles Sertraten zu Dr. Draper, io hat ex mohl Sirund, die

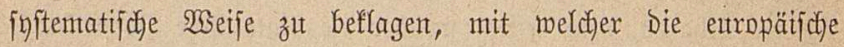
Riteratutr es berftanden hat, uns unjere miffenjufaftlichen $\mathfrak{B} e x=$ pflichtungen gegent die Âtraber vergeffen zut machen *).

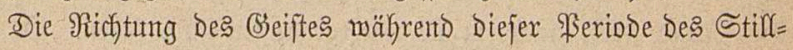

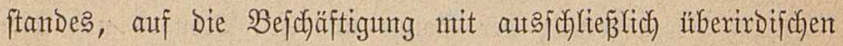
Dintgen, unter Sernad)läjfigung nake Yiegender \$robleme, mußste

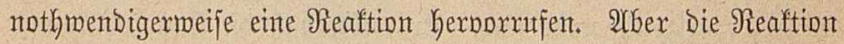
ging fachrittmetje bor fict); Denn ber Boben war gefährlich, da eine Semalt borkanden max, Die Den $z$ it vermegenten Sritifer zermalment fonte. Un Dieje Siemalt zu ungehen und Doch die

*) Intellectual Development of Europe p. 359. 
Mioggliçfeit einer Mceinungäuñerung zu mahren, murbe die Rebre von Der Doppeljeitigen Wahrheit exfunden, vermïge Derent eitte Meimung fich "theologifa" und bie entgegengejeste "philojo= phifch" behaupten läf̆t*) So wurben im breizebnten Jahx $=$

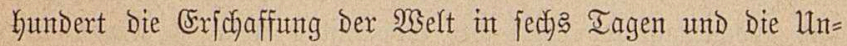
beränberlichfeit bex menjalidyen Seele, meldye non Thomas non 2lquino fo beftimmt bekauptet morden mar, beide philofophifd

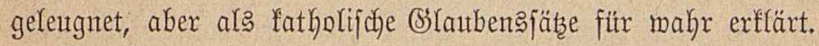

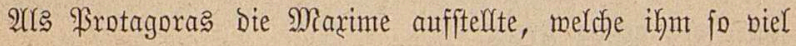

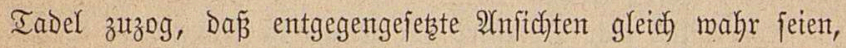

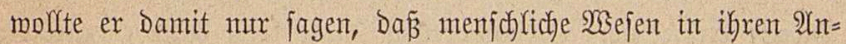

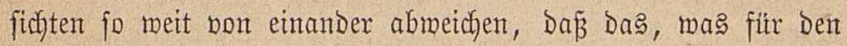
einten fubjeftio to a hx jet, für bent andern jubjeftio it ntwahr fein

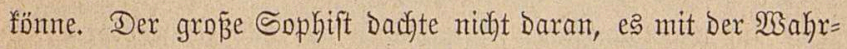
Geit Yeidyt zu nehmen und zu behaupten, Daß̃ eine bon zmeien, bon Demfelben Snoibioum aufgeftellten Behauptungen Denfbarer= weife feinte \&itge fein fönte. (Es max nidyt "Sophifterei" fondern Die Furcht vor theologiffyer Rache, was Diejes Doppelte Spiel mit Der Heberzergung erzeugte und es ift merfmürbig zu beob= achten, weldye 2Uluflühte Miännern, Die in Dem (Sebraudbe Der Sünfte Diejer 2 rt gejchifft maren, zit Sebote ftanden.

Begen das Ende der F̧eridde Des Stilffandes bemächtigte

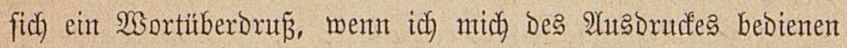
Darf, Des menjidichen (Sseiftes. Das Chriftenthum war bon Der

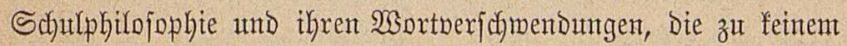

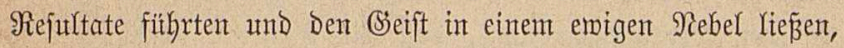
überfättigt. Şier und da bernahn man eine ungebuldig Durch Die Wifte rufende Stimme: "Nitdyt bon ariftoteles, nidyt von

*) Sange, żweite 2̂tıgabe p. 181. 182. 
jubtilen Scypothejen, nifgt pon ber Rirche, Der Bibel oder Der

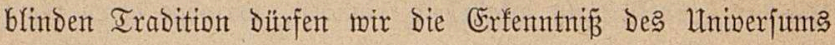

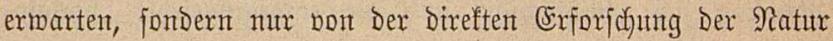

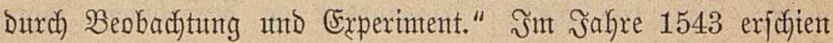

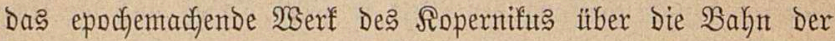
Şimmelaförper. Der totale Utmifturz des ariftotelifchen gejdiloj= fenen Univerjums, mit Dex Erbe als Centrum, max bie Folge und "Die Eroe bemegt fich" wurbe eine 2(rt bon Rofunggmont unter Dent geiftig Freient.

Ropernifus war Domberr Der Sirche in Frautenburg in Der Diöceje Ermeland. Dreitndoreisigig Jahre lang hatte er zutrüd= gezogen bon Der WSelt gelebt und fich Der 2lubarbeitung jeine? grofen Flanes des Somnen=Syftems gewiomet. Er baute baj= jelbe auf unvergänglichen Bintudlagent auf und jelbit Denen, bie jein Enffem fürchteten und Den 1 tmfturz Deffelbent herbeifehnten,

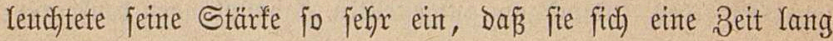

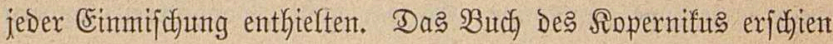
in feinent leţten Rebengiahre; mant fagt, Der Breis habe ein Exemplar beffelben wenige Tage bor feinem Tode exhalten itto fet Dann in Frteden geftorben.

Finer Der frübeften Eonwertiten Der neten Iffronomie war

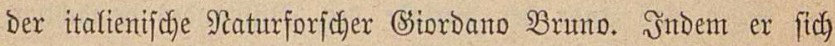

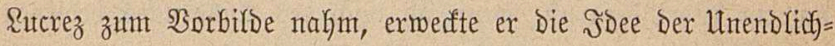
feit Der WSelten zu neutem Reben, und gelangte, indem ex bie Refre Des Sopernifits damit in Serbinoung bradjte, zu Der ex=

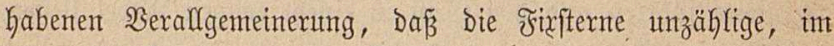
Raume zerftreute und von Satelliten, weldje in Demjelben $\mathfrak{B} e r=$

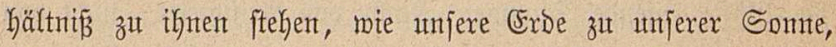
Doer unjer Miond zu unjerer Eroe, begleitete Connent feien. Schon das war eine Ermeiterntng von außerordentlidfer WBichtig= 
feit, aber Bruno fam unjerer heutigen 2lujidautung nod) näher. Nachbem ifhn bas Froblem Der Erzeutung und Erfaltung Der Srganismen lange bejdäftigt Katte, fant er zut Dem Sd)luffe, Daß Die Natur an ifrent Frobuttionent Die Technif Des Menjdyen nicht nadfahnte. Sie gefft auf Dem 2 ege Der Entwirrung und Entfaltung vor. Die Itnendididfeit Der Formen, unter weldyent Der Stoff exfdeint, ift ifm nidft bon aupert her vont einent Ritnftler auferfegt, jonbern jeine eigene intere (raft bringt bieje Formen herbor. Der Stoff ift nicht nur bie nactte leere Fäajig= feit, als welche gshilofophen ihn bargeftellt haben, fontbern bie affgemeine Mentter, welche alle Dinge als Die Frutcht thres Seetbes Keroorbringt. Der Mann, Dex Das fo offen atsjprach, war uts=

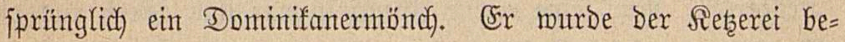

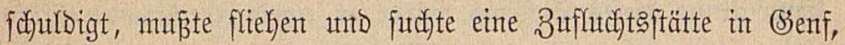
Baris, England ind Deutfallant. 1592 fiel er in Bentedig Der

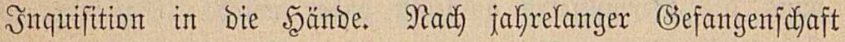
mährend Der gegen ifn gefiuffrten Unterputod)ung murbe er Degra= Dirt, excommunicirt utnd Den bürgerlicfen Begörden mit Dem

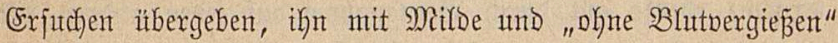
3t behandelrt. Das heiṕt, ex folle verbrant merden und Dem= gemäã murbe ex am 16. Februar 1600 verbramt.

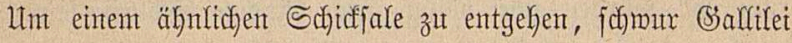

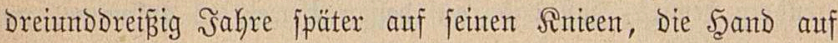
Den heiligen Evangelten, Die heliocentrifde Sefre, bon Der ex muß̄te, Daß̃ fie mahr jei, ab.

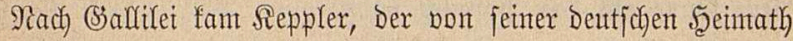

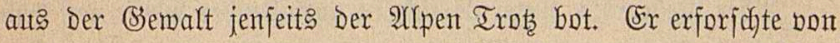
borfandenten Beobadjtungen aus Die Bejefte Der plantarifdyen Bemegutg.

So max das Froblem für Nenton vorbereitet, melcher 
Die empirifdyen (Bejetge Durch), Das Frinzip Der (Srabitation ver= bant.

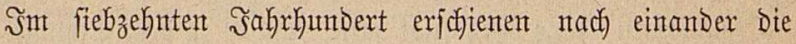
Wiederherfteller der \$Gilojophie Bacn und Descartes. Ber=

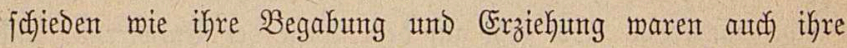

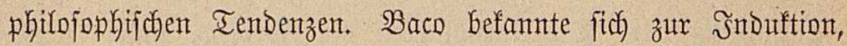

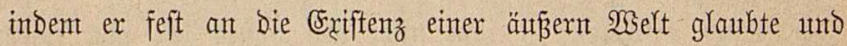
gejanmelte Exfahrungen zur Bafts alles Wiffents madjte. Die

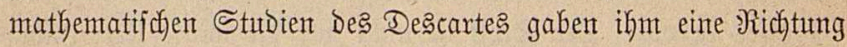
auf Debuftion und fein (Srundprinzip war mejentlid daffelbe wie das des Srotagoras, Der das Snotwioutum zum Map̃itabe

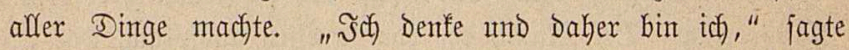
Descartes. Nur feine eigene Sontität war ihm gemiß̄ uno bie

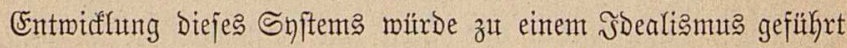

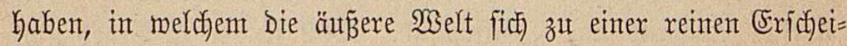
mung Des Bemup̃tjeins aufgelöft haben mürbe. Cáafiendi, ein 3eitgennfie Descartes', bon Dem wir noch mebr Görent werben,

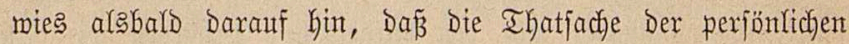
Exiftenz ebenfo gut Dutrdy Bezugnafme auf jeben andern 2 fft, mie Durch Bezugnahme auf Den 2lft Des Denfens bemiejen mer=

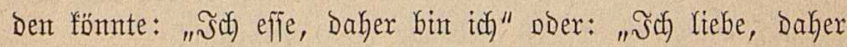

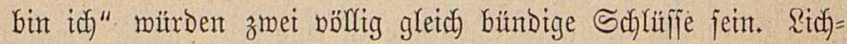
tenberg bemies, Daß̃ Das, anf Deffen Bemeis es anfommte, ıth= vermetidich in Den beiDen exften Worten: "J̛l Denfe" geforbert jet und Daß̃ fein \$oftulat auts Dem Sdyluffe Denffarermeife ftärfer fein föme als das Foftutat felbft.

2(ber Descartes entfernte fitch in auffallender WSeife bon Dem,

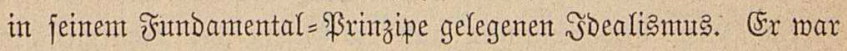
Der exfte, weldfer in entinentent (Sirabe bie Srobe Des menjid = lidfen Sorftellungsuernögens beftand, Rebenserjdyeinungen auf 


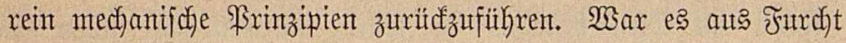
ober aus Siebe, furz, Descartes mar gut firchlid gefinnt; Dent= gemä̋̃ vermirft ex Den 2tomenbegriff, weil es lächerliç) fei, anzı=

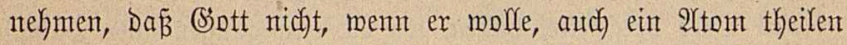
fönne; ex jetzt an Die Stelle Der 2ltome fleine runbe Theildyen Int) leidfte Splitter, auts Denten or Den Srganismuts exbautet. (5r entwirft, mit bewumberungsmitroiger phyfifalijtyer (5in= fidft eine Dutrdy Waffer bewegte Majdine, meldye Die Rebens= thätigfeit illuftrixen foll. Er batte es fid flar zu madjen ge=

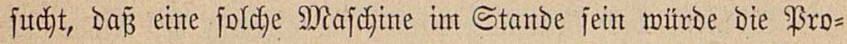
zeffe Der Berbautng, Dex Ernährung, Des Wart)sthums, Des

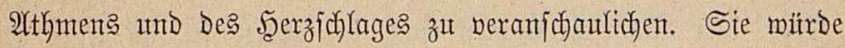
im Stande jein, Etnorủcfe von äußeren Sinnen zu empfangen, Diejelben in Dex Sintbildungsfraft und Dent Beoächtnif̧ aufzu= ipeidfern, Die inneren Betwegungent Dex Begierden und Die äuneren

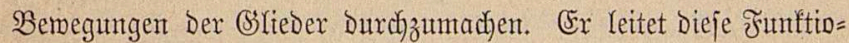
nen feiner Majdjine lediglid, aus Dex (Einxidytung iffer Drgane

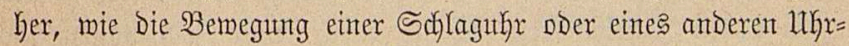
werfes fich auts feinen (Semidhten und Räbern herleiten läp̃t. "So meit Dieje Funftionen in Betradyt fommen," fagt ex, "ift es nidft exforberlich, ingend eine bejondere vegetative ober jenft= tive Seele ober ein anores Frinzip Der Berwegung DDer Des Rebens anzunehmen, als das SBlut und Die Rebensgeifter, meldje Durch) Das im Scerzen unabläffitg brennende Feuter in Bemegung

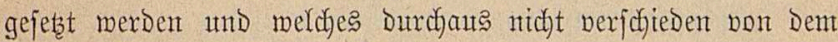
Fenter ift, melches in intelebten Sörpern bremt." Scätte Descartes die Dampfmajdytute gefannt, mitride ex Diejelbe amftatt eines Wafferfalles zu jeiner Triebfraft genommen mo auf bie

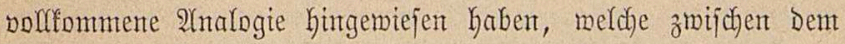

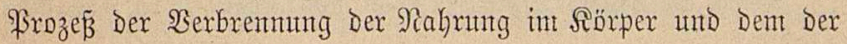


Soble im Dfen befteht. (5x mürbe unzmeifelhaft jajon por Mayer Dą vom Seerzen auझftrömente Bhlut Das Del Der Rebents= lampe genannt und alle Rebenßberwegung bon Der Serbrennung Diejes Sels hergeleitet haben, mie die Bemegungen einter Dampf=

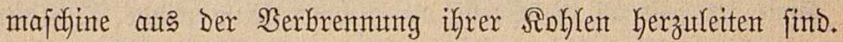
Wte die Dinge jedody Yiegen und in Betracht Der Beitumftände, bilden bie Sïfnheit, Slarkeit und Bräzifín, mit Denent er Das

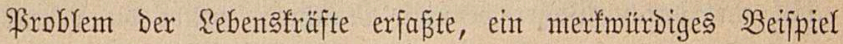
geiffiger fraft*).

Während Des Mittelalters war Die Doctrin Dex Altome an=

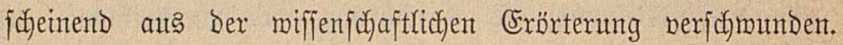

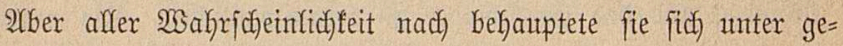
mäfigten uno rufigen Denfern, obgleid) meder Die Sirche nod)

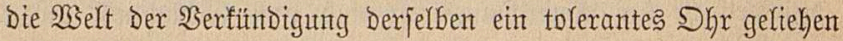
Gaben mitrde. Einmal im sahre 1348 murbe fie jeboct) be= ftimmt autgeiprochen. Ulber unmittelbar nachker mup̃te fie mieder zuxidfgenommen merben uno fo entmuthigt fochlummerte fie bis

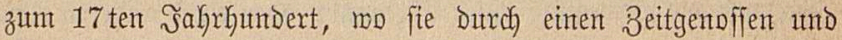
Freund bon Scobbes und Malmsbury, Den orthodoxen fatholi= fden \$ater Bafjendi zu neutem Reben exmedt murbe.

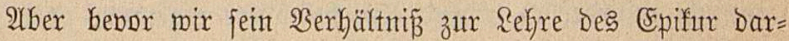

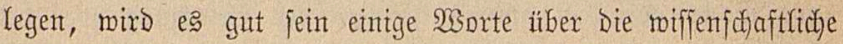
Wirfung Der allgemeinen (sinfiffurung Des Monotheismus unter Den enropäijden Nationen zu jagen.

"Würben Die Mienjujen," jagt Scume, "Durdy Die Betradytung

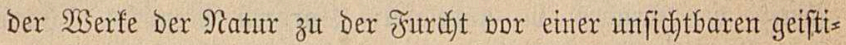
gen Madft gefübrt, fo bätten fie unmöglich) ie eine andere $\mathfrak{B}$ or $=$ ftellung als bie eines einzigen 23 ejens geminnen tömen, welches

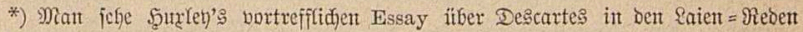
pp. 364 ti. 365 . 
Diejer gemaltigent Mafdyine Reben uno Sroming verlieb unt alle jeine Theile zu einem Snftem zujammenfügte." Mit Bezug auf

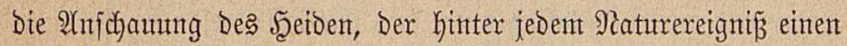

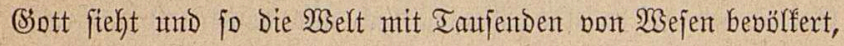
Deren Raumen unberectenbar find, zeigt Range bie ltmmöglidffeett

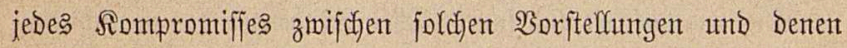

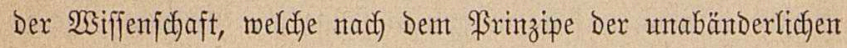

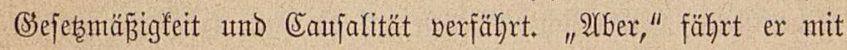
charafteriftifchem Sofjarfitut fort, "fobard Der grope Bebante eines (Sottes in feiner Wirfunt als Eingeit auf bas Univerjum einmal erfapit mordent ift, fo ift Der 3 ujammentang Der Dinge in Hebereinftimmung mit Dem Bsejeţe Der Earjalität nidjt nur

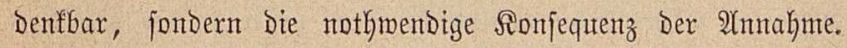

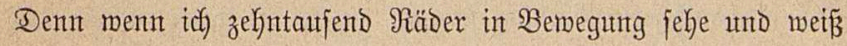

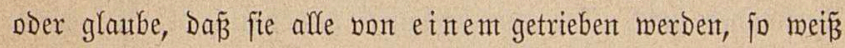

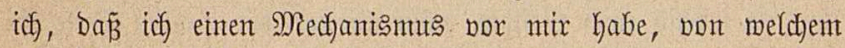
jeber Theil in feiner Wirfinng Durd Den Blan Des Banzent be= ftimmt wiro. Sobals Dieje 21mabme feftgeftellt ift, folgt Daraus, Daßj ich Die Struftur Diejer Majdjine und bie verjdiedenen $\mathfrak{B}_{e}=$ wegungen ihrer Theile exforichen fann. Fiur jeţt aljo madyt bieje Soee bie miffenjufjaftliche efftion frei." Mit anderen 230 orten: Säße ein Yaunenhafter Bontt auf jedem Rabe und am Endoe

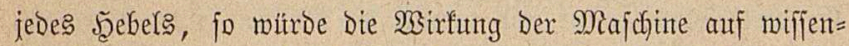

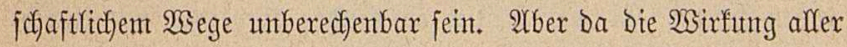
iffer Iheile Durch iffre $\mathfrak{B}$ erbintoungen unt Beziehungen ftrent beftimmt ift und bieje Durrch ein einziges jelbjtbemegtes Triebrad

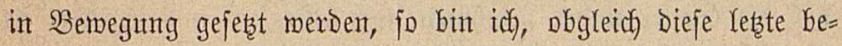
megende Itrjache midy täufichen fann, Doch noch int Stande, Die Majdinerie, meldye Diefelbe in Bemegung jeţt, zu begreifen.

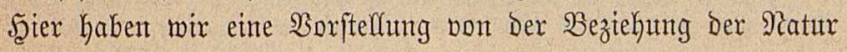


zu threm Hrheber, welche einigen (Seiftern bollfommen annehmbar,

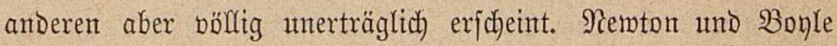
rebten unb mirften glituffich) inter Dem Einfluffe Diejer Borftellung;

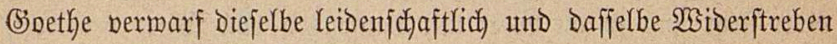
offenbart fid in (Earfyle*).

Die analntijchen und funthetifijen Iendenzen bes menichlidyen

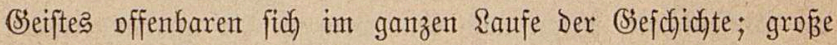
Sdjriftfteller ftellen fidf bismeilen auf bie eine, bismeilen auf Die antere Seite. Männer von tiefer Empfintung, Dexen (Sienuith

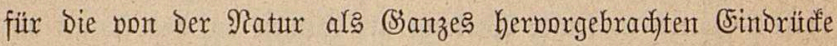
Dffen war, Deren lteberzeugung Daker mehr auf ethifdhen als auf logifhen (Srumblagen beruhte, haben fich Der innthetifthen Seite zugeneigt, mährend Die aralntijche Seite beffer zu Der präzifern

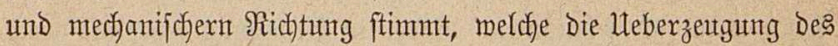
Serftandes jutcht. Die eine adoptirte gewöhnlich) Den Fanthets= mus in irgend einer Beftalt, währent von Der andern Seite pit

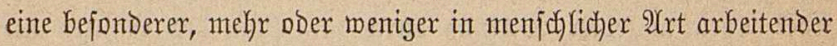
Scjüpfer angenommen murbe. Sbaffendi fann faum einter vont

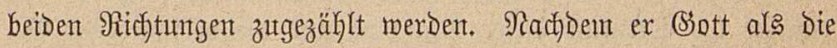

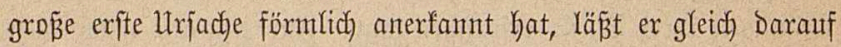

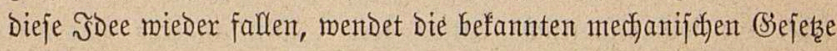
auf Die 2 tome an und Deducirt Daraus affe Rebenserjajeinungent.

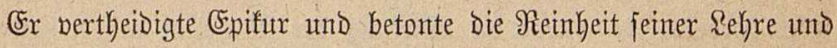
jeines Rebent. Ex war-freilich ein Szeide; aber Das war Arift $=$

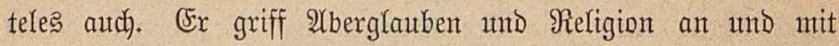

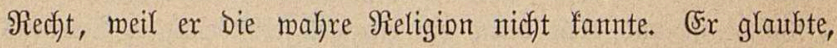
Dap Die Gsötter meder belohnten nod) beftraften und verebrte fie

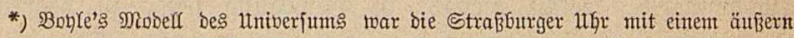

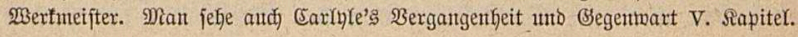




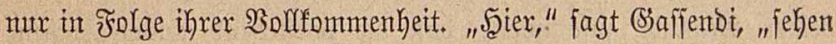
wir Die EFfrfurcht Des Ritndes anftatt Der Frutcht Des Sflaven."

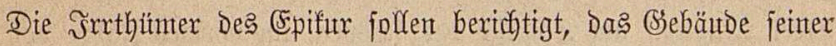
wahrbeit joll erfhalten merden. Und Dann geht (Safjendi, wie es jeber Seetbe thut fömnte, Dazat bor bie 23 elt unto alles, mas pon 2tomen und Moleculen in Derjelben ift, aufzuerbauten.

(3ott, meldjer ErDe und Waffer, Fflanzen und Ifiere fduff,

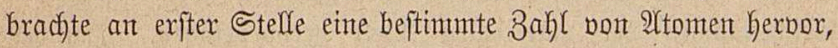

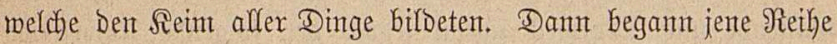

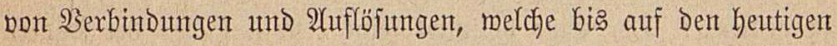
Iag thren Fortgang nefmen tho bis in alfe Buflunft fortbatern

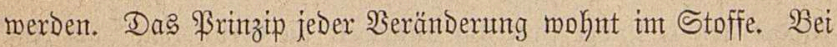
fïnftlidfen Froduftionen ift das bemegende Frinzip verfociedent bon Dent bearbeiteten Material; aber in Der Natur arbeitet Der $23 e r f m e i f t e r$, melcher der thätigfte und bemeglidyfte Theil Des Materials felbft ift, bout iment heraus. So maddt es biejer fiufhne

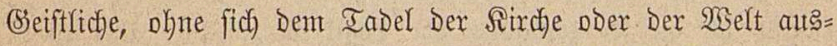
zufeţen, mögfich), Darmit zunorzutonment. Diefelbe Dispofition,

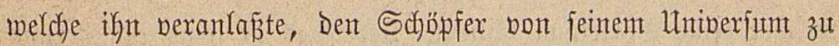
trennen, bradjte ifhn aud dafin, Die Seele vom Rörper zu trenten, obgleich) er Dem Rörper einen jo bedentenden Einflú

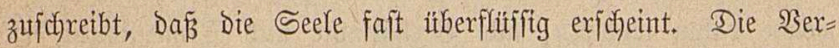
irrungen Der $\mathfrak{B}$ ermumft maren nach jeiner 2Unficht eine Sadhe Der materiellen $\mathfrak{B} e j$ chaffentheit Des Behirns. Beiftegtranflyeit ift Bsefirnfranffeit; aber Die unfterbliche Shermunft hat igren be= jondern Sitz und fant von Der Rranffeit nidgt beriffynt merDen. Die Beiftesfrantheiten find Fehler Des SSEerfzentges, nidjt Des Werfmeifters.

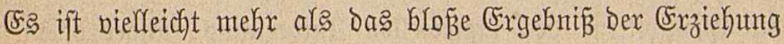
un๖ Gängt wahricheinlich tiefer mit Der geiftigen Srganijation 
betber Mänter zujammen, Daj Die vorftehend ausgefprochene

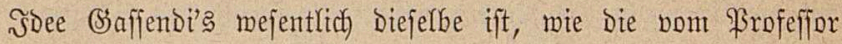

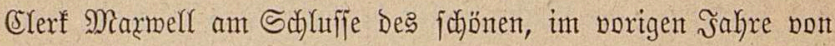

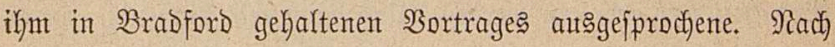
beiden Shilojophen find Die Altome, menn idf recht verftehe, Die vorbereiteten Materialien, meldye, pon Der Sefdjicflidffeit Des

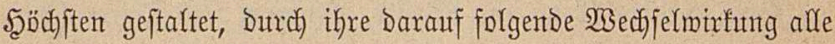
Erjobeimungen ber materiellent Welt herborbringen. 3mif ben (Saffenti und Marwell jueint jedod) Der folgende unterfajied zut beftehen: Dex Eine poftulirt jeine exfte 1trjadje; Der 2Indere

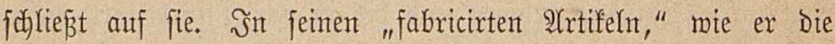

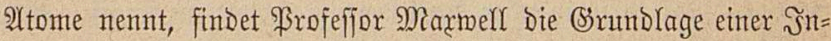

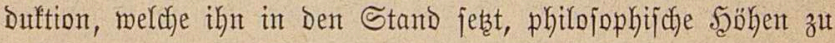
exfteigen, melche von Sant für unzugänglich erflärt morden maren, un auf Iogijdyem Wege pon Den 2Utomen zu ifyrem Schöpfer zи

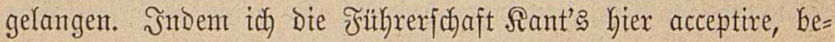
zmeifle ich Die Berechtigung Der Sogif Maxwell's, aber es ift

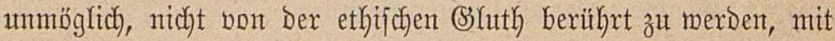
meldjer jeine SBorlejung fabließ̂t. Heberdies ift jeine Schilberung von Der Feftigfeit Der 2(tome bon einer an Increz erinternden

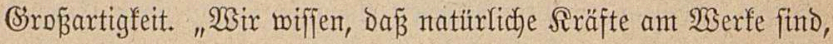

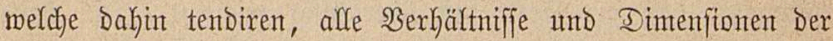
Erde und Das ganze Sonnenfyftem zu modifizixen, menn nicht fá)lieplicy zut zerftören. 2(ber wenn aud in Saufe Dex Beiten in Den Scimmeln Rataftrophen eingetreten fint und noch eintreten fönnten, menn audich alte Weltinfteme fich auflöjen und neue

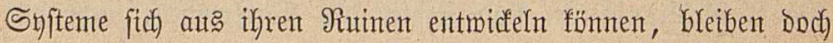
die Mroleculen, aus meldyen dieje Syfteme fidy auferbaut haben, Die Grumbiteine bes materielfen Itniverjums, ungebrochen und unabgentbet." 
Die 21tomenooctrin wurbe ganz oder theilmeife pon Baco, Descartes, Scobbes, Rodfe, Nenton, Bayle und ifrent Madfolgern

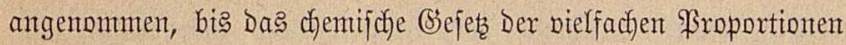
Dalton in Den Stant jetzete, Derfelben eine ganz nete Bebentung zt berleihen. Sn unjeren Tagen fommen AYbFälle bon Der Theorie wor; aber fie fteft noch immer feft. Sofduntot, Stoney uno

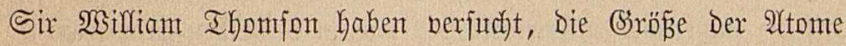
zu beftimmen, oder vielmehr bie Girenzen zmijdjen Denen ifyre

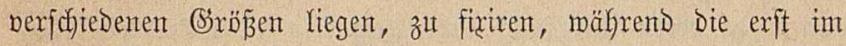

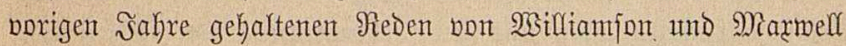
Die 21rt ilfuftriren, wie bie vorgefdrittenften Beifter Der Biegen= wart an ber Selgre fefthalten. Hnd es num in ber That be= zmeifelt werben, $\mathrm{Db}$, fo lange es an biejer Fundomentalauffaffung fehlt, eine Iheorie Des materiellent Hntwerjums itberfhaupt einer

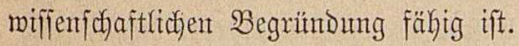

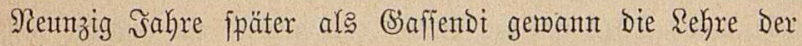

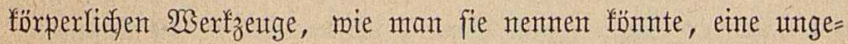
Geutre $23 i d$ tigfeit in Den Scänden Des Bifthofs Butlex, welcher in feiner berithmten $\mathfrak{L}_{1}$ alogie Der Religion bon einem ihm eigenen

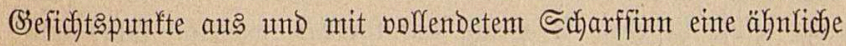

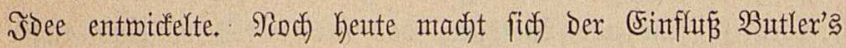
auf überlegene Beifter geltend und ę wird fid Der Mühye lohnen,

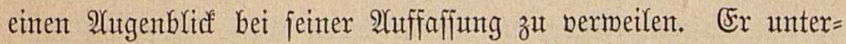

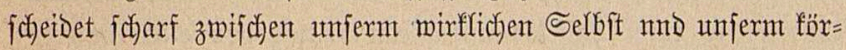
perlidjen 2 Serfzenge. So weit idf midf eximnere, bebient ex fid

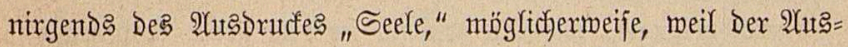
Drute in jeinen Tagen wie fajpn feit bielen Bsenterationen böllig

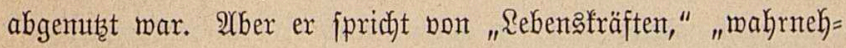
menden" DDer "aufnefłmenden Rräften," bemegenden Sräften," "umjerm Selbft," in Demielben Sinne, wie wir Den 2 tusburud 


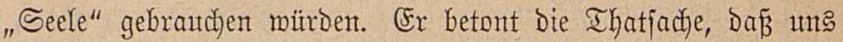

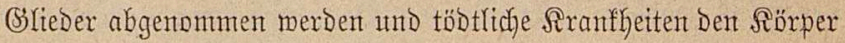
befallen fönnen, mährend der bieift fait bis zum 21tgenblicfe Des Iodes flar bleibt. Err erinnert an ben "Sallaf“ und Die

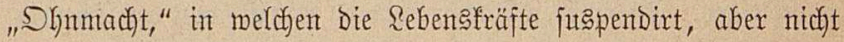
zerftört find. (Ex betrachtet es als ganz ebent fo leicht, eine Exiftenz anferhalb unjerer 尺örper wie in Denjelben zu begreifen,

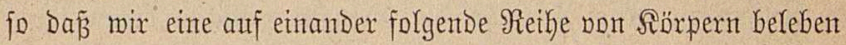
fönnen, Da beren 2 Itflöjung nidf)t geeigneter jei, unfer wirfliches Selbit aufatlöjen ober ung der Rebenthräfte, Der Fähigfeiten

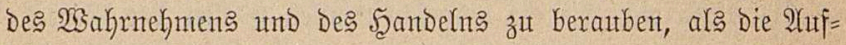
löjung irgent eines fremben Stoffes, bon Den mir bet Den ge=

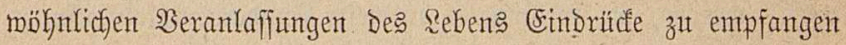
Dber (sebrauth zu madjen im Stande find. Das ift Der Schlufis=

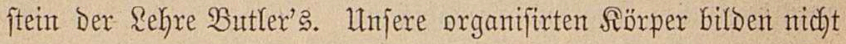
mefre einen Theil unferes Selbit, als irgeno ein anderex auß̌er unts liegender Stoff. 3um Bemeife Deffen Yentt ex Die 2uffmert= jamfeit auf Den (siebrauth Der Shläjer, melche genau mie das 2luge Siegenftände für die aufnefmende Sraft vorbereiten. Das

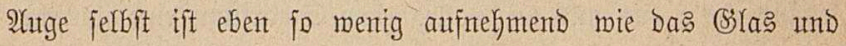
ift eben fo jefr das Werfzeug Des mafren Selbit und auth Dem mahren Selbjt ebenjo fremb, wie dab Bilab. "Und wenn mir mit umferen 2lugen mur in Derfelben

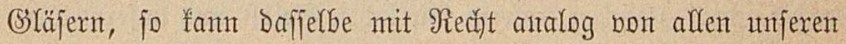
Sinnen gejकlofien merden."

Sucrez gelangte, wie Sie mifīen, zu Dem grade entgegenge=

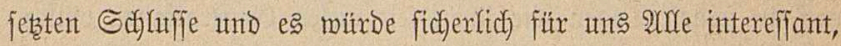

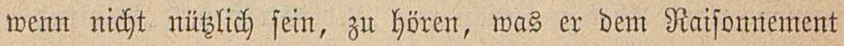
Butter's entgegenzuftellen haben mürode. Da eine furze Erör: terung diejes \$sunftes uns in Den Stand jeţen miro bie eigent= 


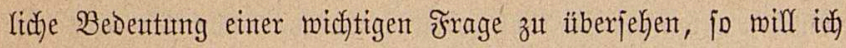
Gier eitrem Schüler bes \&ucrez geftatten, Die Stärfe der $\Re_{0}$ fittion Butler's auf Die \$robe zu ftellen utno Dann Butter geftatten, gleithes mit gletdyent zu be m 3 meefe zu pergelten, Die Sdymierig= feit, menn er fant, auf Seiten Des \&ucrez erfodeinen zu laffen.

Die Discuffion fömute in folgender 2 seife yor fid geken:

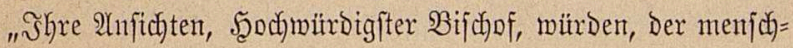
licken $\mathfrak{B}$ orffellung unterbreitet, für viele Beifter eine groß̃e, ment nidyt unübermindlidje Echwierigfeit barbieten. Sie reden bon "Rebengfräften," "aufnehmenden" oder "wahrnehmenden Siäften" und "unjernt Selbft;" aber fönten Sie fith, bont einent biejer Factorent abgetremt, bon Dem Srganismuts, Durdf welchen Der=

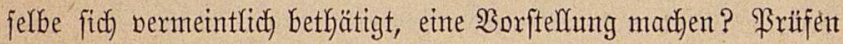
Sie fid aufridhtig uno fehen Sie, ob Sie eine Fäähigleit befiben, Die Ste in Den Stand jekzen mitrbe, eine foldje Borftellung zut faffen. Das mahre Selbit hat nach şhrex 2luffafjung in jebem bon uth einen örtlidfen Sith, muß $\mathrm{e}$ s nidyt, fo localifint, eine (S)eftalt befitien? Hno went, meldye Bieftalt? Scaben Sie fich einen 21tgenblidf Danon eine beftimmte Borftellung gemadft? $23 e n n$ ein Bein amputirt mirb, fo wiro Der Rörper in zwei Theile getheilt; wohnt das wahre Selbft in beiben ober in einem bott beiben? Thomas non 2̂quinto würbe vielleidyt fagent, it betben; aber Sie Ditrfen es nidft; Denn Sie berufen fith auf Das Bemustfein Des einen Der beiden Theile, um zu bemeifen,

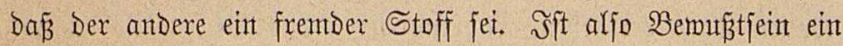
nothmendiges Grement des wahren Selbft? 2 Benn Dem fo ift, wie beurtheilen Sie Den Fall, mo Der ganze Sörper Des $\mathfrak{B} e=$

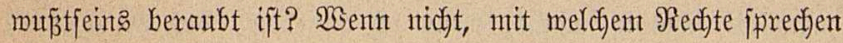
Sie Dem abgetrennten Briede jeden 2 hntheil an Dem mahren Selbjt ab? Es: ift hödjit auffallent, Daß̧ Sie in Э̧hrem jujönen Inndar, Materiafisunts. 


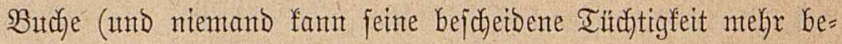

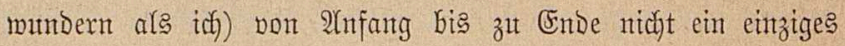
Meal Des Giehims oder Des Nervenjyftems Ermähnung thun. Sie beginnent mit einent Ente des Rörpers unt zeigen, dẩ feine Theile ohne Nachtheil für bie mahrnehmente Sraft entfernt merden fönter. Wie, went Sie mit Dem andern Ende Des Rörpers beginnen unt anftatt des Beines das biehim entfernen? Der fiorper ift wieber wie vorker in zwei Theife getheilt, aber beibe gefbören jeţt in Diejelbe Sategorie und auf feinen fann fich) zit Dem SBemeije berufen merben, Daß̧ der andere frember Stoff fei. Soer es fei, went wir nicfft jo weit gehent mollen Das Befinn felbft zu entferten, mur ein Theil jetner Schädel=

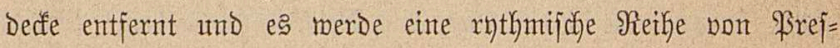
fionent auf bie meidje Subftanz ausgeübt. Bei jeber \$reffion

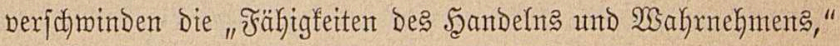

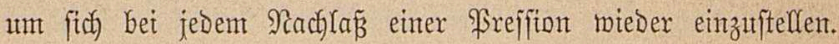

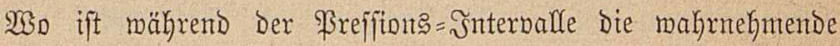
firaft? Einft ging Die Entfabung einer Renden'ichen Batterie,

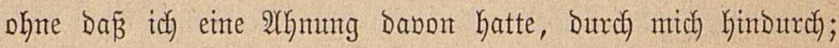

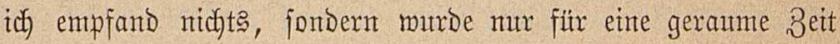
Des Bemuf́tfeins völlig beraubt. Wo war mein wahres Selfft währent biejes Beitraume? Mienjiden, Die, vont Bliţ getroffen, fich wieder erholten, berbarrten viel länger in Demfelbent 3uitante,

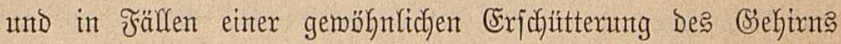

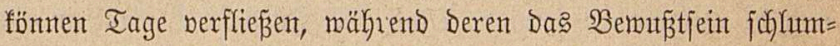
mert. WSo ift ber Mienfich felbft währent der Dauter ber Be=

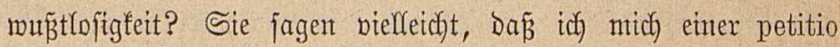

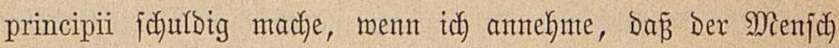

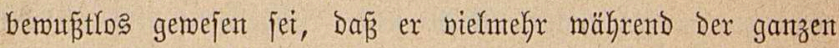
Beit bei Bewuptjein gemejen jei und mur bergeffen babe, mas 


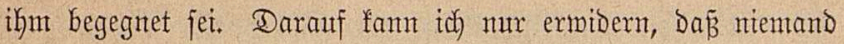
vor Dent foflimmiten Miartem, weldye Der Irberglaube je erfant,

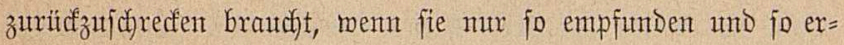

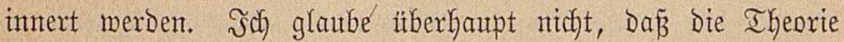

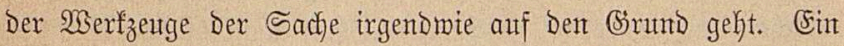
Ielegraphift hat feine Snftrumente, bermittelft Derent ex fith mit

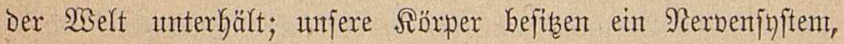

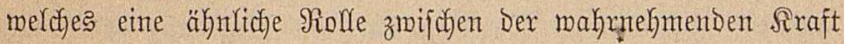
unb Den äuß̃eren Dingen fpielt. Man fanteibe Die Dräbte Des Telegraphiften Durd); man zerbreche feine Batterte, entmagneti= fire feine Nabel, - Dirtch Dieje Mittel trennt man ifnn mit Sicherheit non jeiner SGerbindung mit Der Welt; aber injofern Dies mirflidye 2 Serfzeuge find, beritfyrt ibre 3erftörung Den Men= ichent, Der fich ifhrex bedient, nidyt. Der Telegraphift bleibt lebent und weiß̄, Daß̧ er Yeben bleibt. Was, mödhte id fragen, ent=

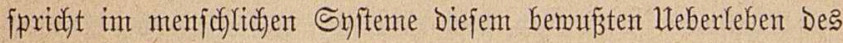
Ielegrapliften, wenn bie Befirnt=Batterie jo geftört ift, baf fie Bemurptlofigfeit herborbringt, ober wenn fie ganz zerftört ift?

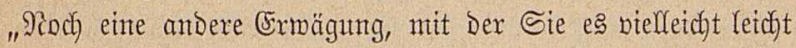

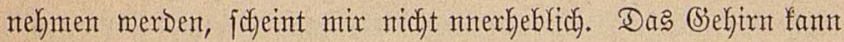
aus Dem Buftande Der Bejundkeit in Den Der Sranffeit ufber= gehen, unb Durch Diefe Beränderung fann Der auggezeichnetfte

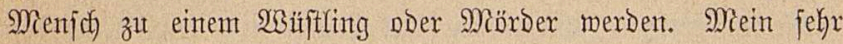
eoler unto bewährter Rehree hatte, wie Sie miffen, Ilnfälle vont molluiftiger Suffternbeit, bie ein ihm non feiner eiferfiutdtigen Fraut eingegebener Tranf ihm in Biefirn geję̧t hatte und, um felbft Der Befefahx zu entrinnen, biefen niebrigen Eingebungen Behör zit geben, bradyte ex finf umb Reben. Wie fonnte bie

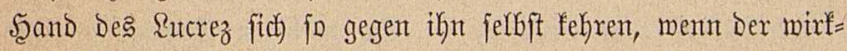
Iiche \&ucrez Dexjelbe geblieben märe mie vorker? Rann das (bie= 


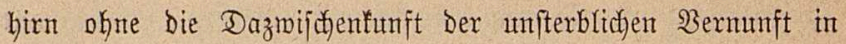
biejer franthaften Wreife hanteln ober nicht? Wenn es das fann, bant ift es ein primäres 2 (gents, welches nur einer gejumben Regulirung bedarf, um es ferbfttätändig verniunftig hanbeln zు

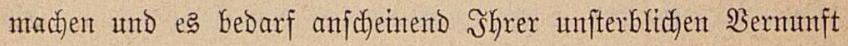
gar nifft. Wesenn es bas aber nicht fann, Dann mun man ber unfterblichen $\mathfrak{B e r n u n f t ~ m i t ~ D e r ~ v e r D e r b l i c h e n t ~ I h a ̈ t i g f e i t , ~ D i e ~ f i e ~}$ auf ein zerbrobenes Werfzentg itft, Die Begehung jeder nur

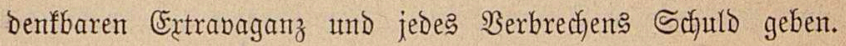

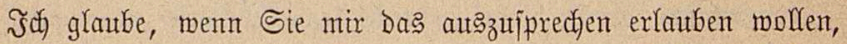

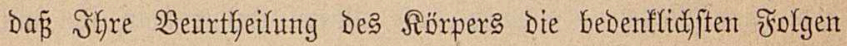
nach) fich zieken mußs. Das Biefirn, mie Sie es mödtent, als einen Stab ober ein 2lugenglas betradten, fitc) gegent bas ganze gekeinnifolle Wejen Deffelben, gegen bie volfonmmene Wectjel=

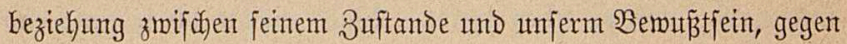

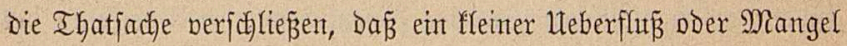
an Blut in Demfelben grade bie Shnmacht, von Der Ste reben, hervorbritgt, unto Daß in Bezıtg Darauf unfer Effien und Irinfen, umjer \&uftgenuß und unjere förperfiçen Bewegungen eine ganz außerordentlidje Wrichtigfeit und Bedeutung haben - alles bas

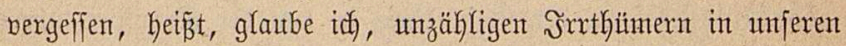
Rebensgemohntheiten Thür und Thor öffnen, und fant möglidjer= meife in einigen Fällen eben bas Reiben und den Darauf fol= genden geiftigen Finin vorbereiten uno beförbern, melche bei meiferer Würbigung biejes ntyfteriöjent Drgans vermieben jein mürben."

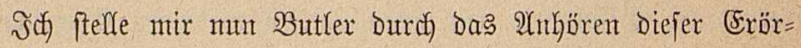
terung nachoenflid) gemadft bor. Ex war nicht ber Maam, fidt)

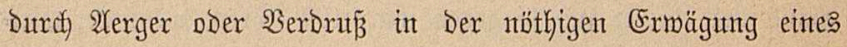

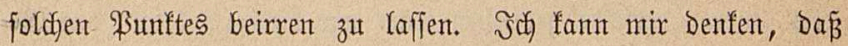




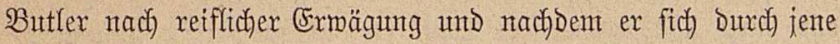

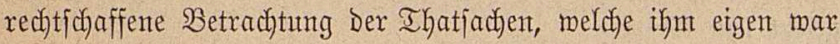
und meldje Die Bereitmilligfeit in fidi) begreift, felbft uns witber= ftrebenden Ihatjachen ihre gebülyrende Beriuffichtigung mitor= fahren zut laffen, geftärft hätte, fo geantmortet haben mïroe: "Ste merben fich eximern, Daj ich in Dex "2tnalogie Der Reli= gion," Deren Sie fo freundlid) (Erwähnung gethan haben, nirgends Den 2(njprutch exhoben habe, irgend etwas abjolut zu bemeifen,

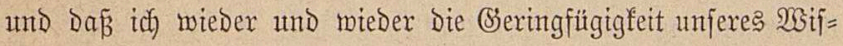
fens, oder viefntefyr Die Tiefe unferer Unmiffentheit in Betreff Des ganzen Smitems des Uniberjums anerfant und fofarf herbor= gehoben habe. Mein 3med war, meinen Deiftifdyen Freunden,

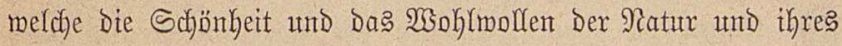
Senfers jo bereot atseinanderjetzten, währent fie nichts als Spott

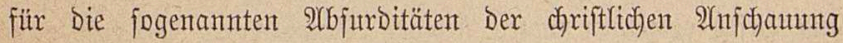
hatten, zu zeigen, Daß̧ ifre Rage nidjt beffer fei, als bie unjrige

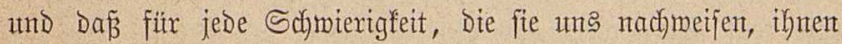
eine ganz ebenfo grope Schmierigfeit nadfztmeijen fei. Jich will

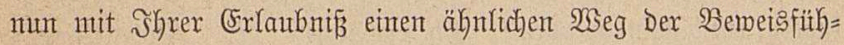

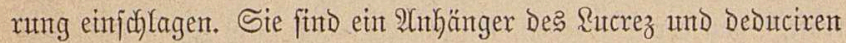

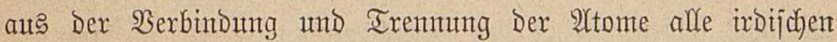
Dinge, organifache Frormen und ifre Ericheinungen mit einbe= griffent. Rafjen Sie mich) Э̧hnen bor alfen Dingen fagen, wie meit

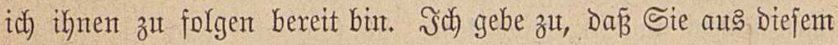
Spiel molecularex firäfte friftallinifd)e Forment herftellent fönnen, Daß Der Diamant tuto Der 2(methyft mahrlaft munderbare fo

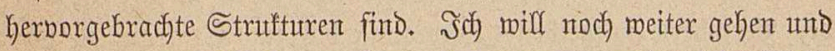
anerfennent, Daß̧ felbft ein Baum ober eine B̧hume in Diejer 2 Seife

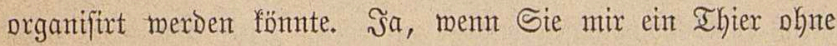

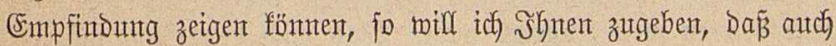


Das Dutrch Das angemeffene Spiel molectlarer Siräfte zufanmen= gefertat fein fömnte.

"Bis Dabin ift unjer 2 Seg frei, aber mun fommut meine Sdimierigfeit. Shre 21tome fint einzelnt ohne Empfintont und noch viel mehr ofyte Snttelligenz. Darf ich) Sie mut bitten, Die

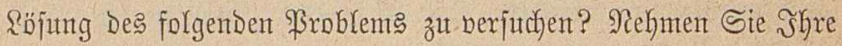
todten $\mathfrak{W a f f e r f t o f f =}$, Rohlenftoff=, Sauterftoff=, Sticffoff=, \$Ghos= phor = unt affe bie anderen 2 (tome, bie fo toot fint wie Schrot= förner und ans Denent Das Ssefirnt gebildet ift. Stellen Sie fie fich getrennt und empfindungslos nor, beobadften Sie fie, wie

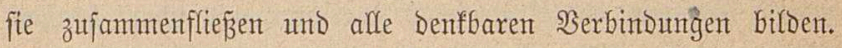

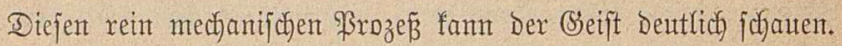

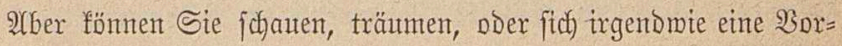
ftellung Dawon madjen, wie auts Diejem mechanifidjen 2lfte uno auts biejen einzelnen todten 2Ytomen, Empfindung, S̈edanfe und Yetbenichaftliche Bsemüthsbemegung herborgehen follen? BSlauben

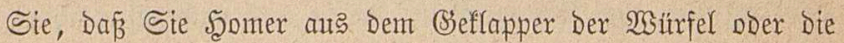
Differentialrectuming aus Dem 3ufammenjalfagen Dex Billarb=

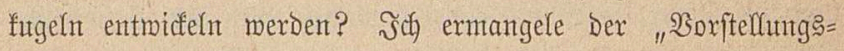

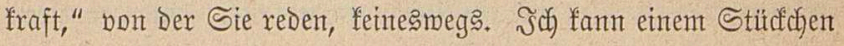

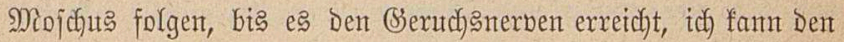
Sdjallwellen folgen, bis ifre Sdymingungen die Flüffigleit Deß Rabyrinthes int Shre erreidyen und bie Stolithen und Die Corti'= jchen Fajern in Semegung jetzen, ich fant mir atth bie 2lether=

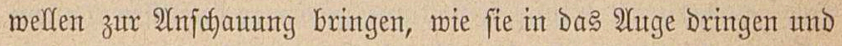
Die Netzhaut treffer. Ja noch mefr, id bin im Stande, Die fo Der Feripherie mitgetheilte Bemegung bis zum Eentrum zu ber= folgen unt mit meinem geiftigen 2 (htge Die Moleculent Des Bre = firns in Sdjwingungen verję̧t zu jehert. Dieje phyfifdyen Firo= zeffe beirren mein Эnneres nidjt. $25 a$ as mid beirnt und mir un= 
vorftellbar ift, bas ift bie Joee, Daß Sie aus Diejen phyfitident Saldwingungen, Denfelben fo völlig incongruente Dinge mie Entupin=

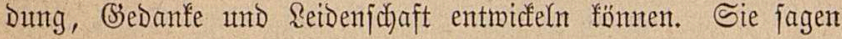

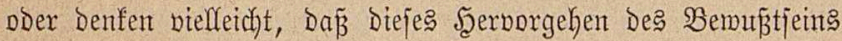

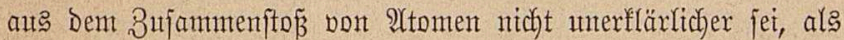
Das Szerborgehen Des Blities aus Der Sereintintng bont Sater=

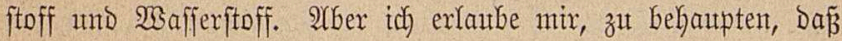

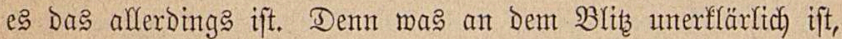

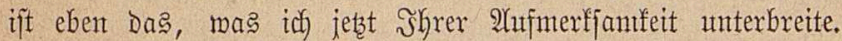

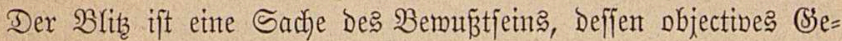

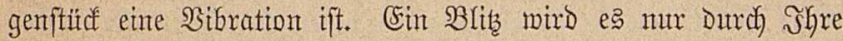

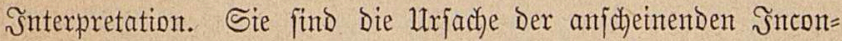
gruität, unt Sie find Das Ding, Das id nitht zu faffent vermag.

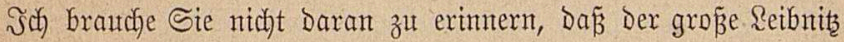

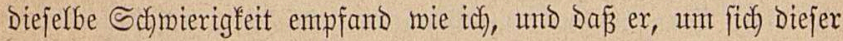
momftröfen Şerleitung Des Rebens aț Dem Iode zu entlebigen,

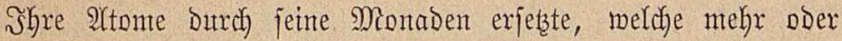
mentiger volffommente Spiegel bes Utniverjunts waren und ats Deren Summixung unt Sntegrixung nach feiner Meinung alle Rebenterjcheimungen Des (Empfindens, Des Dentents und Der Reident idhaft herborgefent.

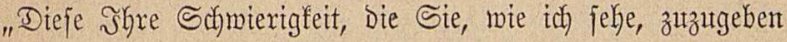
bereit finto, ift Daher ganz jo grofs, wie bie meinige. Sie fönten

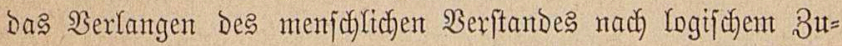
jammenhange zmifdhen molecularen Sirozeffen und Dett Exichei= mungen Des Bemurifteins nidjt befriebigen. Das ift ein Gelfen,

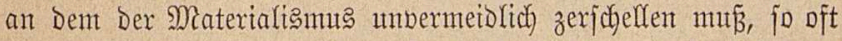
er Den 2(njpruch erbebt, eine wollftändige \$̧Gilofophie des Rebens zu jein. Was ift Die Mroral Davon, mein lucrezijdfer Freund? Sie und ich werben uns fdymerlich) bei ber Discuffition biejer 


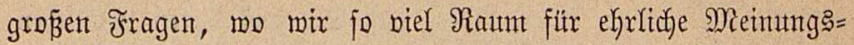

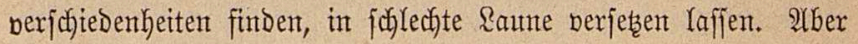
es gieft, thy jage es in aller Dentuth, anf betbent Seiten Rente von geringerm Wit Doer größ̈erer Bigotterte, Die inmer bereit

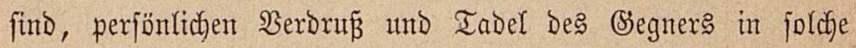
Discuffionen Ginein zut tragen. Es giebt z. 2 . Kentzutage bedeu=

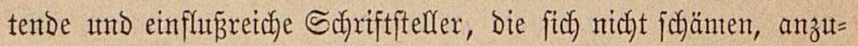

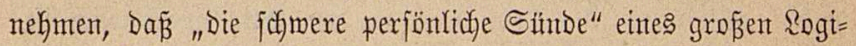
fers bie Utrjache jeines Itnglautbens an ein theologifdyes Dogma jei. Und es giebt andere, weldje bebaupten, Dẫ mir, bie wir unjere

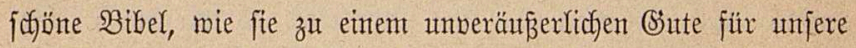
Borfahrent utto Durch) Bererbung auth) für uns geroorben ift, lieben, nothmendig heuthlerifac) und unaufricttig fein müfifen. Saffen Sie uns folche Seute verleugnen und befchämen, indem wir ohnte 2 sanfent an Dem Gilautben fefthaltent, Dañ, was an unferex betDer 2Uuffafijung gut und mafr ift, zum Bejtent Der Menjuhkeit exhalten bleiben, während alles Schledjte und Faliche verjafminten mirb."

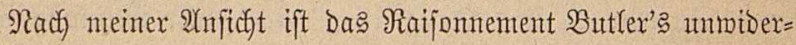
Yeglich) und jeine Riberalität Der (Befinmung nachahmungsmerth.

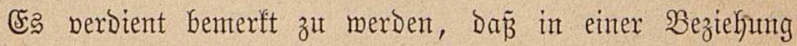
Butfer Das \$robuct feiner Beit war. Schon lange bor feiner 3eit war bie Nattrx ber Seele ein jo befiebter und fo allgemeiner

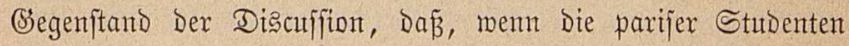

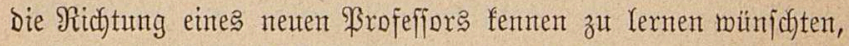
fie ihn ohne meiteres baten, ignen eine Worlejung über Die Seele 3u halten. 3u Bifchof Butler's Beit murbe nidft nur rebhaft über bie frage verhandelt, jombern aud ihr $\mathfrak{B}$ ereich) ausgedefhnt. Sdfarffinnige Miämner, bie fich in biefen Streit gemilicht hatten,

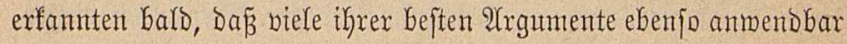




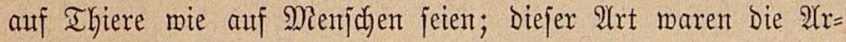
gumente Butler's. Er exfannte es, geftand es zu, acceptirte bie Sonjequenzen mo nahm fiugn bie ganze thierijdje 23 elt in jeinen Silan ber Itnfterblidufeit auf.

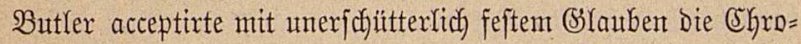
nologie bes alten Ieftamentes umb bezeidynete fie als Durch bie

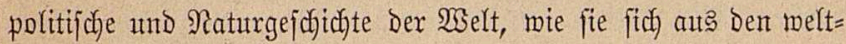

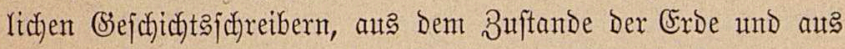
Den neteften Erfindungen Der Rünfte und Wiffenfdaften ergebe, beftätigt. Diefe Worte bezeicfnen einen Fortjd)ritt; fie múfffen

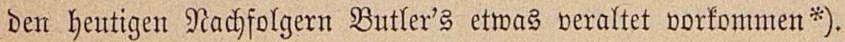

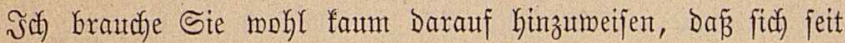
jener 3eit Das Bebiet Des Raturforfdjers ungeheuer ermeitert hat, Da feitbem erft bie ganze Wiffenffaft Der Beologie mit ifyen erftaunlidyen Entbedungen in Betreff Des Rebents Der Erde gefdaffen morben ift. Jit Der Strenge Der fritherent 21uffaffungen hat man nachgelaffen und bie offentlidge Meinung bat fich all= ntälig an Den Gebanfen gemöfnen gelernt, Daj̃ bieje Errbe nithyt jeit jedjstaujeno, audj nidyt jeit jedjszigtaujeno, aud nicht jeit jechs Mitlinnen Jahren, jontern feit 2fennen, welche ungezähite Millionen von Sabren umfafjen, Der Scjauplate bon Reben umb Tod gemejen ift. Das Räthjel des Bsefteines ift von ben juk= cambrijden Iiefen bis zu Den Sdjidten, Die fidf noch hente auf Dem Mieeresgrutnde ablagen, bon ben Biedlogen und won ben Fraläontologen gelöit morden. Uno auf Den Blättern Diejes ftei= nernen Butches find, wie Sie wiffen, Dentlichere unt zuberläffigere Rettern eingeprägt, als bie mit Der Tinte Dex (Bejedicfte gejufrie=

*) Nur (Einigen, betn es giebt Mürbenträger, bie nod) jetzt vout ser Felsftufte ber Erbe als bon ebenfo vielen, bei ber Sd)öpfung für bie Menichen bereit gebaltenem

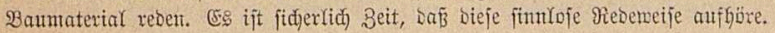


benten, Rettern, welche Den Bseift in 3eitabgründe zutüuffübren,

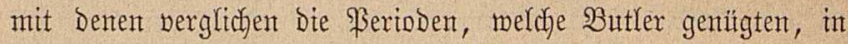
ifrer fileintheit völlig verjhmintoen.

Rachbem Der Schacht Der EntDedingen einmal gebffrnet mar,

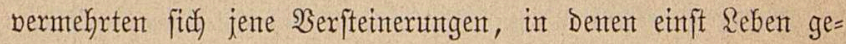

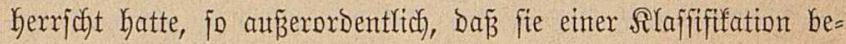
Durften. Sie mutrben entfprectjent Dem (Srade Der zmifchen ifynen beftehenden 2Yehnlidffeit in Benera, Species mo Barietäten gruppirt. So murbe SBermirrung permieden, indent jeber Bjegen= ftanto fich in bem für ihn und feine Gienoffen bon ähntlichem morphologifchemt ttitb phyfiologifhent Eharafter paffendem Fache zujammenfano. Bald ftellte fich) Die IGatjache keraus, Daß in Der tiefften Tiefe mur Die einfachften Rebensformen borfommen

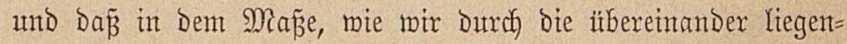

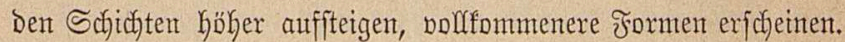

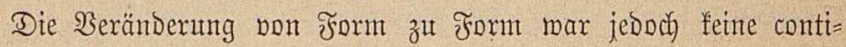
mitrliche, jondern ging in bald fleineren balo größ̈eren Sduritten

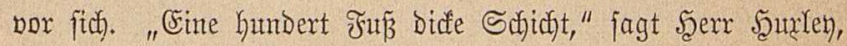

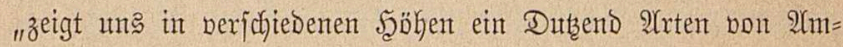
moniten, won Denen feiner über jeine bejontere $\Omega$ alf $=$ ober IGon= foficht Kinaus in bie unter ober bie über ifym liegende Sdjifft itbergeht. Soldjen Ihatfactjen gegenüber war es unmöglict, bie Frage zu umgehen: Sind Dieje Formen, in Denen fith), mem auch) in unterbrod)enen Stabient uno mit vielen Unregelmäß̈ig= feiten, ein unverfentbares allgenteines Frortichreiten finto giebt, nicht einem Bejęze continutirlicher Entwidflung ober Baxiation untermorfen gemejen? WBäre unjere Erziehung rein miffenjdajt=

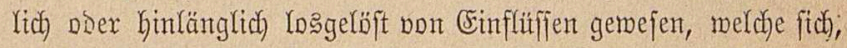
wie verebefnit fie auth auf einem andern (sebtete gemirit haben ntögen, inmer als Scemmniffe und Täuffhutugen ermiejen Gaben, 
fobald fie fith als Factoren auf Dem Bebiete Der Naturmiffen= fdhaften gelteno madhten, fo mitrbe ber miffertidyaftliche (seift nie in Der Frorictung eines Entwifflungsgejęzes nachgelaffen, Doex fidh Den 2Unthropomorphismuts geftattet haben, welcher jede Der

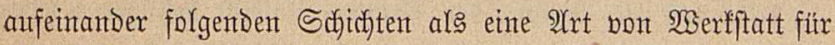
Die Fabrifation von neuten, aufier alfer Bezziehunt zut Den altent ftehenion $\mathfrak{2}$ renten betradjtete.

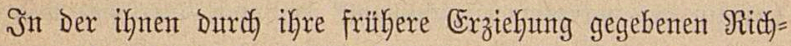
tung glaubte jeboch bie grofe Mefryahl Der Naturforidjer einen

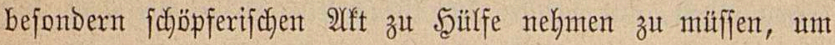

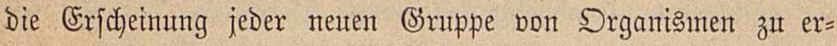
flären. Utnzmeifelhaft gab es jefrr Biele, Die flar genurg Dachten,

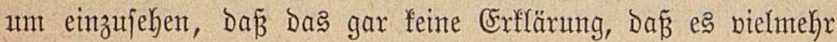

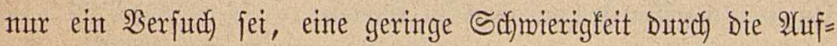
ftellung einer größ̄enn zu exflären. Da fie aber feeine Errflärung zit bietent hatten, zpgen fie es Der Miehrzahl nach bor zut faymetgen. Uno Doch war es natïrlich unto nothiventig, daf̉ Denfende Meän=

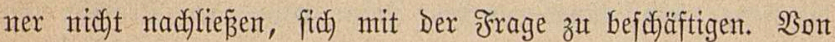

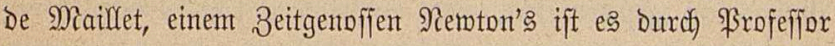

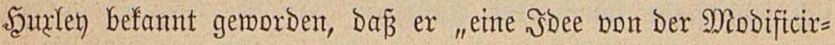
barfeit lebender Formen" hatte.

Jึ meinen häufigen Ituterhaltungen mit Dem verftorbenten Six Benjamin Brobie, einem Manne von hödjft philojophif dem Beifte Yenfte Derjelbe meine 2lufmerffamfeit oft auf bie Ihat=

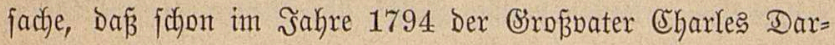
win's feit $\mathfrak{B}$ orläufer mar*).

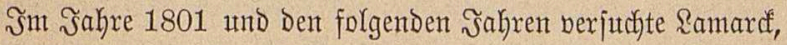
Deffen 2 nfifuten, in Der Denfelben non Dem SBerfaffer Der "Spuren

*) Zoonomia Vol, I pp. 500-510. 
Der Sdjöpfung" zu Theil gemordenen energithen Darlegung, einen fo groß̧en (Eindrut auf Das \$̧ublifum Kerborbrad)ten, Die Entmicfluntg Der 2(rtent Durch Verändentngent threr Rebensge= wogntbeiten und äıţeren $\mathfrak{B} e r f$ ältniffe.

1813 Ia马 Dr. 2Sella, Der Bründer unferer beutigen Thau= Iheorie, in Der föniglichen Ilfademie eine AYbhandlung, in meldyer ex, unt mich eines 2Atsorudes Darmin's zu bedienten, "Das Frinzip Der natïrlicten 3utchtmahl" beftinment anerfennt unt Da马 ift bie erfte befannte 2 Inerfennung. Die Hteberzengunggtreute und (Bemantheit, mit meldyer Dr. WSella feine 2 lrbeit berfolgte into bie entjojtedene Utnabfängigfeit jettes Sharafters hat ibn jeit langer 3eit zu einem meiner Rieblinge gemadft unto es hat mir ein bejonteres 2 Bergnitgen gemährt, auf Diejes neute Zeugnifß feintes Scharffitms Ginmeijent z̆t fömen.

Brofeffor Brant, Fatrid Mathem, v. Buth, Der Berfaffer

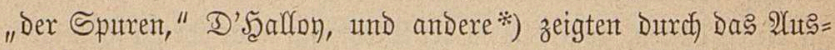

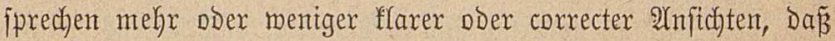
Die Frage fothon lange bor Dent Sahre 1858, wo Darmint unto

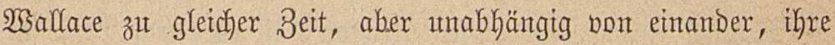

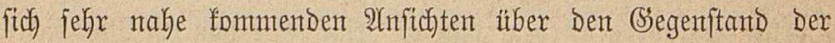
Sintéfichen Béejellichaft vorlegten, gegährt habe.

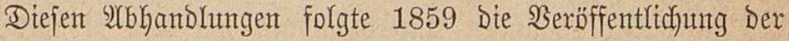

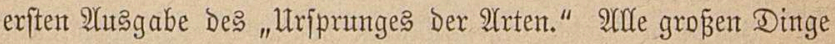
wersen ficher geboren. Soperniflus brittete, wie idj oben er= wäbnt habe, Dreitnobreiştg Sabre über feinen groß̧en Werfe.

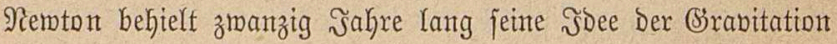

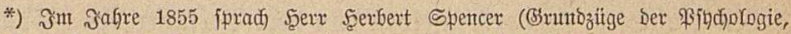
2. 2uffage, Bant I p. 465) bie Heberzengung auts, baß bas Sebent itt affent feinen (Be= ftalten auf Dem WSege fogenaunter natïrlidjer Irjadjen ants eittex 1ntgebrodjenten Ent= wioflung herborgegangen jei. 
für fich, wiomete eine ebenjo lange Beit jeiner (Entbectung ber Flutionten unt mïrde ohne 3meifel fortgefahren feit, fith) nux pribatim bamit zu beichäftigen, wenn er nidjt gefunben hätte, Daß̧ Reibnite auf jeiner Spux jei. Darwin hatte zmeiundzwanzig

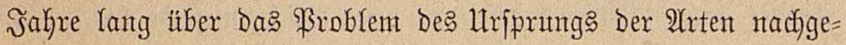
Dactft und mitrde ofne 3 meifel fortgefaffren fein, fith nur privatim

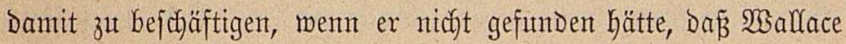
auf feiner Spur jei*). Die Folge mar ein concentrinter, aber

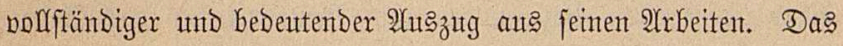

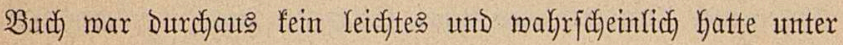
je zmanzig Seuten, bie es Damals angriffen, nicht eirrex es ganz Durchgelejen, DDer war, went er es gelejen hatte, im Stande, jeine eigentliche Bedentung zu erfaffent. ऽd jage bas nicht nur, um Dieje Begner zu biscrebitiren. Denn es gab in jenen Tagen einige mirffich bedeutento wiffenj(haftlidge Meänner, bie, weit er=

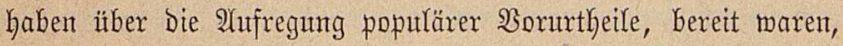

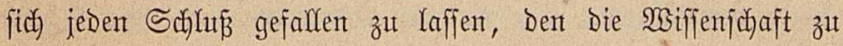
bieten habe, voratsgefetet, Daj Derfelbe Durd) Thatfachen umb

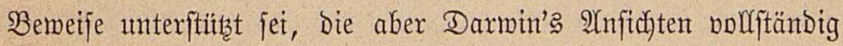

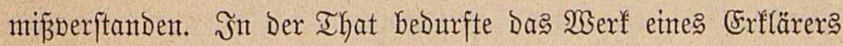

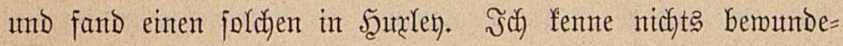
rungsmertheres auf Dem (Sebiete miffenfidfaftlicher Darlegung, als

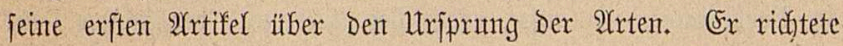
feine Erörterungen auf bie mirflich Gedentfamen Gunlte Des (Siegenftantes, bereidjerte feine Darleging Durd) tiefe, originelle Bemerfungen ind Reflexionen, intom ex oft in einen einzigent marfigen Satz eine Bemeişfüthrung zujammendrängte, zu meldher ein mentger concentriter Bseift Seiten gebrautht haben mürbe.

*) Warface' Benthmen bei biejer Belegenbeit twar bes hödhften sobes twerth. 
2Hber Das Budf felbft macht einen Eimbrud, meldyen feine, nod) fo lidftoolle Darlegung jeines Jnhaltes wiebergeben fant

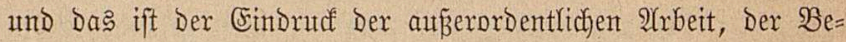
obachtung unto Des Detrfens, welche ber, Berfaffer Darauf ber= mendet hat. Werfen mir einen finzen Bliff auf jeine Frinzipien.

Es wirb von allen Seiten zugegeben, Daß Die jogenanntent

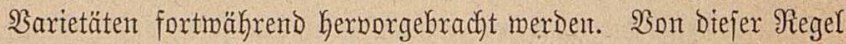

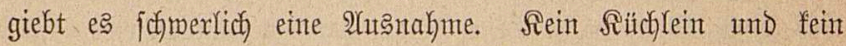
Ritn ift in allen Beziehungen und Beponderheiten Das Seiten= ftituf feines Brutoers oder feiner Sdymefter und in foldjen Dif=

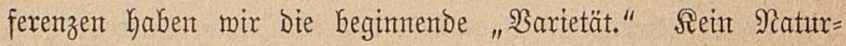
forjuger fönnte fagen, wie meit biefe $\mathfrak{F a r i t i u n g}$ geben fann, aber

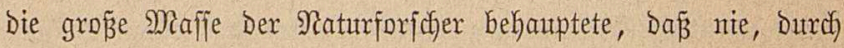
feine noch fo grop̃e innere ober äuffere Veränderung uno Dutrch feine Sierbindung beider bie Nadffommen Deffelben Erzeugers fith jo meit bon einander entfernen tönnten, Daß fie beridjiedene 2rten begritnDeten. "Die 2 lufgabe Des experimentirenten Natur=

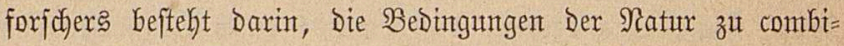
nixen und igre Ergebniffe zt probuciren und Das mar Darmin's

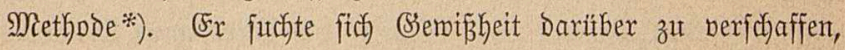
was auf Dem $\mathfrak{W e g e ~ D e x ~}$ Srodutction bon $\mathfrak{B a r i e t a ̈ t e n t ~ b o l l f o n m e n ~}$

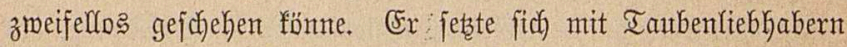
in $\mathfrak{B}$ erbindung - faufte, exbat fich), hielt und beobachtete jebes 3udfteremplar, das ex exlangen fonnte. Sbgleid) bon gemein= fanter 2 GGftanmunt, waren bieje Iatben fo verichiebent bout ein=

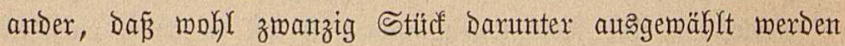

\footnotetext{
*) Sur Der exfte Sd)ritt auf Dem Wege experimentelfer Demonftration ift ge=

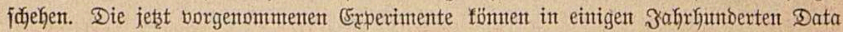
bon unberedjenbarem Wserthe Yiefern, weldje Der Wifjenfdjaft Der 3ufunft zu Bute tommen mitffien.
} 
fonnten, weldfe, went man fie einem Drnithologen gezeigt und

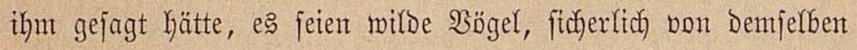
für Exemplare beftinmter, bon einander berfdiebener Ârten er= flärt morden wärent. Sas einfache Srinzip, weldches den Iautben=

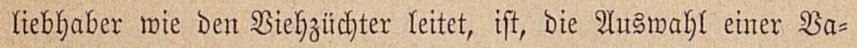

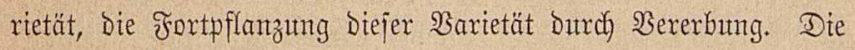
Bliffe nod) feft auf bie befondere (bieftalt gerid)tet, Deren (Eigen= thïnllidjfeitent ex zut fteigern wïnficht, wählt ex biefelbe, io oft fie wie= Derericheint, in aufeinanderfolgenden 3uchteremplaren auts und fügt io 3ugabe zu 3ugabe, bis er eine auferorbentliche Divergenz von

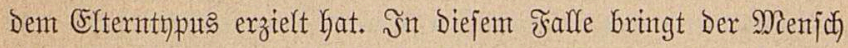
nidfft bie Eremente Der Bartation Kerbor. Er beobacbtet fie ein= fact) und bringt fie Dutrch S2usmahl zujammen, bis ex Das ge=

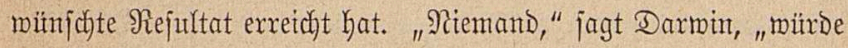

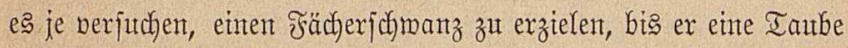

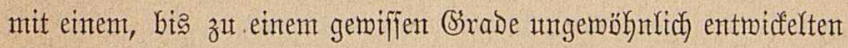
Sdjmanz - oder eine Siropitautbe herborzubringen, bis er eite

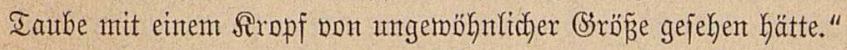
So giebt Die Natutr Den Winf; Der Mienjd handelt Darnach unt ftei=

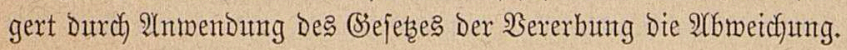

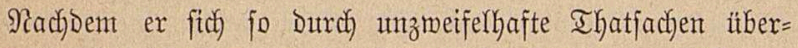
zentgt Kat, Daß Die Srganifation eines Thieres ober einer \$Fflanze, - Demt genaut Diejelbe Behantluntg läpt fich) bei \$flanzen an= menden -, bis zu einem gemiffen Grabe billojam ift, gebt ex

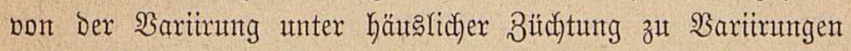

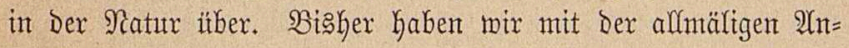

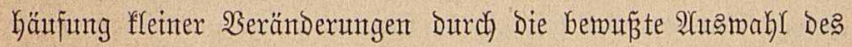

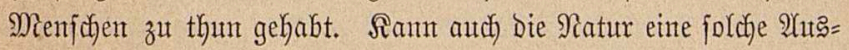
makl treffen? Darmin's 2Yntmort lautet: "Beseifi fann fie es." Die 2Inzahl erzetgter lebender Wejent itberfeigt bei meitent bie Zafl 


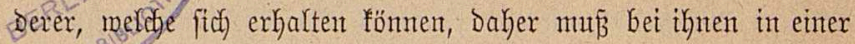

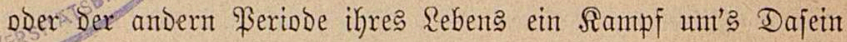
ftaftfindent. Utnd mas ift Das unfehlbare Ergebnif̧? Wenn ein Drganisnuts ein vollfommenes Ebenbilo Des andern in Bezug

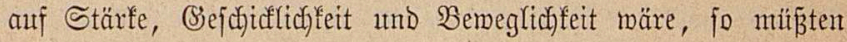
äupere Itmftände bei jentem Sampfe entfheidend jein. Das ijt aber nicht Der Fall. Şier haben mir Die Thatjache von Barie= täten, Die fich Der Natur Darbieten, wie fie fich in Dent frühern

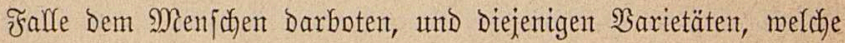
am menigften geeignet fint Den Rampf mit Den ßerbältniffen aufzumebmen, merben unfehlbar Denen Slats madjen, weldhe am fähigiten zu jenem Rampfe find. Der Sdymädjfte unterliegt; aber ber trumphirende Theil vermehrt fid mieder bis zux Uleber= probuttion und itberträgt Die (Eigenja)aften, weldje jeine Erbaltung ficherten, liberträgt fie aber in verjofiedenen Graben. Der Sampf

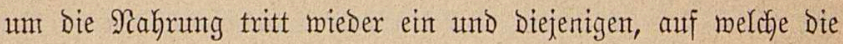
vorzügltchere Begabung im Göchften Brabe itbergegangen ift, merDen ficherlidy mieber triumphiren. Man fieht leidyt, daj̃ mir

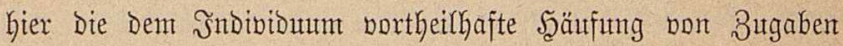
noch) ftrenger burdigefüfyrt vor uns haben, als in Dem Falle Dex häıミlidfen 3üfftung; Denn nicht alfein merden Die mentger be= gabten Exemplare bou Der Natur nidbt auggemäblt, fondern fie merden bernichtet. Das ift es, was Darmin "natürliche 3udits =

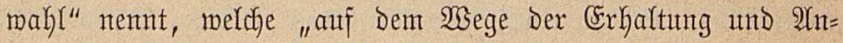
fäufung fleiner bererbter Modificationen, bon Denen eine jebe

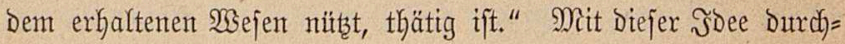
bringt Darmin mie mit einem Satterteig Den angeheuren $\mathfrak{B} D \mathrm{r}=$ rath von Thatjacten, ben ex und andere gejammelt haben. Wix fönnen, wenn mix unjere 2lugen nidyt auts Furdyt oder

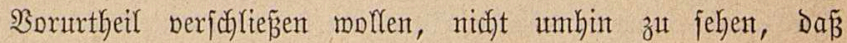


Darmin hier nidft mit eingebildeten, fondern mit mahren $\mathfrak{l t}=$ fact)en operirt; audd) fönnen wix nidgt perfennen, meldche unge= Geuren Midififfationen in Ginlänglid) langen WBerioden Durch na=

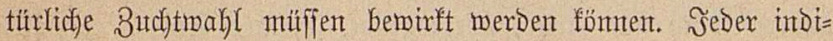
viduefle 3umachs ift vielleidgt Dem ähnlid), was bie Mathema= matifer ein Differential (eine unend lide) fleine Sutantität) nennen;

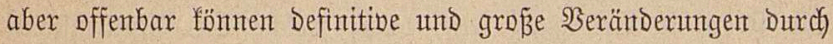

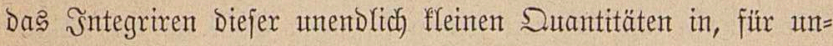
fere Borftellung unendfidjen Beiträunten herborgebradgt werben.

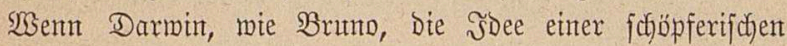

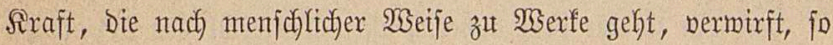
gejdjeht es gemin nicht, weil ihm bie unzähligen auझerlejenent

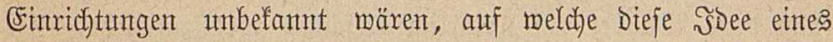

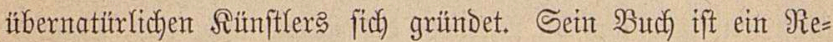
pofitorium Der frappanteften IGatjachen biejer $2(x$ t. Man nehme Die merfmuirbige Beobadftung, meldye ex nach Dr. Eritger citirt unt Derzufolge eine Srdjidee bie Form eines Esinters mit

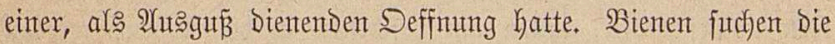
Blutme auf; im eifrigen Sucthent nacth Stoff für ifre Sconigmabent Drängen fie einander in Den Ëimer und Die Durdfunäāten flüdten

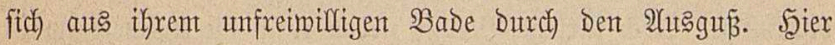

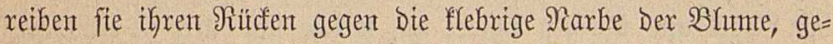

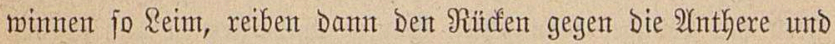
tragen Den an Dem Reinte haftenden Blïthenftaub auf Dem

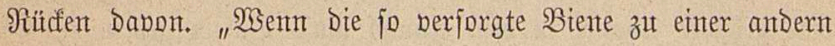
SBlume, Doer ein zmeites Mal zu Derjelfent Blinme fliegt, und bon iffren Rameraben in Den Eimer gedrängt wirb umb Dann

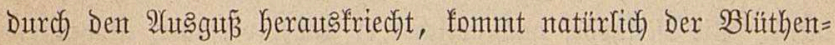
ftaub auf ihrem Rücfent zuerft it Berühruttg mit Der flebrigen Narbe, an melcher nut Der Blïthenftaub Gaften Bleibt," und Introaff, Materialismuts. 


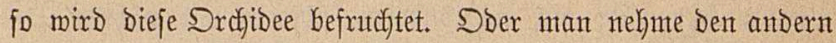
Fall mit bent Catafettm. Bienten juctent Dieje Blitthen auf, um an ithrer Şoniglippe zu nagen; indem fie das thun, berübren fie untwermetolidy eine lange, itberragende, fenfitive Spitze. Sobald Diefe Spiz̧⿻ berifhrt wird, itberträgt fie eine Senjation ober $\mathfrak{B t}=$ bration einem gemiffen Scäutchen, weldję alsbald zerjpringt uno eine Feber in Bewegung fetzt, Durdy meldye Der Blïthenftaub

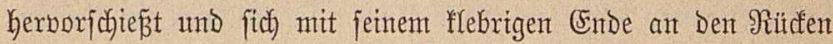

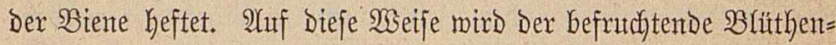
ftaub verbreitet.

Unto eit fo mit bem auserfefenften Miaterial Des Ieleologen

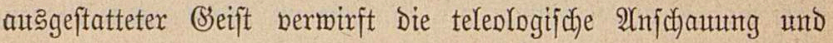

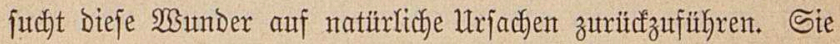

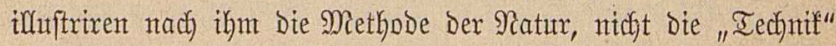

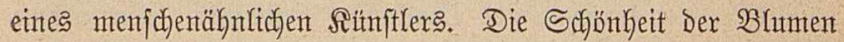
entfteht Durch natürliche Buchtmahl. Diejentgent, weldye fid Durrd lebGaft contraftirende Farben bon Den umgebenien grünen Blät=

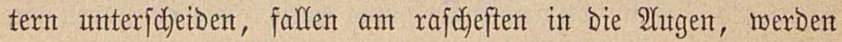
am bäufigftent von כ̋nfeften aufgejudd)t, am bäufigften befruchtet und in Jolge Deffen bon Dex natürlidfen 3utchtwahl ant meiften begünftigt. 2Uud farbige Beeren ziehen rajd) Die 2Yufmerffamfeit Der $\mathfrak{B}$ g̈gel und übrigen Thiere an, weldje fich) Durd) fie ernähren, ihrent mit Dintger vermifdytent Sament untherftrentent und fo Den Bäumen und Sträudjern, an melchen fidd foldche Beeren befinden, eine größfere Çhance in Dem Sampf um's Dajein geben.

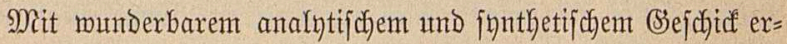
foricht Darwin Den Jnffinft Des 3ellenmachene bei Der Sconig= biene. Die Methode, nach melcher ex dabei verfäbrt, ift nurfer= gülttig. Ex geht bon Dem bollfommenter entricffelten zu Dem

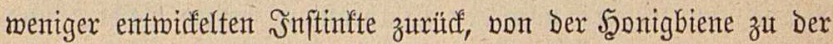




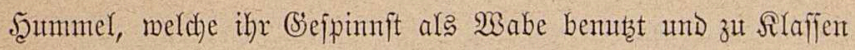

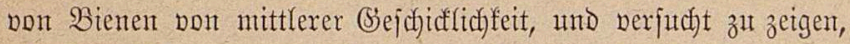
mie Der Hebergang won Der niebrigften zઔ Der hödfiten Ent= wifflung ftufenweije exfolgt fein föme.

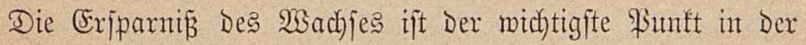

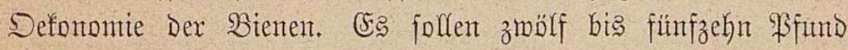
troctenen 3uteres zur Sefretion eines einzigen \$fundes 29 ad) exforberlich jein. Die für Das $2 B a c h$ s exforderlichen Suantitätent

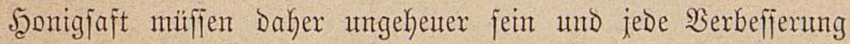

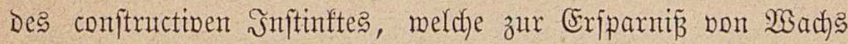

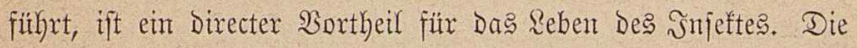

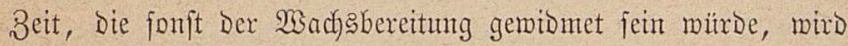

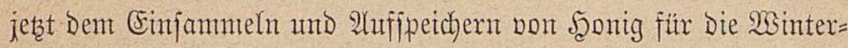
nafrung gemiomet. Darmin geht bon der Scummel mit ifren rohen Belfen, zut Der Mielipona mit ifren fünftlicher gearbeitetent 3ellen und non Diejer zu Dex Şonigbiene und Deren erfaunlicher 2(rdjiteftur über. Die Bienen fteffen fïc) in gleidfen (Entfermungen,

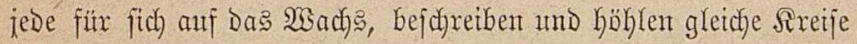

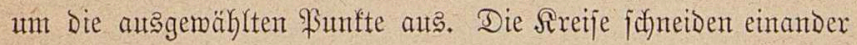

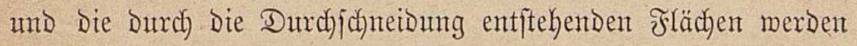
mit bünnen Fiatten überbaut. So merben jedjsectige Belfen ge= bilibet.

Diefe 2(rt, foldhe Fragen zu behandeln, ift, mie gejagt,

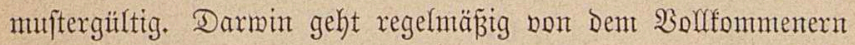
und Eomplicirtern auf bas mentiger 90 olffommene und Einfact)e

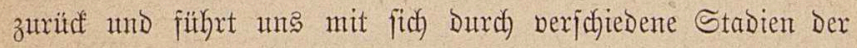

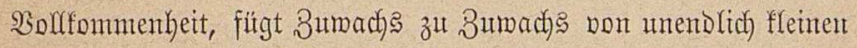
2Seränderungen mo befiegt auf Dieje $25 e i j e$ unjex 2 Siderjtreben, zuzugeftehen, Daß Der außerlejente Şöhepunft Des Banzen ein

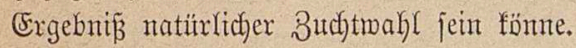


Darmin geht feiner Schwierigfeit ats Dent $2 \mathrm{Gege}$, tho er nutis, wie er Den (Begenftand grïndlich) Durdboad)t bat, beffer als jeine Sritifer jomohl Die Sdjwädje mie Die Stärfe fenter Theorie gefannt haben. Das mürbe natürlidy von geringer Bedentung jein, wäre jein 3medf ein boritbergehentor bialeftipcher Sieg uno

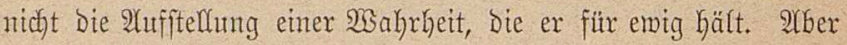

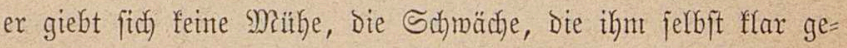
morden ift, zu verbutflen; im Eiegentheil, ex giebt fid) alfe er= Denfliche Miithe, Dieje Sdymädje in bas ftärlfite Ridjt zu ftellen. Geine auferordentfichent Mittel befähigen ihnt mit Einmentoungen 3u fämpfen, Die ex felbft und andere erhoben baben, fo Daj er

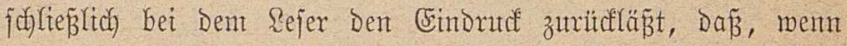
ex Dieje Cinmenturgent nidgt bolftänoig beantwortet hat, fie ifhm Dod nicht verbängnifipoll werben fömen. $23 e n n$ ex fo Die nega= tive Siraft Diejer Einmendungen befeitigt hat, fant man bie un= gehentere Miaffe pofitiver Bemeife frei auf fid wirfen laffen.

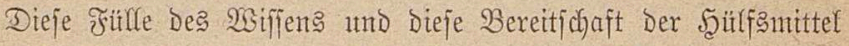

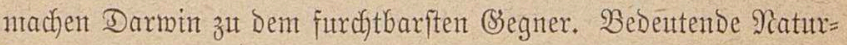
foricher baben icharfe fritijoje 2tngriffe gegen ifn erhoben nidft intmer mit Dem 3med, jeiner Ifeorie bolle Beredigtigfeit

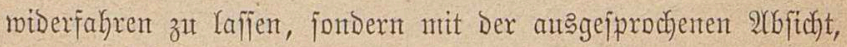
nutr ifgre idjwachen Seiten bloszuftellen. Das irritirt ihn nidft.

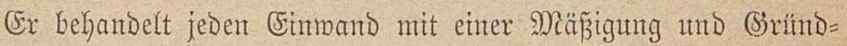

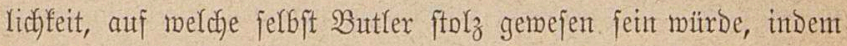
er jebe Ihatjadje mit Dem geeigneten Detail amgiebt, fie in Die ihr gebiithrenden Beziefhungen bringt und ihr in Der Fegel eine

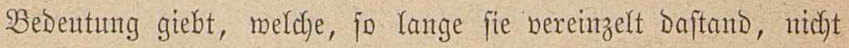
zur Geltung fam. Ilnd das thut er ofne eite Spur von Bese= reiztheit. Err idfreitet mit Der Yeidenfdjafteldjen Stärfe einte

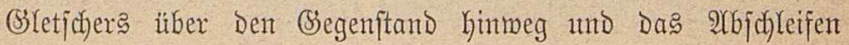


Der Felfen fundet bismeilen fein Seitenfiüuf in Der logijajen $3 \mathrm{er}=$ malnutug Des Biegners.

2Aber obgleich) ex bei Der Behantlung jeines gemaltigen Themas jebe Reidenjuaft zum Sdymeigen gebradht hat, perleigt Dodh eine,

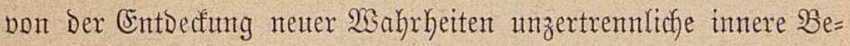
meginng Den Slättern Darmin's oft eine marme Färbung. Sein

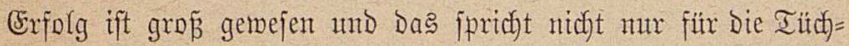

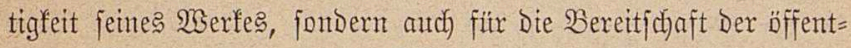
liden Meimung eine joldc) Sffenbarung it fich aujzunehmen. Jn biejer Beziehung hat mix eine Bemerfunt von AYgaffiz Den größ̈ten Einorud gemadyt. 21ts einter Fanilie pon Theologen

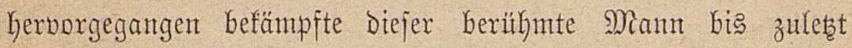

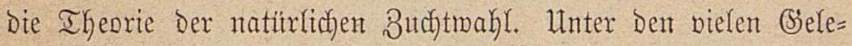

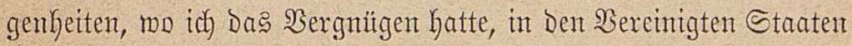
mit ifm zufantmen zut treffen, mar auch eine auf Dent jofpönent Sandftbe Des Şerm Wsinthrop in Bropfline bet Bofton. Vom

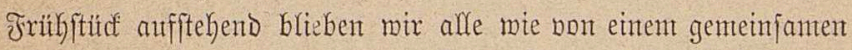
Smmulfe getriebent bor einent Fenfter ftehen unt jetz̧ten bier eine Unterbaltung fort, Die mir bei Tijdje begomen Gatten. Der 2lyorn ftand in jeiner ganzen herbfttidyen Fradbt und bie wun= Derbare Sdjönheit Des Bildes, Das fith unjern Blicfen Darbot, fobient in Diejem falle ungeftört auf Die IGätigfeit Des Breiftes 3u mirfen. Exnft, faft traurig wandte fich) 2 fgafiliz zu ben um=

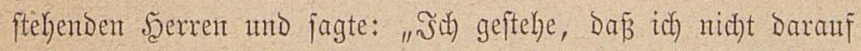

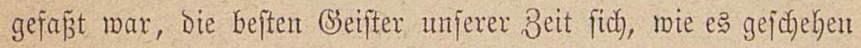

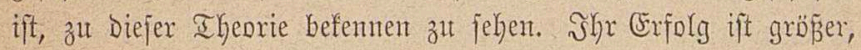
als idíf) es für möglidé) gefyalten lyätte."

Mau ift in unferen Tagen zu grop̧en Berallgemeinerungen gefangt. Die Theorie Des Uriprungs Dex $\mathfrak{Y}$ thten ift nux eine Der= felben. (Eine andere bon nod) meiterm ltmfange und eingrei= 
fenderer Bedentung ift Die von Der Erfhaltung Der firaft, Derent

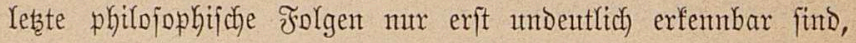
Dieje Doctrin fordert bon jedem 2(ntecedenz feine equibalente Eonjequenz, von jeber Conjequenz ihr equibalentes 2tntecedenz utnd bringt bie Exrcheimungen Des Rebens wie Der Natur unter

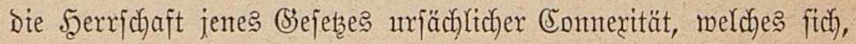
joweit ber menjchliche $\mathfrak{B}$ erftand bis jeţt borgebrungen ift, überall

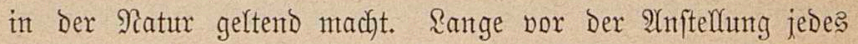
Definitivent Experimentes über Den Begentant war Die Beftän= Digfeit und Utnzerftörbarfeit Des Stoffes behautptet morben und jedes fpätere Experiment redjtjertigte Dieje Behauptung. Spätere Unterjut(f)ungent ermeiterten Die Eigenfalaft Der Unzerftörbarfeit zu einer Siraft. Dieje, anfängliç) nux auf Die unorganifjue Natur

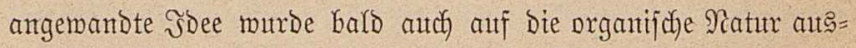

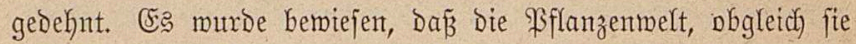
faft alle ifre Sahrung aus umfidftbaren Dueflen zieht, unfähig fet, netren Stoff ober neute Siraft herborzutbringen. Shr Stoff befteht größztentheils aus verwanbelter Suft, ihre Sraft aus ttm= gemandelter Sonnenfraft. (5s murbe ferner bemiejent, Da a antd)

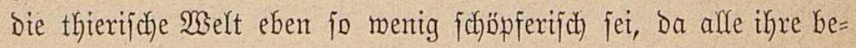

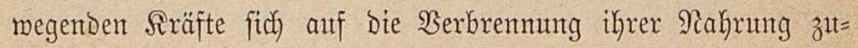

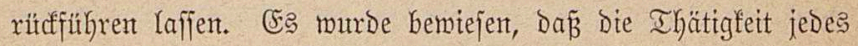
Thieres als eitres Banzen fich aus ber Hebertragung Der Thätigfeiten feiner Mideculen zujammenjeţe. (5) nurbe ge=

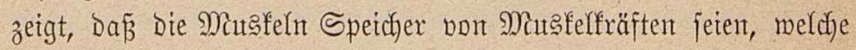
perborgen liegen, bis fie burdh bie Nerben aufgeidhloffent werben

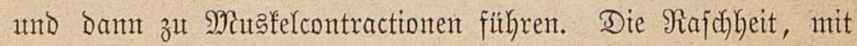
melcher SBotichaften längs Den Nerben hin uttlo her fliegen,

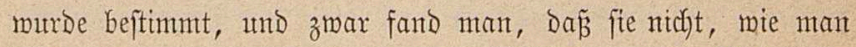

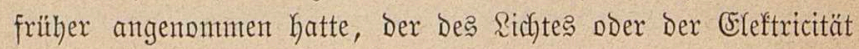


gleiche, fonbent geringer fei als bie Fajuheit eintes fteigenten IDlers.

Das war bas Werf des \$hyjifers, Dam famen Die Erobe= rungen Des vergleidyenden 21natomen und Des \$Shyfiwlogen, welche Die Struftutr jebes Thieres tnto Die Frtuftion jedes Drganes auf Der ganzen biologifchen Stufenleiter, bon Dem niebrigften $300=$ phyten bis zut Dem Mienjdjen Ginauf, flar Darlegten. Das Rer= venfyftent war zum Siegenftande eintes tiefen uttb andauterndent

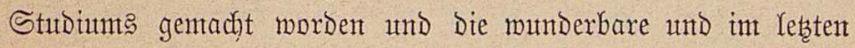

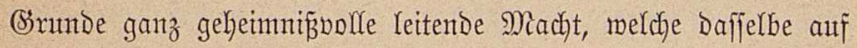
Den ganzent phyfifchen und geiftigen Srganismuts übt, mehr und

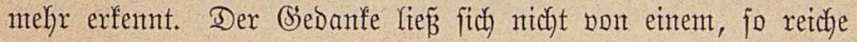
2Uuffid)lüfie verheifenden Begenftande zuritudfalter.

2luß̧er Dem pon Darmin behanderten phyjitichen Reben giebt

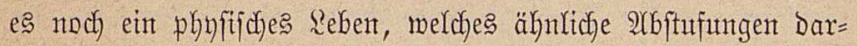
bietet und gleicher 2 eife nach einer \&öjung verlangt. Wiste fint Die berichiedenen (Srabe und Sromungen Des Bjeiftes zu erflären?

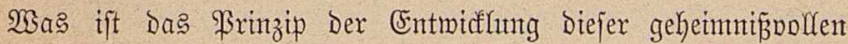
Miadyt, welche auf utufernt \$lanteten in Der Bermutnft gipfelt?

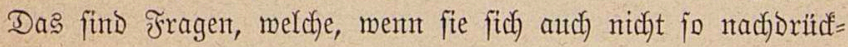
(id) Dex 2lufmerffamfeit Des গ̧ublifums in allgemeinen auf= Drängen, niddyt mur viele benfende Bseifter befchäftigt hatten, jon= Dern von einem Derjelfent nod) bor Dem Ericheinen Des „Utrpxuntgs Der Arten" berifhrt morden waren.

Mit Der, won Den Whyfitern und \$ryyfiologen gebotenen Maffe von Stoff in Der Şant, juct)te Şerbert Spenter vor zmanzig Jahren auf Dieje (Srundlage ein Syftem Der \$inchologie zut

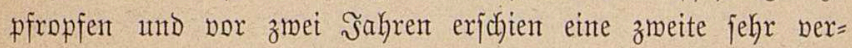
megrte 2Uuflage feine 23 erfes.

Diejenigen, weldye fich mit Den fobönen Experimenten ßlateau's 


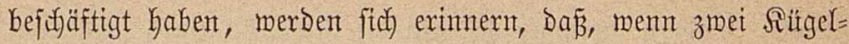
deen Slinenol, weldye int einem, Dem Dele an Dicftigfeit gleidyent (Semifach bon 2ulfolol und Waffer fojmimmen, zujammengebracht merben, fie fich nidft jojort bereinigen. (Etwą mie ein Şäutchen

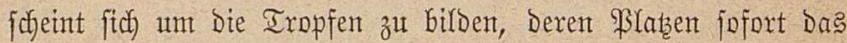

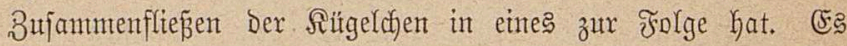
giebt Srganismen, Deren Sebenßthätigleit faft ebenjo rein phy= fiffaliffer Matur ift, mie bie biefer Iropfen Del. Sie fommen

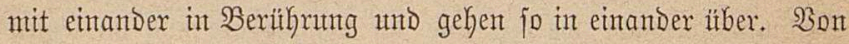
foldyen Drganismen zu anderen, eine Nuance Göher ftehenden und bon biejen zu anderen, nod) eine Nuance höher ftehenden, und fo fort burd eine immer auffteigende Reibenfolge bin, führt

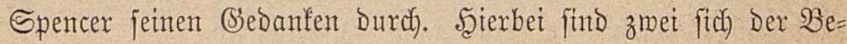

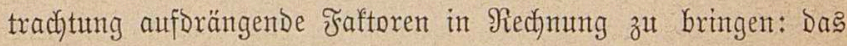
(Bejäppf und Das Miedinn, in meldyem es lebt, ober, mie man

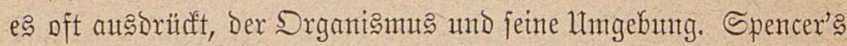
(S)rumbprinzip ift, Daß̃ zmijofen biejen beiden Faftoren eine fort= mährende Wechjefmirfung beftehe. Die Untgebung wirft auf Den Srganismus utto der Srganismuts modificirt fich, um Den (Ex= forberniffen Der Utmgebuttg zu entipredfen. Ex Defintirt Das Reben als eine fortwährenve 2tnpaffung innerer $\mathfrak{B}$ eztefungen:

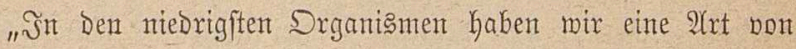
über ifren ganzen Rörper verbreiteten Beffüfrgfinnes; Dann

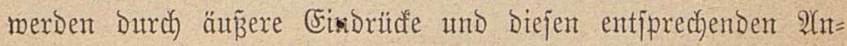
pafiungen beftimmte Theile Der Sberfläche empfänglidcher fitr Reize als andere. Die Sinne entftehen auf Der ihnen alfent ge= meinfamen Bafis jenes einfachen Befitflesfintes, meliffen Der meife Demofrit bor 2300 Jahren als ihren gemeinfdyaftlidyen

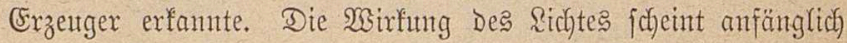

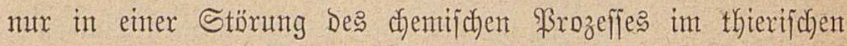


Srganisnuts zut beftehen, ähnlid) Der, wie fie bei Den Blättern

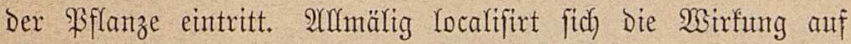
einige Sigment=Bellen, weldje empfindlidjer gegen Das \&idft fint, als Das fie umgebende Berwebe. Scier beginnt Das 2luge. Zuerft ift es nutr in Stande Durdh gant nahe Begenftände herborge= bradfe Alnteridjiede Des Sidftes und Des Sdjattens mahrzunehmen. Wte Der Unterbrectung Des Ridjtes faft in alfen fällfen bie $\mathfrak{B} e=$ rüfrung mit Dem bicht borliegenden Dunfeln förper folgt, fo wiro Das Sehen in biefent Buftande eine $2(x t$ vont anticipirentor $\mathfrak{B} e=$ riffrung. Die 2Yupafjung nimmt ifyren Fortgang; eine Yeidfte

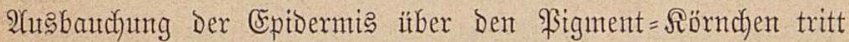
Ginzu. (Eine Sinfe fängt an fich) zut billden und erreidft anf Dent

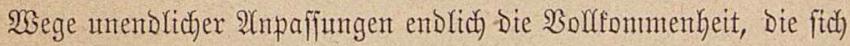
bei Dem Falfent und Dent 2LDler zeigt. So autdy mit Den anderen Sinnen, fie find bejondere Differenzinungen eites Bsemebes,

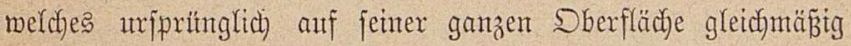
unbeftimunt jenfitio max.

Mit Der Entwidflung Der Sinne Defnen fid Die 2Hpaffungen

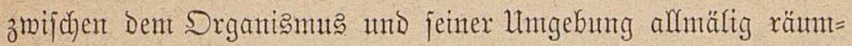
(id) ats 1tnt eine Bervielfältigung Der Erfahrungent und eine

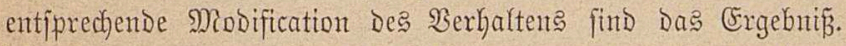
Die 2tnpafiungen Defnen fich) and Der Beit nad) ans und nefment

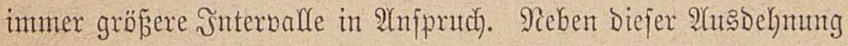

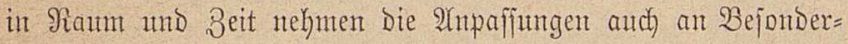
heit und Complexität zu, indem fie Durch Die berfodiebenten Etufen

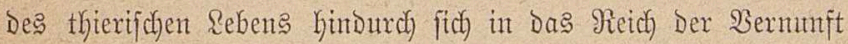
erftrectert. Sefr frappant find Spencer's Benterfungen in $B_{e}=$ treff Der Cinfluffe Des Iaftfinnes auf Die Entwidflung Der Jn= telligenz. Diejer Sinn ift fo zut fagen bie Mutteriprache aller Sinte, in meldhen fie überjeţzt merdent mifffen, unt Dent Drga= 
nismus von Nutsen zu fein; Daker feine Widftigfeit. Der $\mathfrak{S a}=$ paget ift Der intelligentefte unter alfen $\mathfrak{B}$ g̈gelnt tntD jein Iafffint

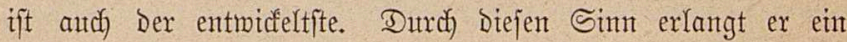

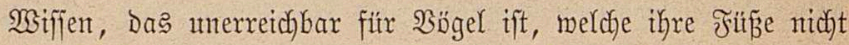
als Şände bentz̧en föment. Der EFlephant ift das fdarffitu= nigite unter dent vierfüfigen Thieren und die CSrmblage diejes Scharffinns ift fein hodfentmicfelter Iaftint fomie bie entipre=

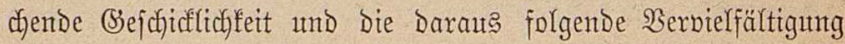

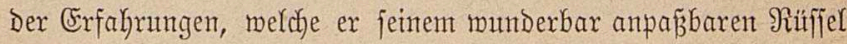

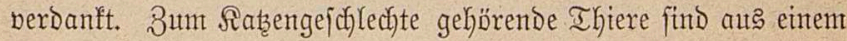

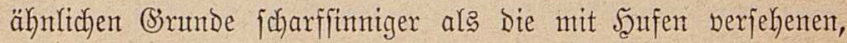
mofitr bem $\mathfrak{B f e r d e}$ bis zu einem gemiffen (Brade Durch Den $\mathfrak{B} e=$ fit fenfitiver, zum (Sreifen geeigneter Sippen Erfat geboten miro. Bei Dent Frimaten geht Die Enntwickluntg Dex Sntelligenz mit Der Entmifflung Der Taftwerfe Şand in Şand. SBei Den in= telligenteften anthropoiden Ulffen funden mir biefe Feinheit Des

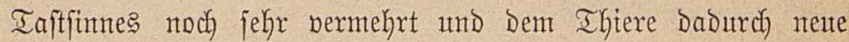
3ugänge Des 23 tiffens eröffrnet. Der Menfch frönt Das (sebäude,

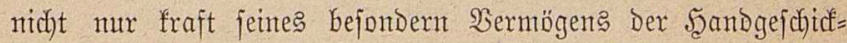

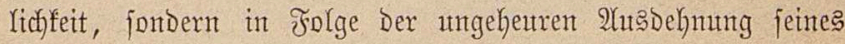
Bereiches Der Erfahrutng, Durch) Die Erfindung bon genauen Injtrumenten, meldhe ifym als ergänzende Simne umb als ex= gänzende BSfieder Dienen. Die gegenfeitige Wirfung Diefer Wert= zenge wird bei Spencer fchön gejchild ert utto illuftrirt. Sene gezilgelte geifftige Retbenjidaft, won Der id in B̧ez̧ug auf Darmin gejprochen habe, fehlt glanbe idf) audf) bei Spencer nidyt. Seine Illuftrationen fino bismeilen bon einer auñerorbentlichent Sraft und Rebertotgfeit und fein Stil bei foldhen Sdhildenungen beredfigt zu Dem Schlufie, Daß̃ Die Banglien Diejes 2lpoftets des Werftandes bismeilen Der Sitz einer beginnenden poetifchen Begeifternng finto. 


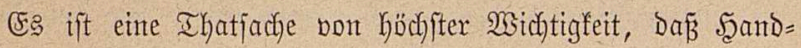

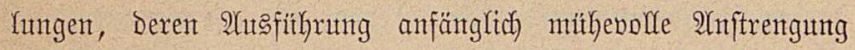

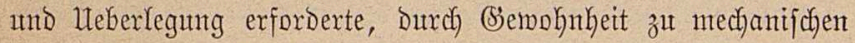
werben fönnen. Beweis: Das langjame Sernen Der Butchftabent bei Dem Rinde und Die ppätere Reidftigfeit Des Rejents bet Dent

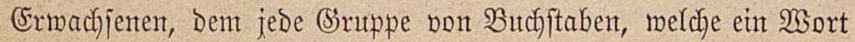
bilbet, fofort unto ohne 2 (1rfftrengung zut einem in einer einzigen

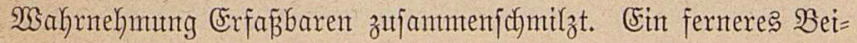

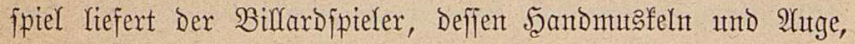

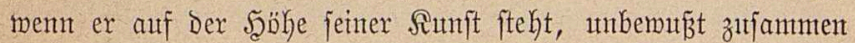
arbeiten; wieber eit anderes Beifpiel ift Der Murfifer, Der fich Durrch) Hefung in Den Stand fetzt, eine Menge von Behburs=, Iaft=

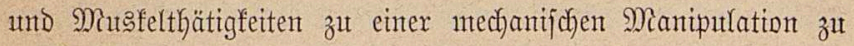
werichntelzent.

Wenn wir foldhe Ihatjacten mit Der Refyre vont Der erblichen Utebertragung in Berbinounty fetzen, fo gelangen wir zut einer Theorie Des Jnftuntes. WSent Das Rübdyein auts Dent Ei friecht,

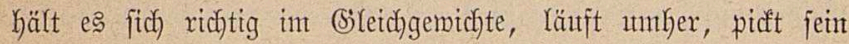

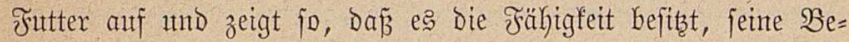

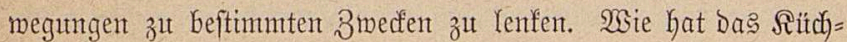
rein Diejes fehr complicirte 3ujammenmirfen von 2luge, Muţeetn

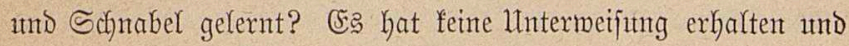

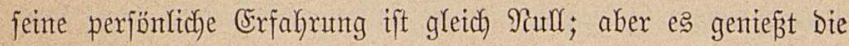
Woblthat einex won feinen Sibrfahren ermorbenen Exfahututg. Эn feiner angeerbten Srganifation liegen alle bie Fräbigfeiten, meldye es bei feiner (seburt entfaltet. So berfält es fid autd)

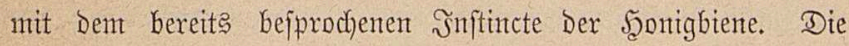
Entfernung, in melcher bie Bienen fich bon einander aufftellen, ment fie ihre Scalbfreife bejarreiben und ifre Bellen bauten, ift Das Ergebnif einer, ifrent Drganismts eingepflanztent Exinnerunty. 


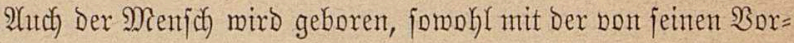
fahren überfommenen phyfijdfen Iextur, als mit Den mit Diefer Textux zujammenfjängenden angeerbten intellectuellen Jäbigfeiten. Die unzulänglidye Entwidflung Des intellectuellen Bermögenڤ während Der findkeit und Der Jugend ift mahridgeinlich mentiger auf einen Mangel an indinioueller Erfahrung, als auf bie That=

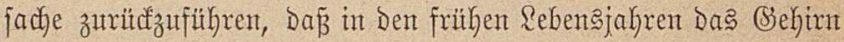
noch) unvollftändig entwicfelt ift. Die zur Berbolfftändigung biejer

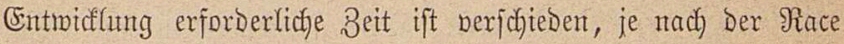
und nach Der Siatur Des Sndibioutum. Wie eine runde fugel an= fänglich bein Berlaffen bes Flintenlaufes eine Spiţfugel überbolt, jo fann Die niebrigere Race in Der Rinbkeit Die Göhere liber= Golen; aber bie höhere überholt bann ipäter vielleidyt mieder bie ntebrigere und erreidt eine böhere Stufe Der (Entwidfung. 2(1th) bei einzelnen Individuen finden mix nicft imnex in Dex frith = reife Dex Jugend eine (Semäbr für eine entiprecbende geiftige Entmidflutg Der reifen Sabre, mährend die Sangfamteit Des (Seiftes in Den finabenjabrent oft einen merfinurbigen Siegenfats

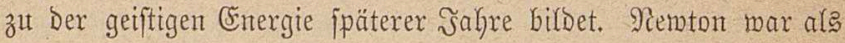

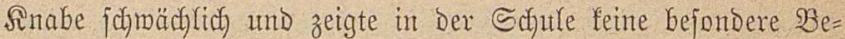
gabung, als ex abex in jeinem adftzebnten Jahre nad) (Eam= brioge fam, jeşte ex jeine Sehrer bald Dutrch fein Ialent für Die Behandlitng mathematijhex \$robleme in Exftaumen. Während Dex ftillen sabre jeiner singeno batte fid) jein Giefirn langiant Darauf porbereitet, Das Srgan jener Sxäfte zu werben, weldhe ex nachjer entmidelte.

Durch Minriaben von Schlägen merben, um midy eines $2 u=$

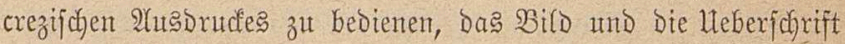
Der äuß̄ern Welt als Buftände Des Bemuß̄tjeins eingeprägt und Die Tiefe Diejer (Finprägung hängt von Der $2(n z a h) l$ Der Ed)läge 
ab. WGent zmei oder mehreere Erfdeinungent gleidfzeitig in Der Ungebung auftreten, jo prägen fie fid in gleidfer Tiefe ober in

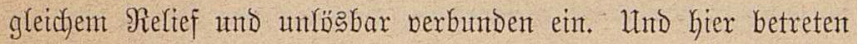

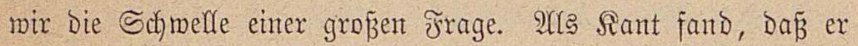

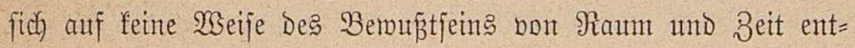
redigen fönne, nahm er an, Daj fie nothinendige Bebanfen= forment, Daß́ fie bie verfdfieden geftaltetent Forment feien, in

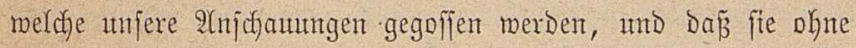
objective Exiftenz nutr in uns mohnen. Mit überrajdyendent Ex= folge zieht Spencer bie Theorie ber angeerbten Erfahrutrg, twie

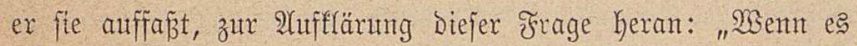
abjolut conftante und intiberjelle äuñere Bez̧ielyungen giebt, melche won allen Srganismen in jedem 2utgenblid ifges wadten Rebents

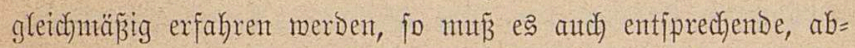
foht conftante und tniverjelle intere Bezitehutngent gebent. Solche Beziefungen fund Die Des Raumes und Der 3eit. 2U(S Dem Sub=

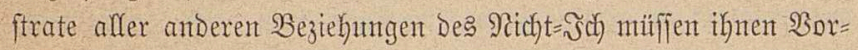

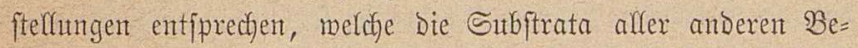

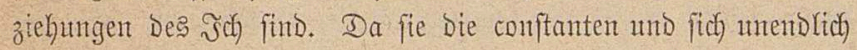
Dft wiederholenden Elemente Des Bebanfens find, muiffen fie bie med)anifiden Elemente Des Biebanfens werden, - Die Elentente Des (Sebantents, Derent fict) zit entrebigen es unmöglich ift -, bie Formen Der 2Ynjdfautung. Mit biefer ganzen 2(nmentung und

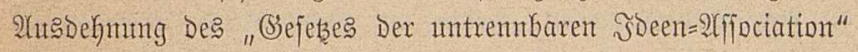
ftegt Spenter auf einem bon Dem John Stuart Mitl's ganz verfficebenten Soben, indent ex Die eingetragenen Erfahrungen

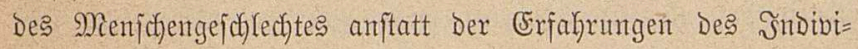
Dutms für jeine Erfahrungen heranziefyt. Siad) meiner 2trtficht ift es ihm nolffommen gelungen, Mill's Bejchränfung Der Ex= fahrung als unfaltbar nadfaztmeifen. Dieje Bejayränfung ignorirt 
Die Macht Der Dem Drganismuts eingeprägten Erfahrung, wie fie jedent Jndibidum auf jetten Rebensmeg mitgegeben wixd; fie ignorint ferner Die beridjiedenen (Srabe Diejer Madft, wie fie

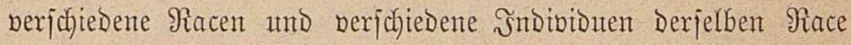

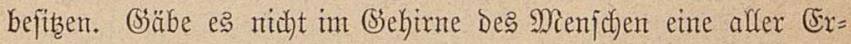
fahrung vorangehende \$otenz, io mitfite ein Shutb ober eine Rałze ebenjo bildungäähig jein wie ein Mienjid. Dieje präbe= terminirten inneren Beztehungen find unabhärnig bon Den $5 x=$

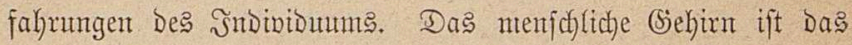
in Den Drganismus eingetragene Berzeichnif unenolich vieler,

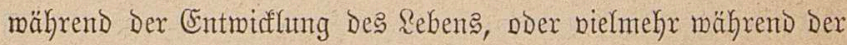

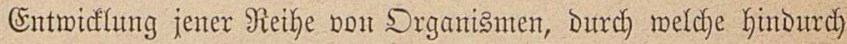
Dex menfeliche Drganismuts zit feiner Entwidflung gelangt ift, empfangenex Erfahxungen. Die Wirfungen Der gleichförmigften unb Käufigften Diefer Erfahrungen find fucceffite vererbt worden unD Kaben fick langiam zu Dex hoken Sintelligenz entwiffelt, meldye latent in Dem neugeborenten finde liegt. So geidjieht es, Daß́ dex (Europäer zmanzig bis Dreifig Subifzoll (cubic inches) mehr (Sebinn exblid) überfommt, als Der Bapuaneger. So ge=

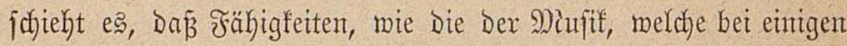

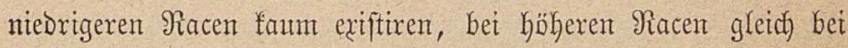
Dex (Seburt porkanden find. So gefditeht es enolidh, Daß̃ aus Wilden, Die nicht ihre Jinger zu zählen im Stande fund und Die eine Sprache reben, meldye mux Scauptmörter und Berben enthält, endlich unjere গemtons und Shafejpeares heroorgehen.

Sthon int Beginne Diejes Sortrages habe ich Darauf hinge= wiejen, Dafis phyjtiche Iheorien, weldye über Das Bereich Dex (Ex= fabrung finaugliegen, Dod) Durch 2(bftraction aut Der (Exjabrung hergeleitet merben. (5) ift leforreid), bon diejem (Siefidftspunfte

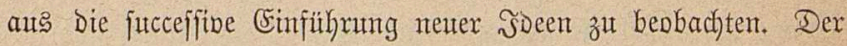




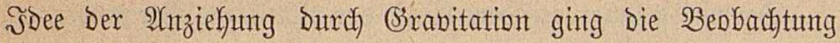
Der 2tnziehuntg Des Sifens Durch einen Miagnet und reidfer Sörper Durch geriebenen Bernftein voran. Die Solarität Des Miagnetisnus und Der Ereftrticität war augenfällig und twurbe

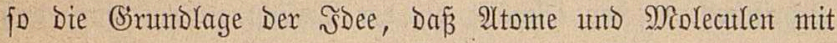

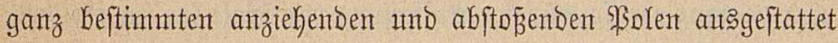
fints, surch Deren Spiel beftintme Formen einer friftallinifdyen 21rchiteftur herborgebracht werden. So wird moleculare firaft

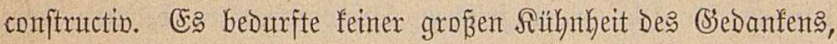

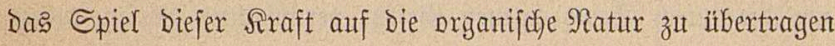
uttro it ber molecularent Sraft Das 2(gens zu erfentren, Dutrch) melches beides, Siflanzen und Ifiere fich bilden. So entftehent auts Der Exfahrung Begriffe, weldhe böllig über Das Bereich) Der Erfahrung hinaultegen. Sieiner bont Den 2ttomiften Des Altter= thrmb hatte einet Begriff bout Diejem Spiele molecularer, $p D=$ Yarer Siraft; aber fie fannten bie Schwere, wie fie fich in Dem Fallent Der Rörper offenbaret. Seieraus abftrahirend ließ̧en fie ihre 2(tome emig Durd) Den Yeeren Fiaum falfen. Demofrit nafm

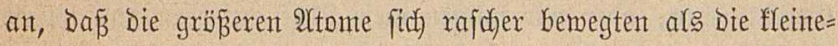
ren, weldge fie daker übergolen und mit Denen fie fidf verbinden tönnten. Evpiftu ging bont Der Heberzentintg aus, Dafis Der leere

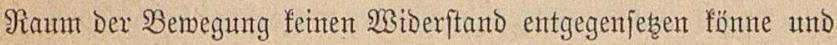
fortieb Daker alfen 2Ytomen Diejelbe Schnelligfeit zu; aber ex fajeint Dabei Die Ẽonjequenz überjehen zu haben, Daj fich Die 2ltome unter folchen Utmftänden niemals bereinigen fömten.

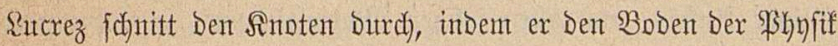

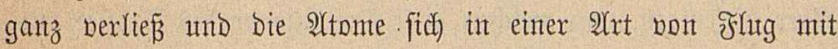
einander betwegen Yiế.

(Sing Der Snftinft, welcher Ruterez fo bon jeitent eigenent Srin=

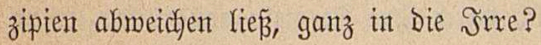


Darwin gelangt auf Demt $\mathfrak{W e g e ~ D e r ~ a l l m t a ̈ l i g e n ~} \mathfrak{B}$ erminterung

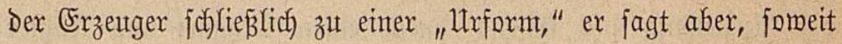
id) midi) erintere, nirgends, wie er fid bieje Itrformt entftandent Dentt. Er citirt mit (Bentgthutung Die Worte eines berifhutent Schrifffellers, Der allmälig zu Der Einficht gelangt war, Daß̧ es eine ganz ebenjo würotge 2Uuffaffung von Biott fei, zı glatben, Dẩ Er einige mentge, Der Selbftentwifflung zu anderen nothiwen= Digent frorment fähige Utrformen gefchaffent habe, als zu glauben,

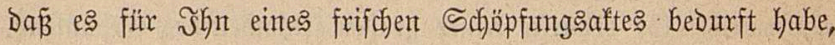

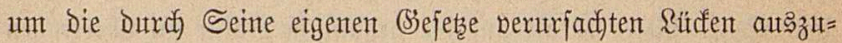
füffen. Was Darmin bon Diefer 2Yuffaffing Der Entftelung Des

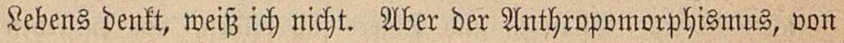
meldyem uns zu befreien Darmin's 3medf zu fein fodjen, ift bon Der (Exidaffunt meniger Formen ganz ebenjo unzertrennlid) wie won ber (Eridfaffint einer Mentge bon Fornten.

Şier bedarf es Der STarkeit anto der Bründlidffeit. Smet Verfahrungsmeifen und nux Dieje find möglich). Entweder mitffent wir ber Soce eines Sdjöpfunghaftes grabe und riutfaltlos ins (Sefid)t fehen, oder wir nuirffen Dieje Soee aufgeben und unfere Worftellung pom Wefen des Stoffes rabifal ändern. Went mir Den Stoff betradten, wie er bon Demofrit geidjildent und

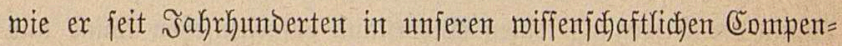

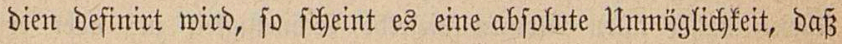
irgend eine Form aus diejem Stoffe herborgeke. Das Dent Biffidof Butler in Den Miund gelegte 2trgument genügt nach) meiner 2 (nfitcht, umt alfen foldyen Materialismuts zu bernidjten. 2tber Diejenigen, wont welchen bieje Defintitionent des Stoffes auts= gingen, waren nicht Biologen, fondern Mathematifer, Deren

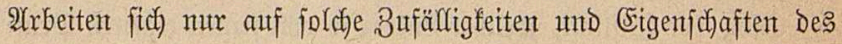

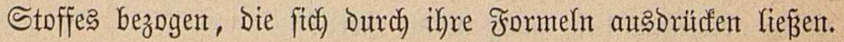


Grabe bie Comentration, mit weldyer fie bie medjantifchen Wiffen=

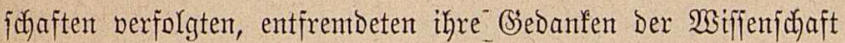
Des Rebens. Sind nidyt vielleidft ihre unoolfommenen Defini= tionen bie wirfliche Hrjache unjerer jetzigen Furdft? Seken wir Der Frage efrrfurchtsooll aber efyrlich ins (Biefitft! Wo follent mir Das \&eben, wenn twir es yom Stoffe fofeiden, finden? Was aud) unjer (B)laube fagen mag, unjer $\mathfrak{B}$ ifjen zeigt fie uns untrentbar verbutndent. Seber Biffent ben mir eifen, jeder Schlud Den wir trinfen, illuftrixt Die geheimnifipolle Controle Des Breiftes Durd) Dett Stoff.

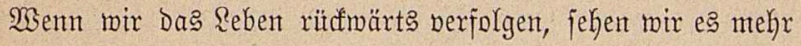
uno mehr fidh Dent näbern, was wir bie rein phyfiftaliface $\mathfrak{B} e=$ idjaffenheit nennen, und gelangen endlich zut Den Drganismen,

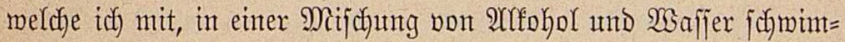
menoen Seltropfen verglichen Kabe, gelangen zu Dem „Protogenes" Şaectel's, in welchent mir "einen Inputs haben, ber fidy won einem Stüd 2(rbumin mur Durdf) feine Freinförnigfeit unter= idjetiot.

Rïnnen wir Dabei fteken bleiben? Wir zerbredfen einen

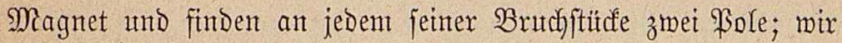
fahren mit bem 3erbrecten fort; aber mie flein autch Die Iheile in Folge beffen merden, ieber befält, wern aud in gejudwädjtem

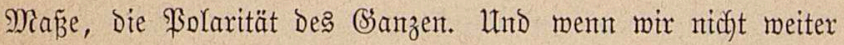
zerbrect)en fömen, füfhren wir mit unferm geiftigen 2 (ltge bie Frocedur bis zu ben polaren Melecutent fort. Drängt fithe utts

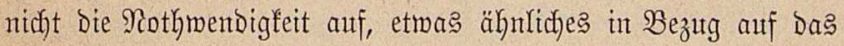

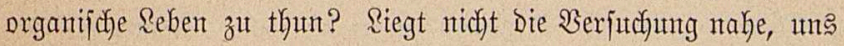
auf Die Seite Des \&utrez zu ftellen, ment er befautptet, daßj bie Natur alles jelbfttändig aus eigenem 2Yntriebe ohne Die Eint=

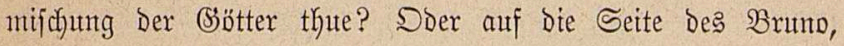


menn ex erflärt, Daj̃ Dex Stoff nidyt jene nur leere Fähig= feit, ars meldye \$3hilojophen fie bargeftellt haben, fondern bie alfgentente Mutter jei, meldye alle Dinge als Frudtht ihres Reibes Kerborbringe?" Ueberzentgt von Der Contututiät Der शatur, wie

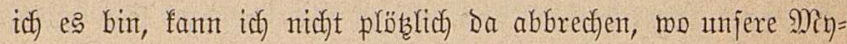
froßfope aufbören fid nüblid zu ermetjen. Şier ergänzt das innere 2uge unmiberleglidh Das äuñere. Mit geiftiger Noth)= mendigfeit îberjafreite idy Die Brenze Des Experimentalbemeifes und unterjadetoe in jenem Stoffe, meldjen wir in unjerex $14 n=$ fenntnifi feiner berborgenen Sräfte und meradtet nnjerer zur Schau getragenten (5hrfurdyt für jeinen Schöpfer bisher geläftert Gaben, Die Berkeipung und ßotenz alles irdijaten Reben?.

Wen Sie mich fragen, ob ber geringfte Bémeis bafür bor=

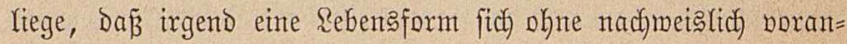
gehentes Reben aus Dem Stoffe entmidfeln fant, fo lautet meine

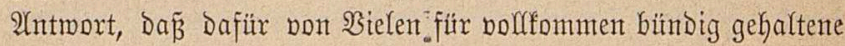

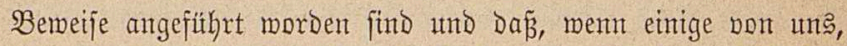
Die wir biejer Frage nadhgedacht haben, einent jehr gemb̈hnlithen Beifpiele folgen und ein Bengnifi annebmen mollten, weil és mit unjerem Silauben ftimmt, wix uns aud Dem angefüfrten

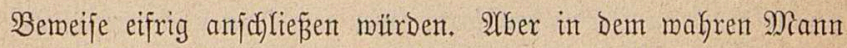
Der WBiffenfdjaft lebt ein Wutufdy, Der ftärfer ift als ber jeinte

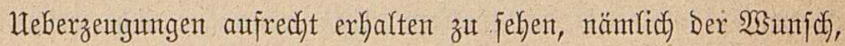
Die Wakrkeit Diejer Heberzeugungen ermiejen zu feben. Und

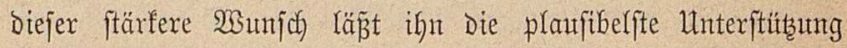

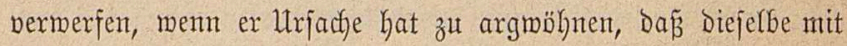
Jruthum berjeţt jei. Die, won Denen idh rebe, als pon foldjen, welche dieje Jrage ftudirt haben, fönnen, meil fie Den zu Gimpten einer "fpontanen Beneration" Dargebotenten Bemeis in Diejer weije mit Jrrthum verjeb̧t glauben, Denjelben nicht antehmen. 
Sie miffen vollfonmmen, baş bie CGhemifer jeţt aus unorganijichem

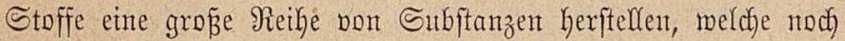

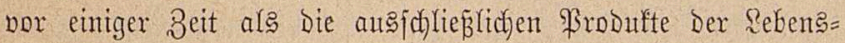
fraft betrachtet murben. Sie find genalt vertraut mit Der ge= ftaltenden Siraft Des Stoffes, mie er in Den Exjofjeinungen Der Sirifallifation zu Tage tritt. Sie fönnen ifren (B)lauben in feine Rraft, unter Den geeignteten Bebingungen Drganismen hervorzubringen, wifferifdaftlich) rectffertigen. 2(ber in (5rmide= rutng auf Эhre Frage merden fie ihre Unfähigfeit, irgeno einen befriebigenden experimentellen Bemeis Dafür z̆ Yiefern, Daß̧ Sebent ohne nadjweislidf vorangelyendes Rebent entricfelt werden fömre, offen zu geftehen. Wie bereits angebeutet, berfolgen fie eine Sinte von Den höchften Srganismen, Durch bie niebrigeren Kindurch) bis zu Den niebrigften Gin unb Die Derlängentung biefer Sinie int Cseifte über Das Bereid) Der Sinne Ginants Yeitet fie 3t Dem Schluffe, melchen Bruno fo fithn ausgejprochen hat*).

Der bier ausgefprodjene "Miaterialismus" ift bielfeifft etmas anderes, als Sie fid Darunter borftellen, und ich erbitte mir Daker ein freundlid) geduldiges (sebör bis zum Sa)luffe meiner 2utsfuthrung.

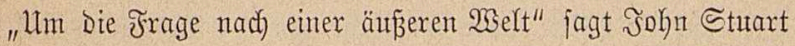
Mill, "Dreht fich Der grof́e metaphyfitaje Rampf." Mill jelbf́t füffrt äuñere Erficheinungen auf Miögliçfeiten Der Empfinoung zuritid. Rant madjte, wie mir gejeben haben, Faum uno Beit

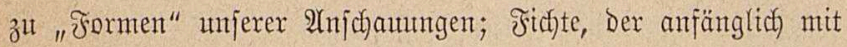

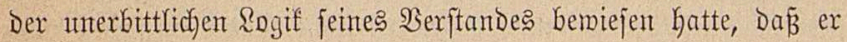

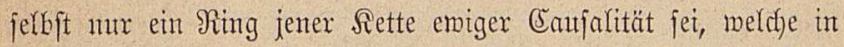
Dex Natur jo ftreng Durdigeführt erjd)eine, zerbrad Dieje Rette getwaltfam und madte bie Natur und alles, was fie umfañt, zut

*) Brun war ein ßantheift, fein 2theift Doer Materialift. 
einer (Exicheinung feines eigenen (Beiftes*). Und es ift feines= wegs leicft, joldhe Borftellungen zu befämpfen. Denn wemt tad)

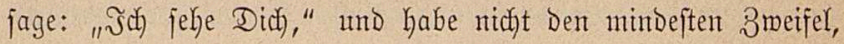

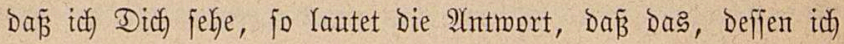
mir bewust jei, mur eine 2rffection meiner Seethyaut jei. Utno

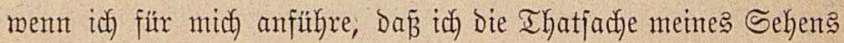

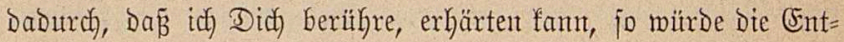
gegnung wieder lauten, dẩ id auch Damit Die (Sirenzen Des

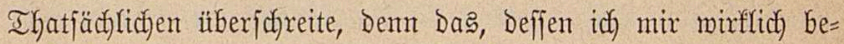

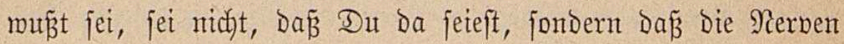

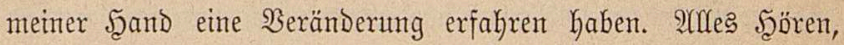
Sehen, Fühflen, Schmedfen und Riecten ift, mürbe man uns entgegenfyalten, eine reine Beränderutug unjeres eigenen 3uftandes, ïber welchen mir nidft um eines Şaares Breite hittanszaglehen

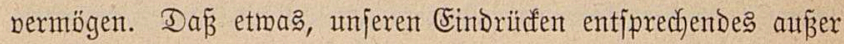
uns exiftirt, ift feine Thatjadje, fondern ein Schluñ , meld)em ein Soealift wie Berfeley doex ein Sfeptifer wie Sctme jede (Sïltigfeit abjprechen mürde.

Spencer fallägt ein anderes $\mathfrak{B e r f a b r e n ~ e i n . ~ F u ̈ r ~ i h n ~ g i e b t ~}$ e马, wie für Den Itngebildeten feinen 3weifel an Der Exiftenz einer äupern WSelt; aber er meidgt bon ber 2 luffaffint Des Un=

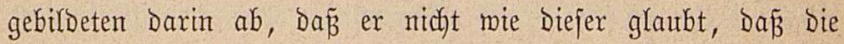

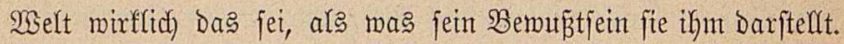

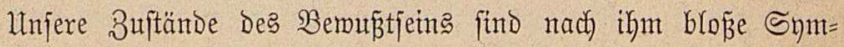
bole eines auner uns Seientent, welches fie herborbringt unt thre Reifenfolge beftimmt, Defifen wirfliche Natur wir aber nie=

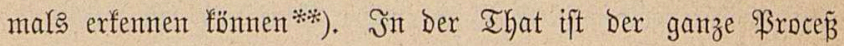

*) Beftimunutg Des Mentiden.

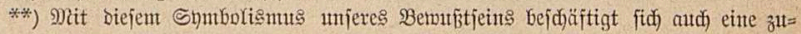
gleid) popnläre uno tiefe, in ben fier bei ?antgman's criffientenen Borträgen von ફ̧elm= 
Der Entrofflung Die Manifeftation einer für Den Beift bes Mienjuen abjolut unerforjolichen Macht. So wentg in unferent Tagen wie in Den Iagen Des Ştob fann Der Menfd) Dieje Madyt Durch Suchen finden. Wenn man Der Sache auf Den (Siund geht, fann man nidft anders als fagen, daf wix in bex Entwidflung Des Rebens, in Der Differenzimung Der 21rten und in ber Entfaltung des Gieiftes aut ifren Itrelementen, während unmę̧barer Beiträume das $\mathfrak{B a l t e n}$ eines unlößbaren Bekeim= nifies alzuerfennen haben.

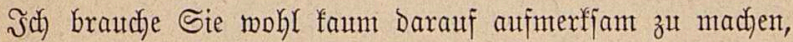
daß̉ Diejer 2ُuffaffung fein fehr vermegenter Materialismuts zu Srumbe liegt. Die Stärfe Der \&ehre pon Der Entmidfung befteht nid)t in experimentelfer Betweisführung, - Denn Der Bsegenftanto

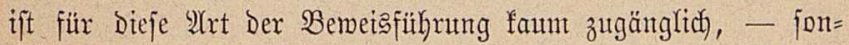

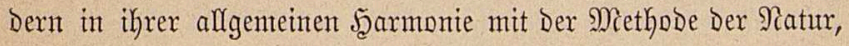
mie mir fie bis jebt fenmen gelernt Kaben. Ueberdies geminnt

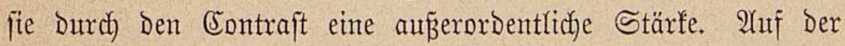
einten Seite haben wir, went wir fie überall jo nenten Düxfen, eine Theorie, weldhe, wie es die in Beginne Diejes Sortrages ermähnten Iheorien waren, nidht aus Dem Stubium Der Natur, fondern aus Dem Stubium des Menjuen Kergeleitet ift, eine

holts enthaltene Sd)rift: "Nente Fortidjutte in ber Theorie bes Schents." Die Sintes=

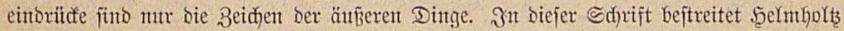

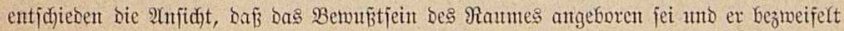
pffentbar bie Fäfigfeit bes Sild)(eins, vhne vorangegangene 2 Beifung, Siörnter auizupiden. "Iteber biejen \$3untt," fagt ex, "bebarf es nod) meiterer Experimente." Soldje (Experi= mente find jeitiem bon Şerm Spalding gemad)t worben, ber bei einigen feiner Beob=

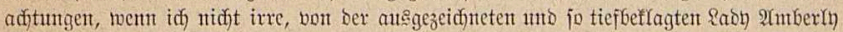

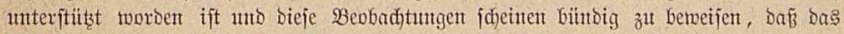
Sïrdjlein feines Nomentes Der Interweifutg bebarf um es zut befäfigen, zu ftefen, zu

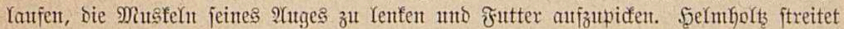

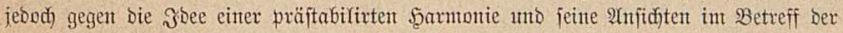
Drganifation bes (sejd)fechtes ober bev 3udft fino mix nidjt befannt. 
Theorie, welche Die Miacht, Deren RYeid Das fidftbare Mniverjunt

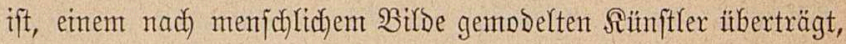
Der in ftofimeijen 2 Unftrengungen, wie mir es bon Den Mienjchen fehen, arbeitet. 2Uuf Dex andern Seite Kaben mix bie $\mathfrak{B}$ orftellung, bẩ alles, was wir unt uns her fehent unt alfes, was wir in

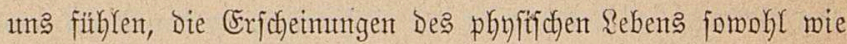

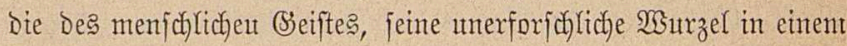

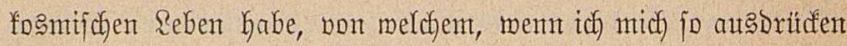

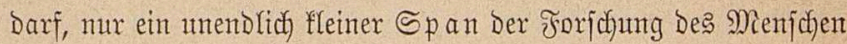
erreicfbar ift. Und jelbft von diejent Span fönnen wir nur einen Theil fennen.

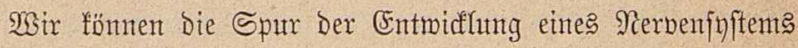
verfolgen uno fönnen die paralfelen \$hänomente der Empfindung

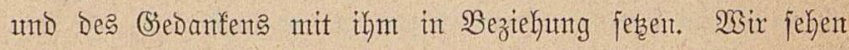
mit unzmeifelhafter Sidjerheit, Daß̉ fie Şand in Scand gehen. 2lber wir verfunfen ins Bodenloje, fobald wir den 3riammen=

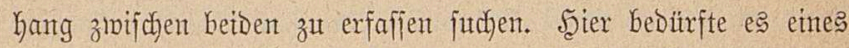

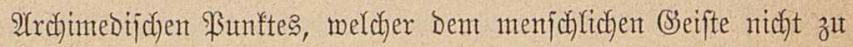

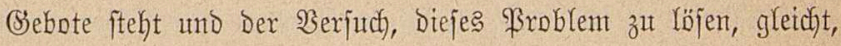
um mich Des Bifloes eines berïfmten Freuntes zu bedienen, Dex 2(1nftrengung eines Miames, Der es verjuctht, fict) an feinem eigenent (Bitrtel in Die Şähe ż zieher.

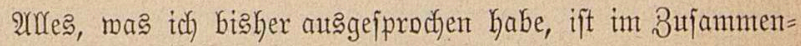

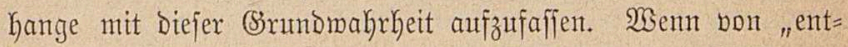
ftekenden Sinnen," went von Der Differenzirung eines, an= fänglich) feiner ganzen Dberfläche nadd) unbeftimmt jenfitiven (se= mebes die Rede ift, und wenn Diefe ßroceffe nit Der Miodifi= cation eines Drganisnus Durdy feine Umgebung in Serbintung gebracht werben, io Yegt Darin Daffelbe Nebeneinanberherlaufent

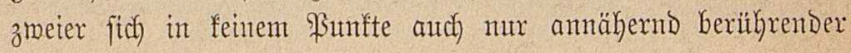


Farallelen. Der Mienidy ars Sbjeft ift Durd eine unitberfteig= bare Rlluft getrennt bon Dem Mienichen als Subjeft, es giebt feine bemegende Siraft in Dem Beifte Des Menichen, vermöge Derent er ofne einen Brutch) Der Sogif Den 3ujammenfang zmijoden betben kerftellen fönnte.

Die Regre von Der Entwifflung läß̈t Den Mienfichen ferner

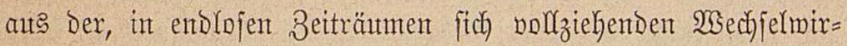
fintg Des Srganisnuts und jeiner Utmgebung Keroorgehen. Der

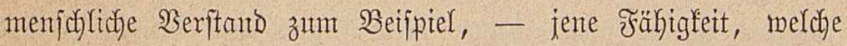
Spenter fo geidjictit atts ifren 2ntecedentient hat herborgehen laffen -, ift felbft ein Ergebnin Des in unendlidjen Beiträument por fith) gehenten Spieles zmifduen Dem Srganisnus und feiner Utmgebuntg. (Ssemif̧ giebt es feinen Fall, in melchem fich das Recht ber Berjährung entichetiender geltent madft. Nant aber

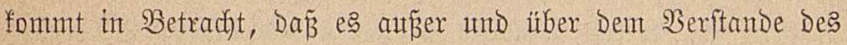

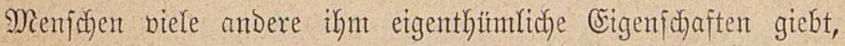

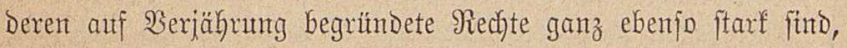

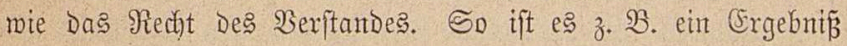
Des Wectjelfpieles bon Drganismus und Itmgebung, Dán Der

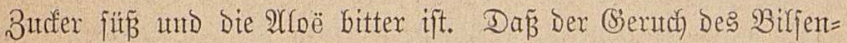

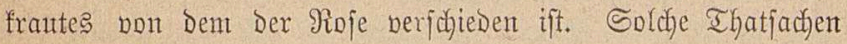
Des Bemuñtfeits, für welche betläufig nodh niemals eine genügende Itrjache beigebradft morben ift, find ganz fo alt wie ber $\mathfrak{B} e x=$ ftand und nod) biele andere Dinge föment fich eines ebenfo alten Uriprunges ritfment. Spenter ipridyt an einer Stefle bont jenter gemaltigften Reidenjchaft, Der Reibenjchaft ber Riebe, als von einer Reidenfduaft, weldyer bet ifyrem exften 2(uftreten feine entiprechente Erfahrung vorangegangen ift, und wir Dürfent Dent 2(njpritch Derjelben als minteitens fo alt tmb jo gültig mie ben Des $\mathfrak{B}$ erftandes betradftert. Ferner giebt es mit Dem Srganismus 
Des Menfichen vermebte Dinge, mie das Biefühl ber heiligent

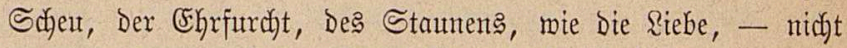
nutr bie eben erwähnte gefdylectytliche, jondern bie Riebe zut Dent

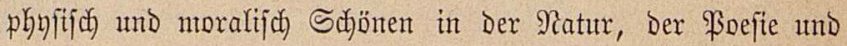
Der Rumit. Da ift ferner jenes tiefgemurzelte (B̉efühll, meldes

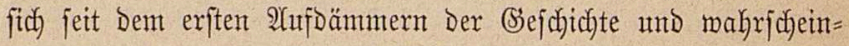
lidi) jujon lange bor aller (Sejujichte in Den Religionen Der Welt

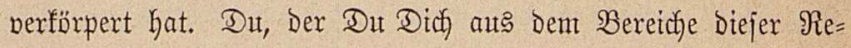

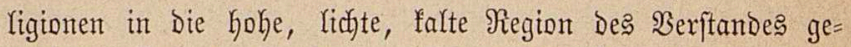
flitchtet haft, mußst biejelben verlachen, aber indem Dut Das thuft, trifft Dein Spott nur nebenjädflidje Formen und Dut itberfieffit

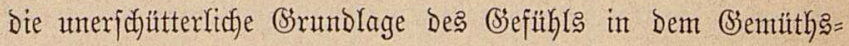
leben des Menjider.

Wie Diejem Befühle eine bernitnftige Befriebigung zu ge= mähren jei, ift Das Sroblem Der Frobleme unferer 3eit. Und wie poffentaft autd, bomt Stanopunfte wiffenfdufftlidjer Bildoung aus betradftet, weele Religionen ber 23 elt maren und nod) fint, wie gefäbrlich, ja berberblich) fïr bie theuerften Empfindungen freier Menjach einige berjelben auth unzmeifelkaft gemejen fint und, went fie fömten, noch fein mitroen, fo wird es bod) meife fein, in ihnen Die Formen einer Sraft zu erfemen, weldhe, bö̈s=

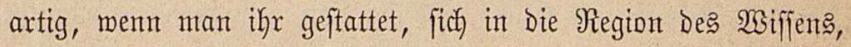

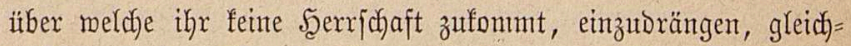
mogl won einer liberalen Denfart geleitet, zu edlen Ergebniffent

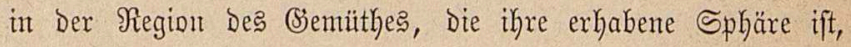
fühtren fam.

Ifle religiöfen Theorien unb Syfteme, welche eine Darfel= lung Der Sosmogonie entfalten oder fomftwie das Bereidy Der= jelben berühren, müffen fidf, jofern fie Das thın, Der Eontrole Der Wriffenifuaft unterwerfen uno jeden Bedanfen an eine 
ihrerjeits itber bie Wiffenffhaft zu itbende Controle aufgeben.

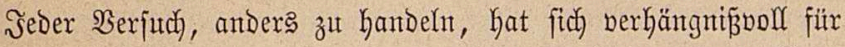

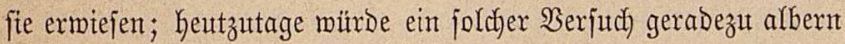
jein. Sebes Syftem, meldyes dem Schicéfal eines Drganiemmts, Der zu ftarr ift, um fid feiner Untgebung anzupaffen, entgehen

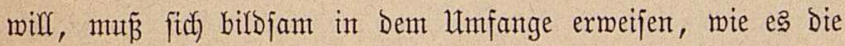
Wififenfichaft verlangt. Wenn man fich volfftäntsig mit biejer Wabrheit Durchbrungen haben wird, wirb man mit ber Starr= Geit nadflaffen, mirb man meniger exchlufit merben, wird man Dinge, bie man jeţt für mejentlid bält, fallen laffen umb mente, die ntan jetzet verwirit, affimiliren. Worauf es anfommt, Das ift Die Erböhung Des Rebensniveauts 'und fo lange es ge= lingt, Dogmatismuts, Fanatismuts und Mndulojamfeit ferm zut Galten, fömnen verfhiebene Scebel angefeţt merben, um baß Reben anf ein höheres Niveaut zu erheben.

Die 2 Biffenjidaft jelbjt entlehnt nidjt jelten einer itber bie Wiffenjuaft Ginausliegenden Dutlle eine bewegento Rraft. Whe= welf jpricht von enthuffiaftichent Temperament als einem Şentm= nif̧ Der Wsiffenfdaft; ex Dentt aber mur an Den Entfuffasmus

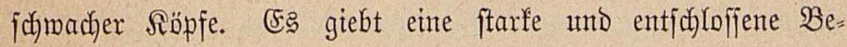
geifterung, an welcher Die Wiffenjuaft einen Berbirndeten hat

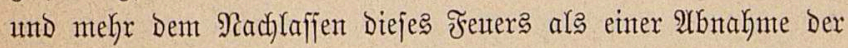

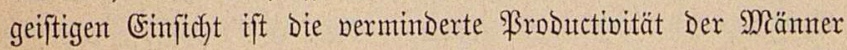

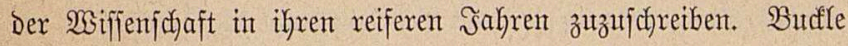
hat es berjucht geiftige Reiftungen als von fittlicher Siraft un=

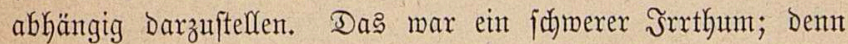
ohne Die fittlidfe Sraft, Die Den Bieift zur Energie treibt, mürben jeine Reiftungen nur bürftig jein.

Mian hat behauptet, die Wififenjichaft trente fidf bon Der Siteratur; Diefe Bebauptung berubet, wie io viele andere, auf 


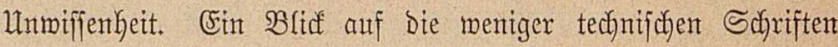

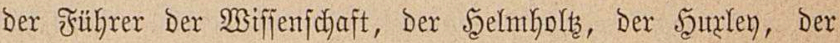

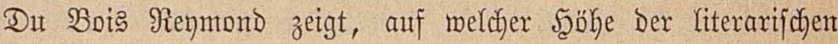
Bildnutg fie ftehen. Bon meldhen modernen Sdyriftitellern mer= Den fie an Silarkeit und Sraft Des Stils itbertroffen? Die

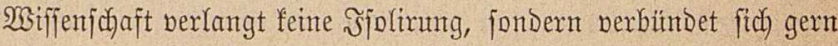
und willig mit jedem Bemühen, Die Iage Der Menjodyen zu ver=

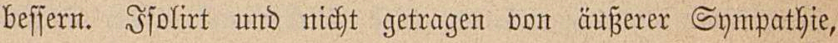
fonden mix bon innerer fraft, hat fie wenigftens einen Flügel

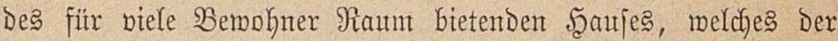
Menidy in jeiner Iotalität berlangt, exbaut. Utnd ment robe Mantern uno borftehende Balfen zeigen, daß̃ das Gebäude an einer Seite noch unoollendet ift, fo fömen mir Dod mut bon einer weijen $\mathfrak{B}$ erbindung Diejer unfertigen Theile mit Dent bereit? bollendeten ein vollfändiges Banze exhoffen. (ss befteht feine nothiwendige Ungleichartigfeit zmifdyen Dem, twas bereits onflendet ift, uno Dem, mas noch zut thun übrig bleibt. Die fittliche (s)luth Des Sofrates ift an und für fich Durdfants nicht unbereinbar mit Der Naturanidjauntg Des Anaxagoras, Die ङofrates fo bitter ver= fpottete, itber bie er aber hentattage faum mebr jpotten mitroe.

Itnd fiex mur idy eines Mannes unter uns gedenfen, meldjex trok feines Goken arters geiftesfrifd ift und Deffen prophetifiche Stimme bor länger als breipig salfren viel nachbaltiger als ingend eine andere in unferer Beit aufjchlofi, was an seben und ebler Beftnmung in Den begabteften Beiftern verborgen lag eintes Mannes, Der mürbig wäre, Sofrates ober Dem Miaffa= bäer Sleazar an die Seite geftellt zu merden, und Siraft bejäß̧e, alles bas zu magen und zu exdulden, was fie expuldet und ge= wagt Kaben - Dex müroig gemejen märe, wie man einft non Fichte jagte, Dex Refrer ber Stoa zu jein und bon Sdjönheit 
und Tugend in Den Şatnen Des Affabemos zu reben. (F马 ift eint grofer $\mathfrak{B e x l u f t ~ f u ̈ r ~ D i e ~ W e l t , ~ D a ß j ~ b i e j e r ~ M a n n ~ b e i ~ e i t t e r ~}$

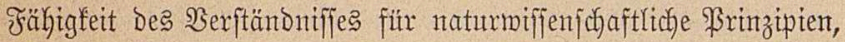

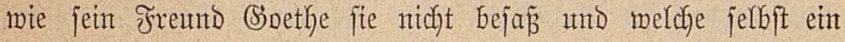
bölligex Mangel an ltebung nicht ganz hat aufheben fönnen, nidft in Der SBlüthe jeiner Sabre feinen (Seift und jeine Sym= pathien Der Wiffenjafl offnete und Die Srgebniffe Dexfelben zu einem Theil jeiner Miffiton bei Der Mienjhlyeit madfte. WHunder= bar begabt wie ex mar, gletch) reich) ausgeftattet mit (5igenjichaften Des Şerzent und Des SEerftandes, Kätte er viel Dazu beitragen fömen, uns zu Yehren, wie Die 2 tnprithe betber in Sinflang zut bringen 1nto wie fie in Dett Stand zu fetzen feien, in fomment Den Iagen einig in (Beifte frieblich) nebeneinanier zu moknen.

Unt jeb̧t fomme idh zunt Sdyluß̄. Sin beffer Befäbigter bätte, mentit ihnt ntehr Beit zu (Sebote geftanden hätte, Das, mas idf) J̧hnen gejagt habe, beffex jagen und Dex Artfnterffamteit werthe, von mix umberithrt gelaffene Sunfte zu einem angemef= jenen 2UEDoud bringen fömen; mit Den bon mix ausgeiprochenent

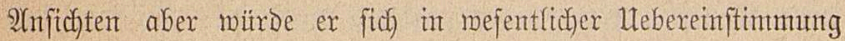
Gaben befinden müffen. Diefe meine 2(nfitchten fund nicht bie Fruddt eines Iages, und was Sie, meine feerren, betrifft, io

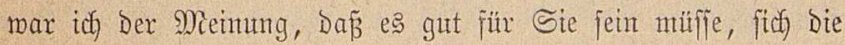
"Ilmgebung" zu vergegenmärtigen, weld)e fidh, mit ober obne Fhre Einmilligung, nit rapider Eile um Sie ker bildet und melcher Sie fid biefleidft in einer ober ber antorn Weije merbent "anzupaffen" Gaben. Sin WBort Saamlet's belehrt ins jedoct) 2rme, wie mix Den Bejdymerden bes täglidjen Sebens ein Ende madjen fönnen, und es ift für Sie und midh bollfonmen möglich), uns 1tm Den अreis geiftigen IoDes geiftigen Frieden zu erfaufen. (5)

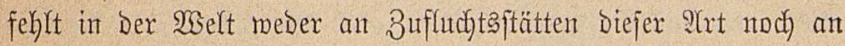


Berjonen, weldhe Dent Sdjuth Diejer Stätten auffutchen und andere

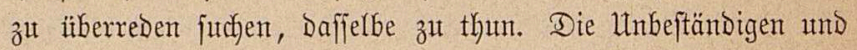

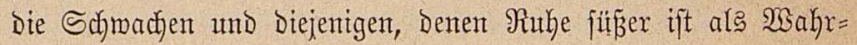
Keit, werben fid überreden Yaffen. Şd möbte Sie aber ermah)= nen, folct)en S(d)uth bon ber Şand zut meifen umb eine folct)e

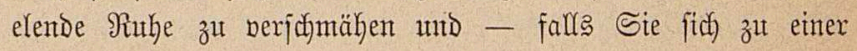
WSahl gebrängt jähen, bie geiftige 2 uffregung Der Ctagnation,

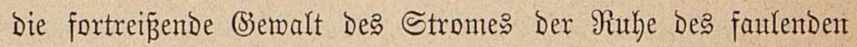
Sumpfes norzuziehen. In Dem Serlaufe Diejes গ̧ortrages habe

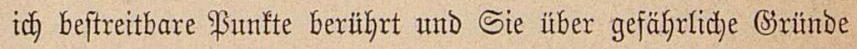
gefülyrt, und zmar theilmeije in Der I(bficht, Şhnen und Durd)

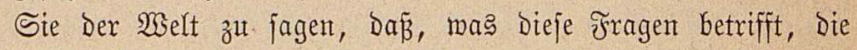

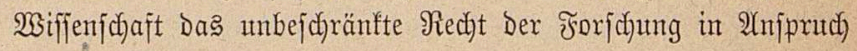
nimmt. (E) fommt hier nidyt Darauf an, ob Die 2 Unfididten bes Sutrez und Des Bruno, Darwin's und Spencer's vielleidyt un=

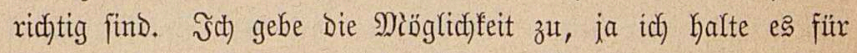

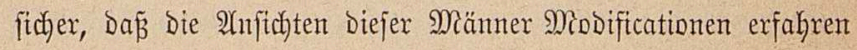

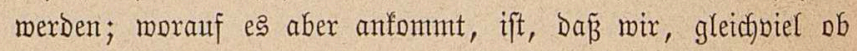

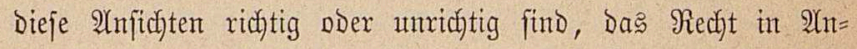
fpruct) nefymen, fie frei zu biscutiren. Sndeffen wiro hier fein

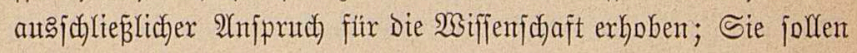

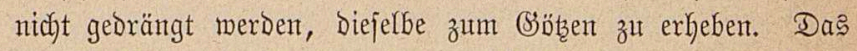

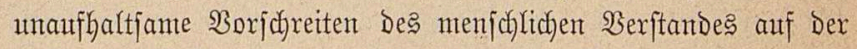

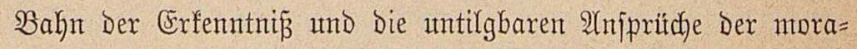

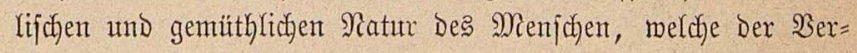
ftand niemals befriedigen fann, werden hier gleid) fehr zur Beltung gebracft. Der Welt gehört nicht mux ein Nemtont, jonbern audf ein Shafeipeare nicht nur ein Bayle, jonternt autd)

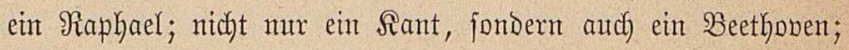
nidyt nux ein Darwin, fontern audy ein Earfyle. Sididt in 
jebem von biejen, jondern in ihnen alfen zufammen befundet

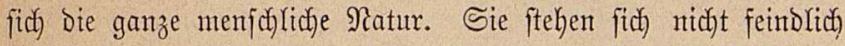

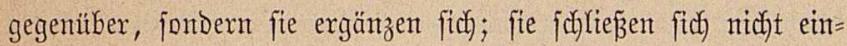
ander aus, fondern wirfen alle gemeinjam. Hno went ber

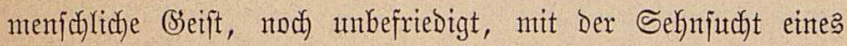
Fitgers nad) feiner fernen Sceimath, fidf) Dem Minfterium, att? meldyem er herborgegangen ift, mieder zumendet und menn er verjudft, es fo zu Modeln, Daß zwijhyen feinem Denfen unt

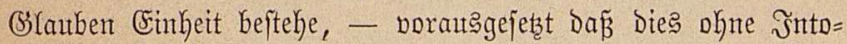
Yeranz unt Bigotterie mit Der erreuchteten Erfenntniz̄ gejofieft,

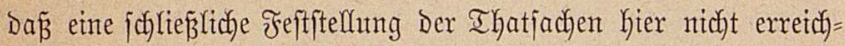

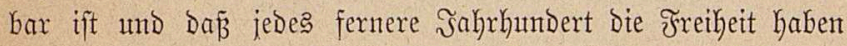

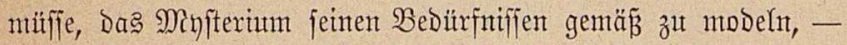

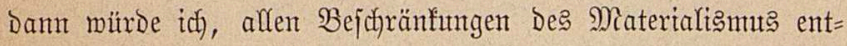
gegen, behaupten, daß̉ bię ein Feld fïr bie edelfte Hebung Defien fei, was man, int Begenfatze zu dent extennenden

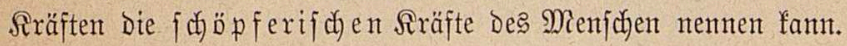

Sioethe läß̧t jeinen Fauft jagen:

"Erfülll Davon Dein Serz, fo gró̉ es iit

"Itno wemn Dit ganz in Dem (S)efinthle feltg bift,

"Nern' eś Dam mie Du millft..."

Wordsmorth hat Das in 23 orten gethan*), meldhe allen

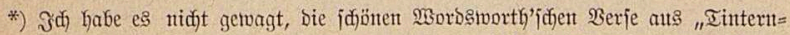

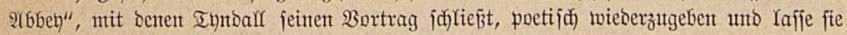
baber bier in Driginal folgent. Sie Yautent:

\section{'For I have learned}

To look of nature; not as in the hour

of thoughtless youth; but having oftentimes

The still, sad music of humanity,

Nor harsh nor grating, though of ample power

To ehasten and subdue. And I have felt

A presence, that disturbs me with the joy

Of elevated thoughts; a sense sublime

of something far more deeply interfused 
Engländern mohlbefannt find, und welche ala ein Şoraushlid und als eine religiöfe Belebung Der leb̧ten und tiefften wiffen=

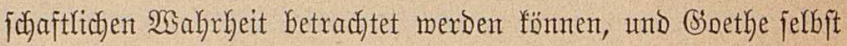
hat es in unvergleidflicter 23 eife getthan in feinem Froention zut "(Siptt und WSelt:"

Sint Minment Defien, Der Sidf felfit eriduf!

3on Emigfeit in foraffendem Beruf;

In Seinem Nomen, Der Den (SIrauben fdhafft;

SBertrutert, Siebe, Thätigfeit und Siraft;

Sn Senes Siamen, Der, fo oft genannt,

Dem Tsejen nad) blieb immer unbetannt.

Soweit Das Dhr, foweit Das Sluge retcht,

Du findeit nur Befountes, Das ifm gleidht,

Und Deines (seiftes tiödifter Feuerflug

Şat fdion ant Bifeidfrifi, fat am Bill genug;

(Ë zieft Didh an; es reizt Didh heiter fort,

Itno wo Dit wandelit, fathuiteft fitch $25 e$ eg und Drt;

Du zählit nidyt mefrr, beredhneit feine Beit

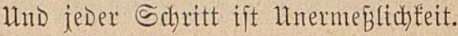

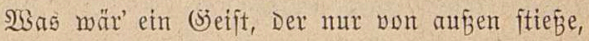

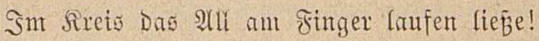

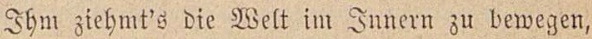

Natur in Sidh, Sidh in Natur zu hegen;

So $D a \bar{B}$, was in ifm lebt und mebt und ift,

Nie Seine firnft, nie Seinen (S)eift vernif́t.

Whose dwelling is the light of selling suns,

And the round ocean, and the living air,

And the blue sky, and in the mind of man:

A motion and a spirit, that impels

All thinking things, all objects of all thoughts,

And rolls through all things.

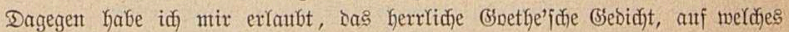

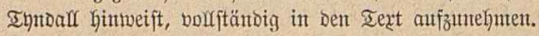




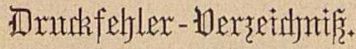

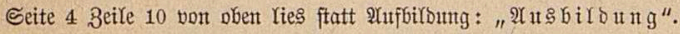

$=4=16==\quad=\quad=$ nirgent: "irgent".

$=11=17$ 1. 18 bon oben lies ftatt Der Neberfterne: "Des Rebels".

$=12=6$ von unten Yies ftatt futroftlojent: "fit dit trojen".

$=31=2$ = Dben $=$ = Bable: "Boble".

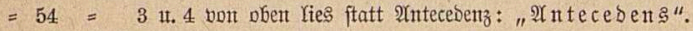

$=55=12$ bon oben Yies ftatt ertennt: "erfannt".

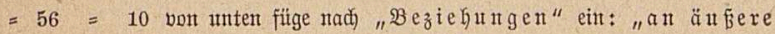
Bebingungen".

$=65=1=$ oben Yies ftatt Enutentration: "E.

$=66=5=\quad=\quad=$ Mitrogtop: "Nifrogfop".

$=67=12=\quad=\quad=\quad=$ zu geftehen: "zugeftehen".

$=76=3=$ inten $=$ = Bat)le: "Dolle".

$=77=8==\quad=\quad$ of nature: "on nature"

$=78=8==\quad=\quad$ selling: "setting"

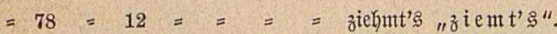




$$
\begin{gathered}
x \\
x=35 \\
x=3
\end{gathered}
$$


Derlagshutflfandenter vout Intluts Springer in Berlin N., aroubijoupfąs 3 .

\section{Die

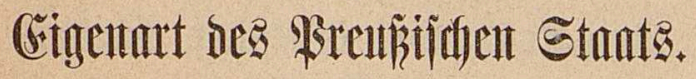

Solt

MuDolf (Sineift.

Brets 1 Miart.

Der tiedststant.

Bolt

Mubolf (5)teipt.

Wreţ 4 Niart.

\section{Heber \\ frarfamentarifore Defatten. Bon}

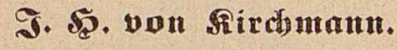

Freis 1 Marf 20 Ff.

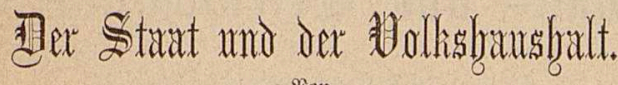

Jobn \$rince= Cmith.

Frets 80 Ff.

\section{Heber \\ Welt - uno stantsweisbeit. \\ Bont}

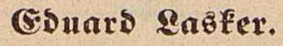

Freis 80 \$i. 
Đerlagshutblyatiolung non Inlius Springer in Berlin N., gronbijoupfą̧ 3 .

\section{Der

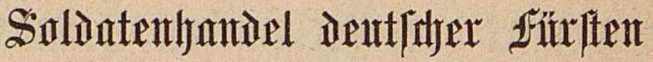 \\ tua fit Rturtika.}

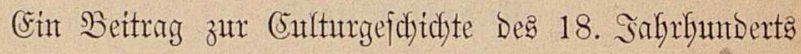
bon

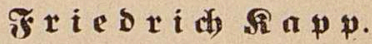

3 weite verbefferte ut bermehrte 2 uf fage. Sreis 4 Marf 20 Pf.

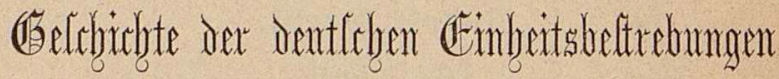

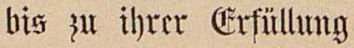

$1848-18 \% 1$

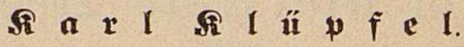

2 Bät

Brets 16 Marf.

\section{Stants- und (Ge rellidaftaxedht} Dex

frantzojtichent Revolution

$$
1 \% 89-1804
$$

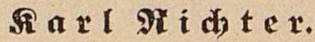

$2 \mathfrak{B} a ̈ \pi$ be.

Breis 17 Mint.

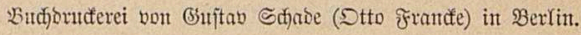



$380 / 80 / 401816$

Freie Universität Berlin

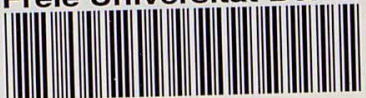

$3275179 / 188$ 


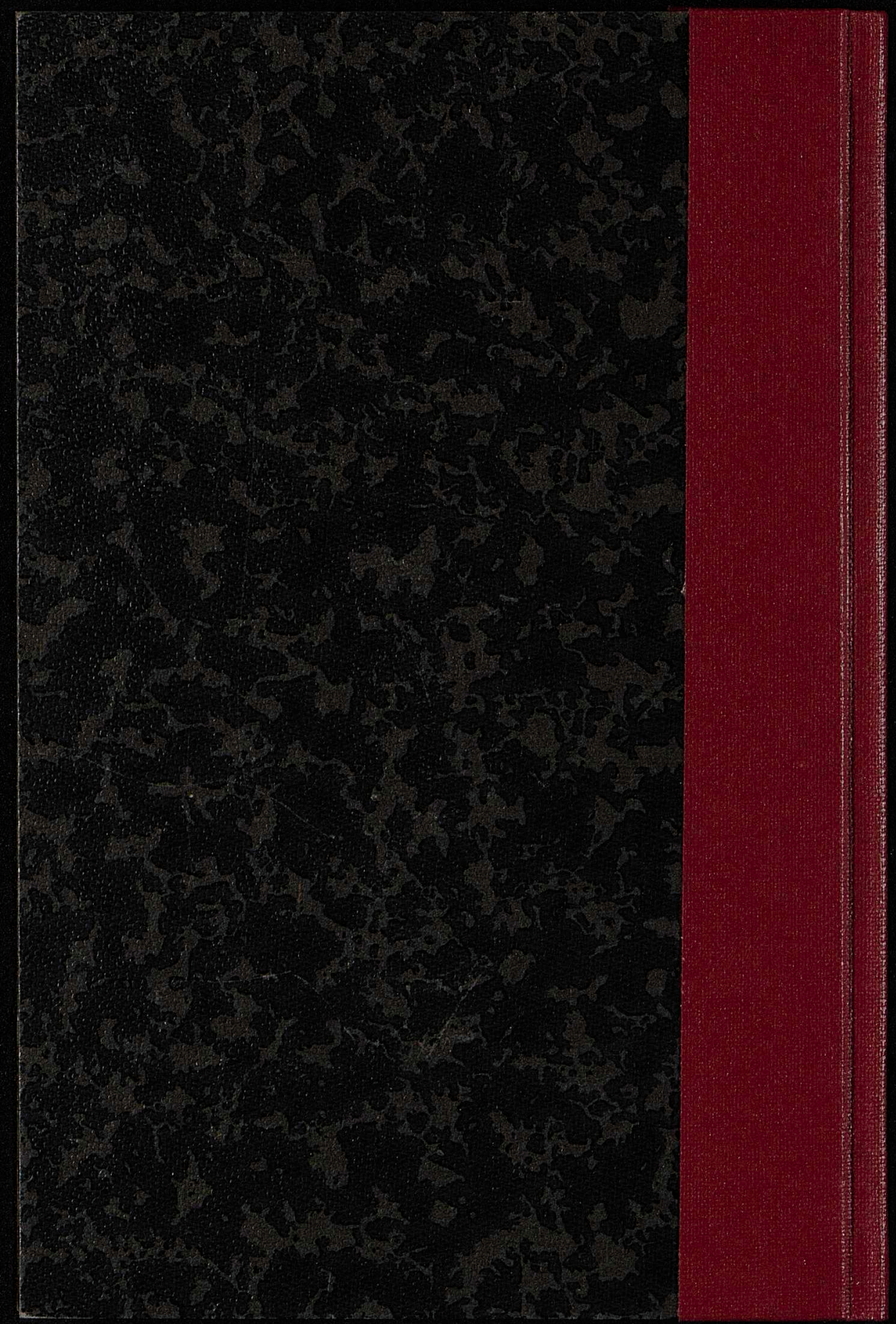



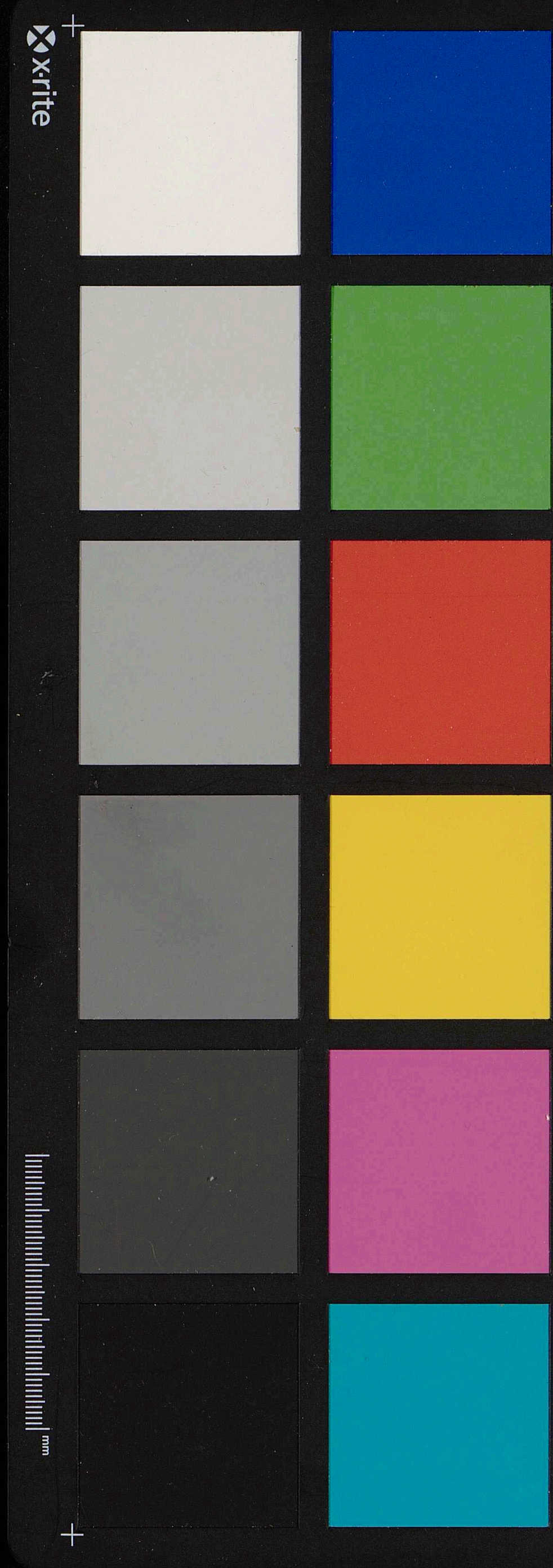

$+$
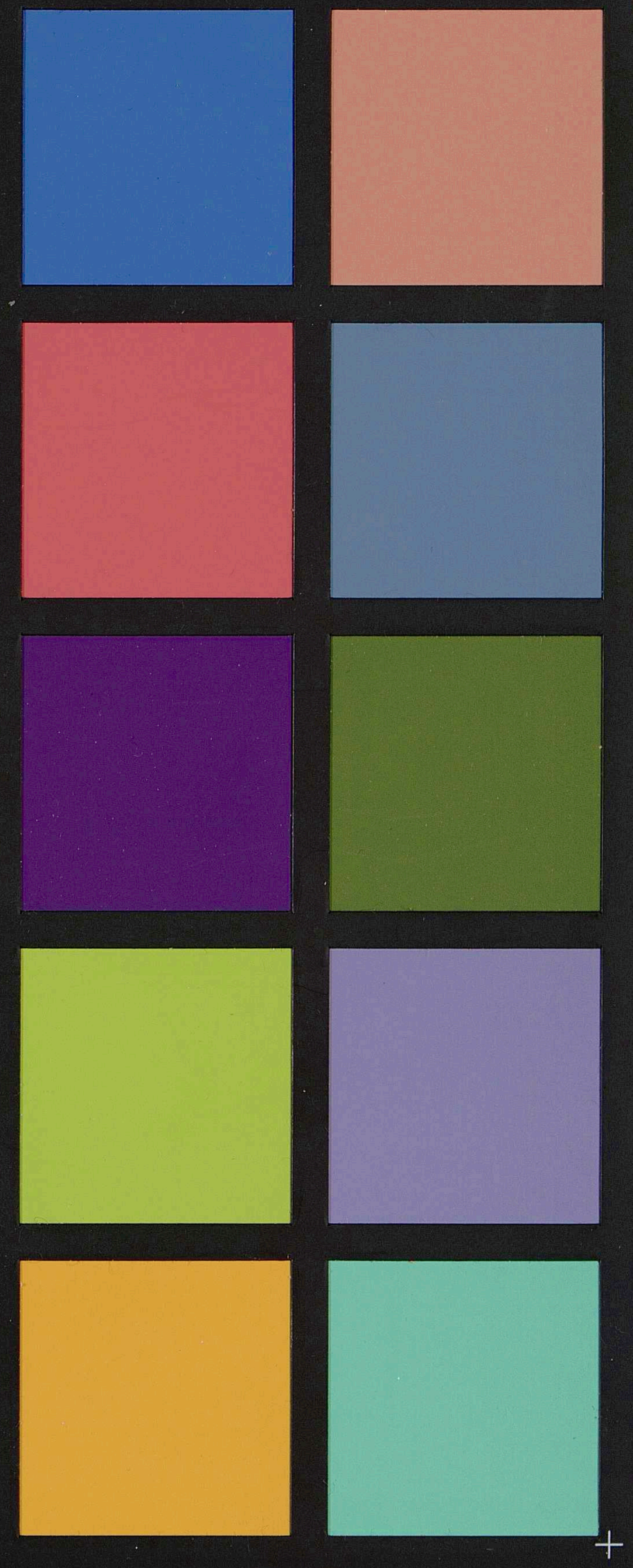

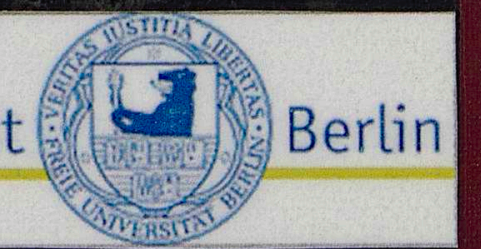

